RAFAEL LEME COSTA

MÉTODO DE MODELAGEM E VERIFICAÇÃO FORMAL APLICADO A SISTEMAS DE TRÁFEGO AÉREO 

RAFAEL LEME COSTA

\section{MÉTODO DE MODELAGEM E VERIFICAÇÃO FORMAL APLICADO A SISTEMAS DE TRÁFEGO AÉREO}

Dissertação apresentada à Escola Politécnica da Universidade de São Paulo para obtenção do título de Mestre em Ciências

São Paulo 

RAFAEL LEME COSTA

\section{MÉTODO DE MODELAGEM E VERIFICAÇÃO FORMAL APLICADO A SISTEMAS DE TRÁFEGO AÉREO}

Dissertação apresentada à Escola Politécnica da Universidade de São Paulo para obtenção do título de Mestre em Ciências

Área de concentração:

Engenharia de Controle e Automação Mecânica

Orientador:

Newton Maruyama

São Paulo 
Autorizo a reprodução e divulgação total ou parcial deste trabalho, por qualquer meio convencional ou eletrônico, para fins de estudo e pesquisa, desde que citada a fonte.

Este exemplar foi revisado e corrigido em relação à versão original, sob responsabilidade única do autor e com a anuência de seu orientador.

São Paulo, de de

Assinatura do autor:

Assinatura do orientador:

\section{Catalogação-na-publicação}

Costa, Rafael Leme

Método de modelagem e verificação formal aplicado a sistemas de tráfego aéreo / R. L. Costa -- versão corr. -- São Paulo, 2018.

$96 \mathrm{p}$.

Dissertação (Mestrado) - Escola Politécnica da Universidade de São Paulo. Departamento de Engenharia Mecatrônica e de Sistemas Mecânicos.

1.Tráfego aéreo (sistemas; modelagem) 2. Verificação e validação de software I.Universidade de São Paulo. Escola Politécnica. Departamento de Engenharia Mecatrônica e de Sistemas Mecânicos II.t. 


\section{Agradecimentos}

Gostaria de agradecer a todos que contribuíram no meu trabalho, começando pelo meu orientador Prof. Dr. Newton Maruyama, por todas as reuniões e por todas as orientações e conselhos dados para que o trabalho fosse o melhor possível. Gostaria de agradecer ao Prof. Dr. Fabio Kawaoka Takase e ao Prof. Dr. Eric Conrado de Souza também pelo apoio e por toda a ajuda que deram, começando desde o projeto de pesquisa até a minha participação no programa Pesquisador Atech, que me incentivou a seguir por essa extensa jornada. Um agradecimento especial vai para a Atech por me permitir essa oportunidade e por acreditar e investir em mim e em meu trabalho através desse programa.

Gostaria de agradecer aos meus amigos e colegas de Atech: Cristian Seiji Gushi e Tadao Ando Júnior, que me ajudaram com seu extenso conhecimento a identificar os módulos do sistema de tráfego aéreo interessantes para o meu trabalho e também a fazer a modelagem e a identificação de propriedades relevantes para verificação formal. Gostaria de agradecer também ao meu amigo e colega de Poli e de Atech: Fabio Seiti Aguchiku por toda a ajuda, apoio e companheirismo durante todos esses anos de mestrado.

Gostaria de agradecer ainda aos meus pais e familiares e também aos meus amigos pelo apoio e compreensão, principalmente nos momentos decisivos e em todos aqueles em que foi necessário me manter um pouco afastado do convívio social para me dedicar ao desenvolvimento deste trabalho. 



\section{Resumo}

O desenvolvimento de sistemas críticos é atualmente um dos problemas mais desafiadores enfrentados pela Engenharia. Há frequentemente uma pressão para se reduzir o tempo total de desenvolvimento, o que dificulta a entrega de sistemas com um mínimo aceitável de defeitos. Nos últimos anos, houve um aumento no tráfego aéreo, o que demanda uma modernização dos sistemas de tráfego aéreo atuais, muito dependentes na figura do controlador. Sistemas de tráfego aéreo são sistemas considerados críticos em segurança e de tempo real. O objetivo do presente trabalho é estabelecer um método de modelagem e verificação formal para sistemas críticos, com aplicação no domínio de tráfego aéreo. Com a adoção de técnicas de modelagem e verificação formal, pretende-se garantir a corretude dos sistemas frente aos requisitos incialmente especificados e a detecção de erros em fases mais iniciais do projeto, o que resultaria em menores custos envolvidos na sua correção. São fornecidas diretivas para a aplicação do método através de um estudo de caso, baseado em três módulos de um sistema ATC em baixo nível de abstração, para a validação do funcionamento de módulos de software. Para verificação formal, é utilizada a ferramenta NuSMV e as propriedades a serem verificadas são descritas na lógica computacional de árvore (CTL) para garantir que o sistema satisfaça requisitos dos tipos vivacidade e segurança.

Palavras-chaves: CTL. sistemas críticos. tráfego aéreo. verificação de modelos. verificação formal. 



\section{Abstract}

Developing safety critical systems is one of the most challenging problems in Engineering nowadays. There is usually a pressure to reduce the total time of the development, what makes it difficult to deliver systems with an acceptable low level of defects. In the recent years, there has been an increase in air traffic, what demands a modernization in the current air traffic systems, which are very dependent on the human controller. Air traffic systems are considered safety critical and real time systems. The objective of the present work is to establish a modeling and formal verification method for critical systems, applicable to the air traffic domain. By adopting modeling and formal verification techniques, it is expected to ensure the systems' correctness compared with the initially specified requirements and the error detection in the initial phases of the project. Guidelines are provided for applying the method by means of a case study, based in three modules of and ATC system in a low abstraction level, for the validation of the operation of software modules. For the formal verification, it is used the NuSMV tool and the properties to be checked are described in the computational tree logic (CTL) to ensure that the system satisfies requirements of liveness and safety types.

Keywords: air traffic. CTL. formal verification. model checking. safety-critical systems. 



\section{Lista de ilustrações}

Figura 1 - Crescimento da aviação mundial - Adaptado de ICAO [2018). . . . . . 25

Figura 2 - TS para a máquina de vendas de bebidas - Retirado de Baier e Katoen (2008). . . . . . . . . . . . . . . . 32

Figura 3 - TS para dois semáforos sincronizados e para sua composição paralela Retirado de Baier e Katoen[(2008). . . . . . . . . . . . . . . . . 33

Figura 4 - Deadlock para o sistema de semáforos - Retirado de Baier e Katoen

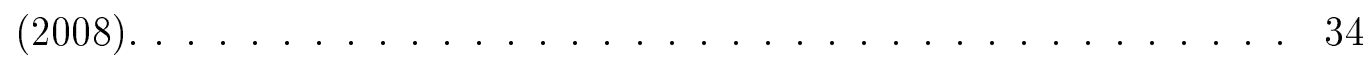

Figura 5 - Deadlock para o problema de exclusão mútua - Retirado de Baier e Katoen (2008). . . . . . . . . . . . . . . . . . . . . . . . . . . . . . . . . . .

Figura 6 - Modelo de autômato de Büchi. . . . . . . . . . . . . . . . . 38

Figura 7 - Visualização da semântica de algumas fórmulas CTL básicas - Retirado

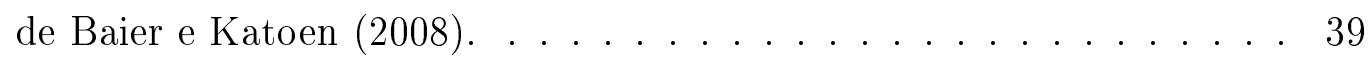

Figura 8 - Divisão do espaço aéreo brasileiro em 5 FIR - Retirado de DECEA

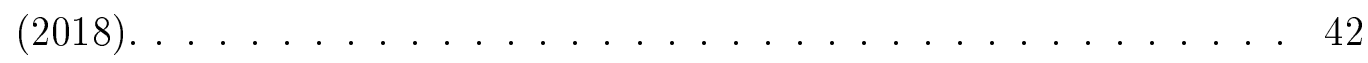

Figura 9 - Evolução temporal do controle de uma aeronave. . . . . . . . . . . . 43

Figura 10 - Elementos de representação de uma Pista. . . . . . . . . . . . . . . 43

Figura 11 - Exemplo de formulário de plano de voo - Retirado de $\mathrm{ICAO}[(2007 \mathrm{a})$. . 45

Figura 12 - Arquitetura do CATM - Adaptado de Azzopardi $(2015)$. . . . . . . . . 47

Figura 13 - Diagrama simplificado de interfaces de um sistema ATC. . . . . . . . . 48

Figura 14 - Arquitetura do sistema ATC americano - Adaptado de (STILLMAN, 1997). . . . . . . . . . . . . . . . 4 49

Figura 15 - Arquitetura do CAUTRA - Adaptado de Rugina et al. (2008). . . . . . 53

Figura 16 - Método proposto para verificação formal. . . . . . . . . . . . . . 57

Figura 17 - Ciclo completo da construção de um sistema. . . . . . . . . . . . . . . 59

Figura 18 - Ciclo completo ideal da construção de um sistema. . . . . . . . . . . . 59

Figura 19 - Método proposto para modelagem e verificação formal. . . . . . . . . . 60

Figura 20 - Simulação do estudo de caso: transferência de um plano de voo entre ATCs - Retirado de Aguchiku et al.[(2015). . . . . . . . . . . . . . . 62

Figura 21 - Desenho esquemático do estudo de caso e de seus componentes. . . . . 63

Figura 22 - Diagrama representativo do modelo do sistema de tráfego aéreo utilizado para o estudo de caso. . . . . . . . . . . . . . . . . 64

Figura 23 - Representação de uma strip eletrônica - Retirado de SimSoft (2018). . 66

Figura 24 - Máquina de estados representativa do modelo do DET. . . . . . . . . . 67 
Figura 25 - Máquina de estados representativa do modelo do REC. . . . . . . . . 68

Figura 26 - Dependências entre os módulos do estudo de caso. . . . . . . . . . . 69

Figura 27 - Identificação de novas propriedades - Estado final. . . . . . . . . . . 77

Figura 28 - Verificação de propriedade inversa - Estado final. . . . . . . . . . 78

Figura 29 - Verificação de consistência de propriedade - Estado final. . . . . . . . . 78

Figura 30 - Análise combinatória de indicativos de plano de voo referentes à equa-

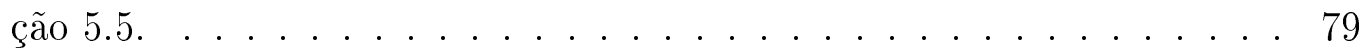

Figura 31 - Verificação de propriedade parcial - Estado final. . . . . . . . . . 80 


\section{Lista de tabelas}

Tabela 1 - Custo relativo de correção de defeitos, com base no momento em que são introduzidos e detectados - Adaptado de McConnell [2004).] . . . . 23

Tabela 2 - Notação LTL em forma de símbolos. . . . . . . . . . . . . . . 37

Tabela 3 - Notação CTL em forma de símbolos e em forma textual. . . . . . . . . 39

Tabela 4 - Derivação de propriedades LTL em CTL. . . . . . . . . . . . . . . 39 



\section{Lista de abreviaturas e siglas}

AADL Architecture analysis \& design language (Linguagem de análise e descrição de arquiteturas)

ACC Area control center (Centro de controle em área)

ADL Architecture description language (Linguagem de descrição de arquitetura)

ADS Automatic dependent surveillance (Vigilância dependente automática)

AIDC Automatic identification and data capture (Identificação automática e captura de dados)

AP Atomic proposition (Proposição atômica)

APP Approach control (Controle de aproximação)

ASBU Melhorias em blocos do sistema de aviação (Aviation system block upgrades)

ATC Air traffic control (Controle de tráfego aéreo)

ATFM Air traffic flow management (Gerenciamento de fluxo de tráfego aéreo)

ATM Air traffic management (Gerenciamento do tráfego aéreo)

CATM Computational air traffic management (Gerenciamento de tráfego aéreo computacional)

CAUTRA Système de contrôle automatisé du trafic aérien (Sistema de controle automatizado do tráfego aéreo)

CORR Módulo de correlação de planos de voo e pistas

CR Correlação

CSP Communicating sequential processes (Processos sequenciais comunicantes)

CTL Computational tree logic (Lógica de árvore computacional)

DET Módulo de vigilância e detecção de aeronaves 
DG Data general computer (Computador geral de dados)

FAA Federal Aviation Administration (Administração da Aviação Federal)

FDP Flight data processing (Processador de dados de voo)

FDR Failures-Divergence Refinement (Refinamento por falhas/divergências)

FPL Flight plan (Plano de voo)

FPP Flight plan processing (Processamento de planos de voo)

GANP Global air navigation plan (Plano de navegação aérea global)

GIS Geographic information system (Sistemas de informação geográfica)

GSPNs Generalized stochastic Petri nets (Redes de Petri estocásticas generalizadas)

ICAO International Civil Aviation Organization (Organização Internacional da Aviação Civil)

IHM Interface Homem-Máquina

ISSS Initial Sector Suite System

KPAs Key performance areas (Áreas chave de desempenho)

KPIs Key performance indicators (Indicadores chave de desempenho)

LT Linear time (Tempo linear)

LTL Linear temporal logic (Lógica linear temporal)

MBE Model-based engineering (Engenharia baseada em modelos)

NASA National Aeronautics and Space Administration (Administração Nacional do Espaço e da Aeronáutica)

NBA Nondeterministic Büchi automata (Autômato não determinístico de Büchi)

ONU Organização das Nações Unidas

pP2P Peer-to-peer (Ponto a ponto) 
PVS Prototype verification system (Sistema de verificação de protótipos)

RDP Radar data processing (Processamento de Dados Radar)

REC Módulo de recepção e difusão de planos de voo

RPK Revenue Passenger-Kilometres

SAE Society of Automotive Engineers (Sociedade de Engenheiros Automotivos)

SMV Symbolic model verifier (Verificador de modelos simbólicos)

SSR Secondary surveillance radar (Radar de vigilância secundário)

TS Transition system (Sistema de transição)

TWR Control tower (Torre de controle) 



\section{Sumário}

Lista de ilustrações $\ldots \ldots \ldots \ldots$. . . . . . . . . . . . . 13

Lista de tabelas . . . . . . . . . . . . . . . . . . . 15

$1 \quad$ INTRODUÇÃO $\ldots \ldots \ldots \ldots \ldots \ldots$

$1.1 \quad$ Contextualização $\ldots \ldots \ldots \ldots \ldots \ldots$

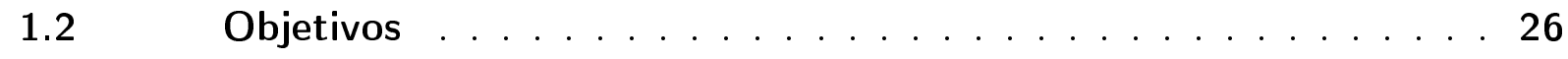

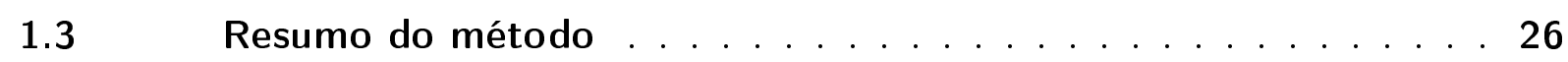

$1.4 \quad$ Contribuições . . . . . . . . . . . . . . . . . 27

$1.5 \quad$ Organização do trabalho $\ldots \ldots \ldots \ldots \ldots \ldots \ldots$

$2 \quad$ VERIFICAÇÃO FORMAL . . . . . . . . . . . . . 29

$2.1 \quad$ Linguagens de Descrição de Arquitetura (ADLs) $\ldots \ldots \ldots$

$2.2 \quad$ Sistemas de Transição $\ldots \ldots \ldots \ldots \ldots \ldots$

$2.3 \quad$ Propriedades de Tempo Linear . . . . . . . . . . . . 32

2.3 .1 Deadlock . . . . . . . . . . . . . . . . . . . . . . . . 34

$2.3 .2 \quad$ Segurança $($ Safety $) \ldots \ldots \ldots \ldots \ldots$

$2.3 .3 \quad$ Vivacidade (Liveness) $\ldots \ldots \ldots \ldots \ldots \ldots \ldots \ldots$

$2.3 .4 \quad$ Imparcialidade (Fairness) $\ldots \ldots \ldots \ldots \ldots \ldots \ldots \ldots$

$2.3 .5 \quad$ Lógica Linear Temporal $(\mathrm{LTL}) \ldots \ldots \ldots \ldots$

2.4 Verificação de modelos LTL baseada em autômatos . . . . . . . . 37

$2.5 \quad$ Lógica de Árvore Computacional (CTL) . . . . . . . . . . 38

3 SISTEMAS DE TRÁFEGO AÉREO $\ldots \ldots \ldots \ldots \ldots \ldots . \ldots 41$

$3.1 \quad$ Descrição . . . . . . . . . . . . . . . . . . . 41

3.2 Conceitos básicos $\ldots \ldots \ldots \ldots 4 \ldots \ldots \ldots$

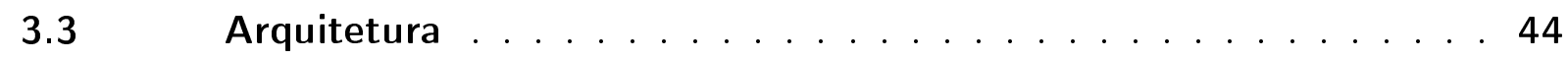

$3.3 .1 \quad$ Gerenciamento do Tráfego Aéreo (ATM) . . . . . . . . . . . . . 44

$3.3 .2 \quad$ Controle de Tráfego Aéreo (ATC) . . . . . . . . . . . . . 47

$3.4 \quad$ Requisitos . . . . . . . . . . . . . . . . . . . . 48

$3.5 \quad$ Iniciativas de Modelagem e Verificação Formal em Sistemas de

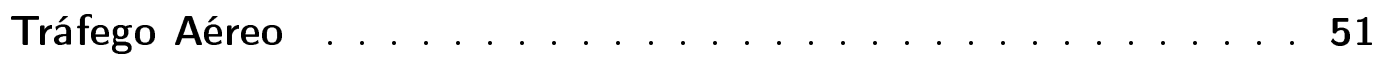

$4 \quad$ METODOLOGIA $\ldots \ldots \ldots \ldots \ldots \ldots \ldots \ldots$

$5 \quad$ ESTUDO DE CASO $\ldots \ldots \ldots \ldots \ldots \ldots \ldots$

$5.1 \quad$ Descrição do sistema $\ldots \ldots \ldots \ldots$. . . . . . . . . . 62 
$5.2 \quad$ Requisitos de sistema . . . . . . . . . . . . . . . . 64

$5.2 .1 \quad$ Módulo de vigilância e detecção de aeronaves (DET) . . . . . . . . . . 64

$5.2 .2 \quad$ Módulo de recepção e difusão de planos de voo (REC) . . . . . . . . 65

$5.2 .3 \quad$ Módulo de correlação de planos de voo e pistas (CORR) . . . . . . . . 67

$5.3 \quad$ Modelagem . . . . . . . . . . . . . . . . . 67

$5.3 .1 \quad$ Modelo desenvolvido em SMV . . . . . . . . . . . . . . . 67

$5.4 \quad$ Especificação de propriedades $\ldots \ldots \ldots \ldots$

$5.4 .1 \quad$ Recepção de planos de voo . . . . . . . . . . . . . . . . . 70

5.4 .2 Deteç̧ão de pista . . . . . . . . . . . . . . . . . . . . 70

$5.4 .3 \quad$ Correlação entre plano de voo e pista . . . . . . . . . . . . . 71

$5.4 .4 \quad$ Verificação de todas as propriedades em cadeia $\ldots \ldots \ldots$. . . . 72

$5.5 \quad$ Resultados . . . . . . . . . . . . . . . . . . . 72

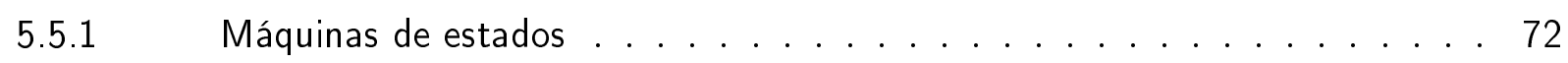

5.5 .2 Utilização do contraexemplo . . . . . . . . . . . . . 73

$6 \quad$ CONCLUSÕES $\ldots \ldots \ldots \ldots \ldots \ldots \ldots$

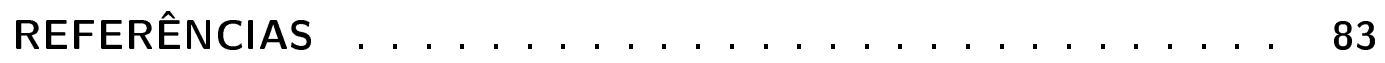

ANEXO A-MODELOS . . . . . . . . . . . . . . . 87

ANEXO B-CONTRAEXEMPLOS . . . . . . . . . . . . 91 


\section{Introdução}

\subsection{Contextualização}

Nos anos 90, Gibbs (1994) alertou para o problema crônico de software: a maior parte dos sistemas ainda eram feitos por "artesãos" e assim, principalmente os sistemas críticos, sofriam com atrasos, aumentos de custos e dificuldade de se lidar com eventuais falhas operacionais. Desde essa época, buscou-se realizar previsões para o comportamento do software no mundo real, através de análises matemáticas, apoiadas em métodos formais.

Atualmente, o desenvolvimento de sistemas críticos é um dos problemas mais desafiadores enfrentados pela Engenharia. Nota-se que há, frequentemente, uma necessidade de se atender requisitos restritivos, por muitas vezes justapostos ou ainda conflitantes e também de se garantir o suporte a certa modularidade, a uma adaptação fácil e ao reuso (NAVASA; PÉREZ-TOLEDANO; MURILLO, 2009). Em Baier e Katoen (2008), afirma-se que, simultaneamente ao aumento de complexidade dos sistemas, também há uma crescente pressão para se reduzir o tempo total de desenvolvimento, o que dificulta a entrega de sistemas com um mínimo aceitável de defeitos.

O objetivo principal na preparação de um projeto é assegurar que os possíveis defeitos sejam encontrados e eliminados o mais cedo possível. Alguns estudos feitos nos últimos 25 anos por empresas como Hewlett-Packard, IBM, dentre outras, mostram que os custos com retrabalho aumentam drasticamente quanto mais o tempo passa (MCCONNELL, 2004). Esse princípio é demonstrado na Tabela 1 dentre as fases típicas de um projeto, destaca-se as seguintes fases - Requisitos, Arquitetura, Construção, Testes e Pós-Entrega. Nota-se que quanto mais cedo o defeito for detectado e corrigido, menos impacto será causado nas fases posteriores e menor será o custo envolvido na sua correção.

Tabela 1 - Custo relativo de correção de defeitos, com base no momento em que são introduzidos e detectados - Adaptado de McConnell (2004).

\begin{tabular}{|l|c|c|c|c|c|}
\hline $\begin{array}{l}\text { Custo de correção } \\
\text { de defeitos }\end{array}$ & \multicolumn{5}{|c|}{ Detecção de defeitos } \\
\hline Introdução de defeitos & Requisitos & Arquitetura & Construção & Testes & Pós-Entrega \\
\hline Requisitos & $1 \mathrm{x}$ & $3 \mathrm{x}$ & $5-10 \mathrm{x}$ & $10 \mathrm{x}$ & $10-100 \mathrm{x}$ \\
Arquitetura & - & $1 \mathrm{x}$ & $10 \mathrm{x}$ & $15 \mathrm{x}$ & $25-100 \mathrm{x}$ \\
Construção & - & - & $1 \mathrm{x}$ & $10 \mathrm{x}$ & $10-25 \mathrm{x}$ \\
\hline
\end{tabular}

O foco do presente trabalho será nas fases de arquitetura e de construção de software. As arquiteturas de software descrevem os elementos a partir dos quais os sistemas são construídos, as interações entre esses elementos, os padrões que guiam sua composição e as restrições desses padrões (HEMER; DING, 2008). Elas podem ser utilizadas para 
diversos fins, tais como para documentar e para comunicar decisões de design e soluções de arquitetura, para gerar código em engenharia baseada em modelos (MBE), para engenharia de produto ou para estimativas de riscos e custos (MALAVOLTA et al., 2013).

Os padrões de arquitetura representam uma forma sistemática de se conceber uma arquitetura. Eles garantem o reuso de conhecimento arquitetural e facilitam tanto a comunicação entre os pares quanto a compreensão da arquitetura de software e ainda garantem um suporte a atributos de qualidade do sistema (KAMAL; AVGERIOU, 2007). Além disso, é possível se obter uma melhora na produtividade e na confiabilidade dos sistemas (BESSAM; KIMOUR, 2008).

O objetivo da utilização de verificação formal para sistemas em geral é garantir a sua assertividade, com rigor matemático. Ao se fazer a especificação formal para definição de requisitos, a modelagem do sistema e em seguida aplicar a verificação formal, realiza-se uma avaliação desse sistema anteriormente à sua construção. Espera-se que isso ajude a identificar e a solucionar problemas em fases iniciais do projeto, já que, caso fossem identificados apenas em fases mais avançadas, poderiam elevar muito o custo do projeto.

O foco do presente trabalho é em sistemas de tráfego aéreo, que podem ser classificados como sistemas críticos, de tempo real. Segundo Azzopardi (2015), a tarefa do sistema de Gerenciamento do Tráfego Aéreo (ATM) é "manter o tráfego aéreo global organizado, interoperável, confiável, eficiente e seguro". Atualmente, a função dos sistemas de tráfego aéreo é dar suporte à decisão dos controladores de voo, sendo que a estrutura básica desses sistemas não evoluiu muito desde os anos 60, quando foi introduzida a tecnologia Radar (OLIVEIRA, 2007).

Dentre as limitações no fornecimento de serviços aéreos no ano 2000, citadas por ICAO (2005), destaca-se as seguintes:

- a dificuldade na troca de informações em tempo real entre centros e com os pilotos, o que resulta em respostas não otimizadas a eventos de tempo real;

- altos lead times envolvidos em desenvolvimento e implementação de sistemas relacionados a Tráfego Aéreo.

Nas últimas décadas, o tráfego aéreo vem se intensificando e isso demanda uma modernização dos sistemas atuais, ainda muito dependentes da figura do controlador. A Figura 1 mostra um gráfico de crescimento do tráfego aéreo mundial de 1950-2012, destacando os momentos de crise mundial que ocasionam uma queda no total do tráfego, medido em Revenue Passenger-Kilometres (RPK), porém logo depois há uma recuperação.

Um documento de intenções lançado há mais de 10 anos (ICAO, 2005) destaca, dentre os benefícios esperados para os sistemas futuros, o uso de ferramentas de simulação, modelagem e avaliação de alternativas, com o objetivo de auxiliar no gerenciamento de estratégias e fornecer flexibilidade no gerenciamento do sistema ATM como um todo. A Organização Internacional da Aviação Civil (ICAO) é uma agência especializada da 
Organização das Nações Unidas (ONU) com o objetivo de definir padrões e recomendações para a aviação civil internacional. O Brasil é um membro-fundador da ICAO e também sugere e segue as normas e recomendações da agência.

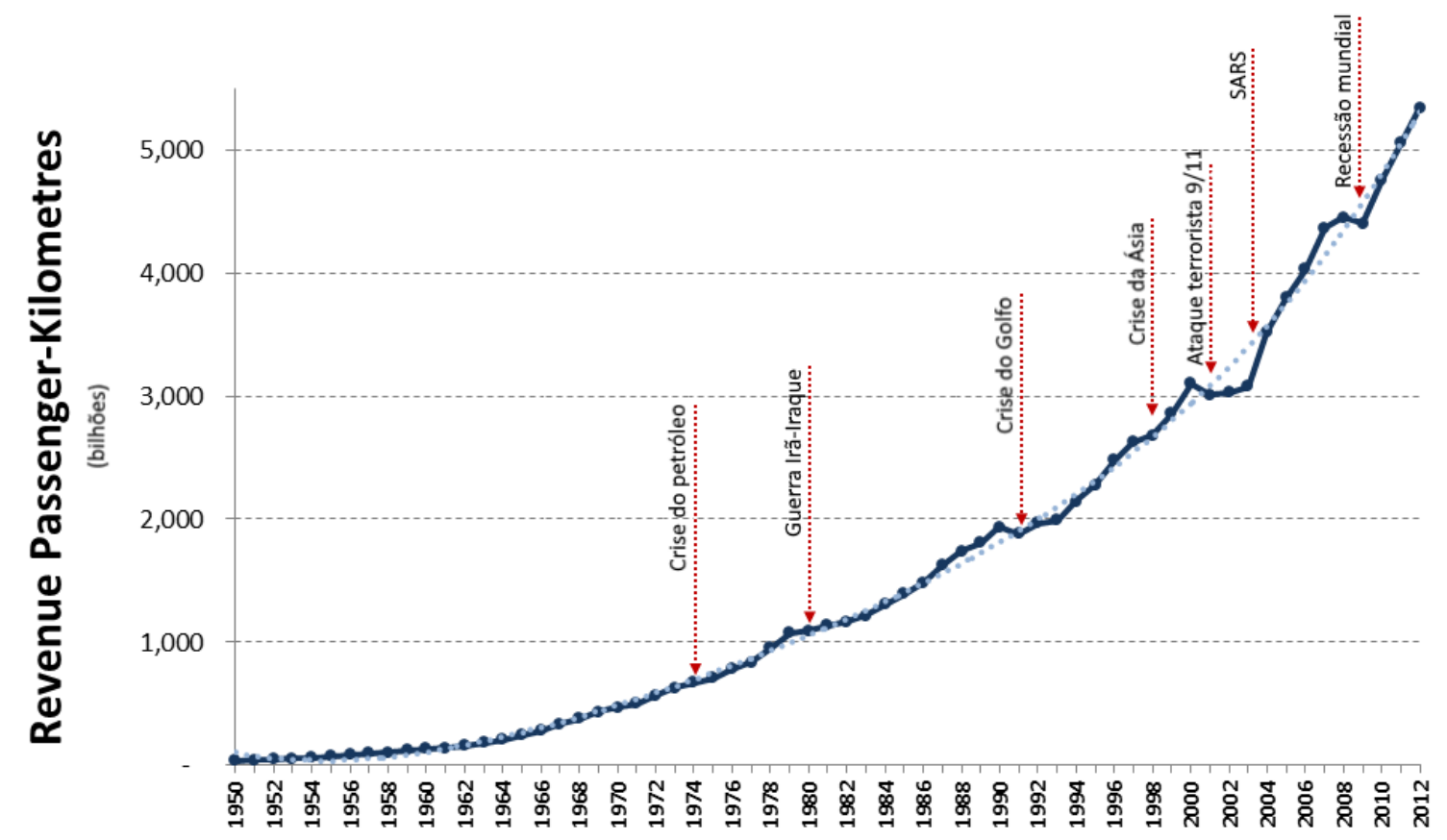

Figura 1 - Crescimento da aviação mundial - Adaptado de ICAO (2018).

Para se cumprir requisitos de desempenho, já no ano de 2005 já se planejava adotar mais a automação em funções tais como rastreamento multi-radar, correlação de pista radar e plano de voo e coordenação automática entre setores ou centros (ICAO, 2005), funções que são casos de estudo do presente trabalho.

Com base nesse documento, foi feito pela ICAO um planejamento para o futuro da aviação civil, com marcos para 2013, 2019, 2025 e 2031. Esse documento, denominado Plano de navegação aérea global (GANP), teve a sua última edição lançada em 2016 (ICAO, 2016), com atualizações de intenções já realizadas por alguns países e de planos previstos para 2019, além de um maior detalhamento de ações previstas para os marcos seguintes.

Em linhas gerais, o objetivo do GANP é o aumento de capacidade, a melhora na eficência e a melhora ou ao menos a manutenção do nível atual de segurança no tráfego aéreo. O GANP propõe uma série das chamadas Melhorias em blocos do sistema de aviação (ASBU). Dentre as ações já realizadas, destaca-se um esforço inicial para introduzir o processamento digital de informações e de dados aeronáuticos e para realizar a integração de informações com sistemas externos, como centros meteorológicos reconhecidos.

Para 2019, destaca-se o gerenciamento dinâmico da separação mímina em turbulência, beaseado em dados de identificação de turbulências em tempo real, auxílio ou tomada de decisão automática envolvendo informações meteorológicas, além de se garantir a in- 
teroperabilidade entre os diferentes sistemas dos Estados membros. Para o longo prazo, destaca-se o apoio de decisão automática para implementar estratégias imediatas de mitigação climática, com apoio de informações meteorológicas para solo e ar, integração de todas as informações de voo para obter o modelo de trajetórias mais acurado para automação de solo e operações baseadas em trajetórias 4D, com deteç̧ão automática de desvio de rota, atualmente de responsabilidade total do controlador de voo. Com essa tendência de se adotar uma maior automação, consequentemente haverá uma maior exigência no desenvolvimento dos sistemas para garantir o seu pleno funcionamento.

Sugere-se a adoção de técnicas de modelagem e verificação formal para garantir a corretude dos sistemas frente aos requisitos incialmente especificados e a detecção de erros em fases mais iniciais do projeto, o que resultaria em menores custos envolvidos na sua correção. Uma descrição do contexto e da arquitetura de sistemas de tráfego aéreo é apresentada no capítulo 3 .

Destaca-se que não há muitos trabalhos na área de verificação formal com foco em sistemas de tráfego aéreo. Identificou-se também uma ausência de trabalhos que forneçam requisitos específicos para o domínio de tráfego aéreo, sendo que a maior parte deles abrange requisitos implícitos ou enumera requisitos muito genéricos.

\subsection{Objetivos}

O objetivo geral do presente trabalho é propor um método de modelagem e verificação formal de sistemas críticos com aplicação no domínio particular de tráfego aéreo. Deseja-se formular táticas, ou seja, um conjunto de diretivas para estabelecer e evoluir os modelos e as propriedades de interesse para verificação formal.

Os objetivos secundários são aplicar o método desenvolvido a módulos específicos de um sistema ATC em nível de abstração próximo ao comportamento de software e fazer uma síntese de um conjunto de requisitos específicos para o domínio de tráfego aéreo.

\subsection{Resumo do método}

O método proposto é dividido em quatro fases. Um breve resumo desse método é apresentado a seguir. Primeiramente, é feita a especificação de requisitos do sistema. Em seguida, é feita a modelagem do sistema na linguagem SMV. Em paralelo, é feita a especificação de propriedades de Segurança e Vivacidade nas lógicas LTL/CTL e é feita a verificação formal e a simulação em NuSMV.

A aplicação desse método foi feita através de um estudo de caso de um sistema de tráfego aéreo. Para definir os módulos de interesse para esse estudo de caso, estabeleceu-se como pré-requisito a necessidade de haver mais de um módulo, com funcionamento em paralelo e alguma dependência entre si. Os requisitos de sistema já estavam previamente 
especificados. O modelo foi desenvolvido na linguagem SMV, as especificações foram feitas em CTL e a verificação formal foi feita com a ferramenta NuSMV.

\subsection{Contribuiç̧̃̃es}

A contribuição mais importante é a formulação do método de verificação formal e de diretivas para sua aplicação, com destaque na utilização do contraexemplo para identificar imprecisões tanto no modelo quanto na propriedade de interesse e para auxiliar na definição de outras propriedades.

Não foi possível encontrar nenhum trabalho que fosse aplicado em módulos baseados em sistemas ATC, em um baixo nível de abstração para a validação do funcionamento de módulos de software, sendo essa outra contribuição do trabalho.

\subsection{Organização do trabalho}

No capítulo 2, são apresentados os conceitos de verificação formal, tais como Linguagens de Descrição de Arquitetura (ADLs) e Lógicas Linear Temporal (LTL) e de Árvore Computacional (CTL).

No capítulo 3, é feita uma descrição sobre sistemas de tráfego aéreo, incluindo aspectos particulares de sua arquitetura e uma síntese de um conjunto de requisitos específicos para o domínio de tráfego aéreo, utilizados no presente trabalho. Faz-se ainda uma síntese dos trabalhos mais recentes, relacionados a verificação formal e a sistemas de tráfego aéreo.

No capítulo 4, é introduzido o método desenvolvido no presente trabalho de modelagem e verificação formal, com aplicação para sistemas de tráfego aéreo.

No capítulo 5, é apresentado o estudo de caso desenvolvido no presente trabalho. É feita a descrição dos módulos de interesse, são apresentados os seus respectivos requisitos, em seguida a sua modelagem e então a verificação formal. Por fim, é feita a exposição de resultados, bem como a apresentação das diretivas determinadas pela aplicação do método, com base na utilização do contraexemplo.

No capítulo 6, são feitas as conclusões finais do trabalho. 



\section{Verificação formal}

De acordo com Sobeih, Viswanathan e Hou (2004), o raciocínio formal para sistemas de hardware e software pode seguir duas linhas distintas: a prova de teoremas e a verificação de modelos. Enquanto na prova de teoremas utiliza-se uma técnica formal para confirmar se a implementação de um modelo está de acordo com a sua especificação, na verificação de modelos são criadas máquinas de estados finitos para assegurar a validade de uma propriedade especificada. Para Winter (1997), a prova de teoremas é interessante para demonstrar propriedades de sistemas de estado infinito, porém, sua contrapartida é a necessidade de utilização de trabalho manual em boa parte da verificação. Por outro lado, a verificação de modelos é uma técnica de exploração de estados normalmente automatizada, o único porém é que se restringe a sistemas não muito grandes, com um espaço de estados finito.

Mais detalhadamente, a verificação de modelos configura-se como uma técnica de verificação formal em que, dado um modelo de estados finitos de um sistema e uma propriedade a ser verificada, confirma-se a validade dessa propriedade através da inspeção dos caminhos possíveis do espaço de estados e, caso ela não se sustente, é gerado um contraexemplo com o caminho em que a propriedade se tornou inválida (BAIER; KATOEN, 2008). O objetivo principal dos métodos formais é garantir a assertividade do sistema, com rigor matemático. Os métodos formais representam um grande potencial para a detecção de problemas relacionados a estados incompletos, ambiguidades e inconsistências em uma fase inicial do projeto.

Segundo Baier e Katoen (2008), o processo de verificação de modelos pode ser dividido em três fases:

- Modelagem: modela-se o sistema e faz-se algumas simulações iniciais. Formaliza-se a propriedade a ser verificada.

- Execução: executa-se o verificador para conferir a validade da propriedade.

- Análise: caso a propriedade seja satisfeita, verifica-se a próxima (se existir). Caso a propriedade seja violada, deve-se analisar o contraexemplo gerado por simulação e refinar o modelo, a configuração ou a propriedade e então repetir o procedimento. Por fim, caso a combinação dos estados alcançáveis cause o esgotamento da memória, deve-se tentar reduzir o modelo e repetir o procedimento.

Na linha da verificação de modelos, Barnat et al. (2009) cita que essa é uma técnica amplamente difundida para a realização de verificação formal. Contudo, há um problema importante a ser superado: a explosão do espaço de estados. Esse problema, relatado por Sobeih, Viswanathan e Hou (2004), Baier e Katoen (2008), Barnat et al. (2010), 
Winter (1997), é caracterizado quando o espaço de estados fica tão grande que se esgota a memória disponível. Uma solução é reduzir o espaço de estados, contanto que se preserve a corretude do modelo frente aos requisitos incialmente especificados (WINTER, 1997).

\subsection{Linguagens de Descrição de Arquitetura (ADLs)}

Nesse contexto, as Linguagens de Descrição de Arquitetura (ADLs) são conjuntos de cadeias que representam um sistema, ou seja, as linguagens que definem arquiteturas de sistemas e também de software.

Na comunidade científica, porém, não há um consenso sobre a ADL no sentido de quais aspectos da arquitetura deveriam ser modelados por ela e quais possíveis ADLs são mais adequadas para um tipo específico de problema.

Em Medvidovic e Taylor (2000), diversas abordagens são analisadas para tentar definir o que é uma ADL. Três características essenciais de modelagem são identificadas para ADLs: componentes, conectores e configurações de arquitetura. Os componentes representam o principal elemento computacional e o registro dos dados do sistema. Os conectores representam interações entre componentes e servem como mediadores das atividades de comunicação e coordenação. As configurações descrevem as interações entre componentes e conectores. Além disso, um problema identificado é a proliferação de diversas ADLs para descrição de arquiteturas, sem um claro entendimento de seus méritos e limitações. Com essa motivação, Malavolta et al. (2013) procurou saber qual é a percepção dos usuários de ADL no campo industrial em relação aos pontos fortes, às limitações e às necessidades, através de uma pesquisa feita com 48 sujeitos. Essa análise resultou em duas descobertas principais:

- As ADLs usadas pela indústria foram feitas na indústria. As ADLs originadas de pesquisas acadêmicas parecem não satisfazer às necessidades da indústria, porém elas são importantes já que algumas delas foram fontes de inspiração na criação das ADLs industriais.

- As ADLs devem possuir características que suportem a comunicação entre tipos diferentes de stakeholders e a análise de atividades individuais.

Outra preocupação dos autores é comparar as diversas ADLs disponíveis. Por exemplo, em Kamal e Avgeriou (2007), um framework de comparação é proposto para analisar o suporte de algumas ADLs de acordo com quatro critérios: sintaxe, visualização, variabilidade e extensibilidade. Outros autores com a mesma motivação em seus trabalhos são Medvidovic e Taylor (2000), Hemer e Ding (2008). As ADLs mais citadas em trabalhos relacionados são ACME, UniCon, Wright e Aesop.

A Linguagem de Análise e Descrição de Arquiteturas (AADL), outra linguagem usada para modelar a arquitetura de sistemas, é um padrão arquitetural criado pela Sociedade 
de Engenheiros Automotivos (SAE), designado para sistemas de tempo real, embarcados, críticos em segurança e intensivos em software nas áreas Automotiva, de Aviônicos ou Aerospacial.

A AADL pode ser expressa tanto em formato textual quanto em representação gráfica. Além disso, ela pode ser usada para descrever requisitos de sistema em alto nível (HANSSON et al., 2010) e assim é capaz de expressar as diversas integrações entre os componentes de um sistema, sendo eles elementos de hardware ou de software. Ele suporta reconfiguração dinâmica, integração de múltiplas formas de análise e possibilita o reuso de componentes (HANSSON et al., 2010, BOZZANO et al., 2011).

Muitos autores afirmam que a AADL carece de uma semântica formal, portanto uma maneira razoável de se realizar a verificação formal é através da transformação de modelos. Trabalhos recentes, de 2006 a 2015 (SOKOLSKY; LEE; CLARKE, 2006; HUGUES et al., 2008; RUGINA et al., 2008; HANSSON et al., 2010; BAE et al., 2011; BOZZANO et al., 2011; ZHANG et al., 2011; JOHNSEN et al., 2012; HU et al., 2015), propõem métodos para realizar a verificação formal de diversas propriedades, tanto funcionais quanto não funcionais, através da técnica da transformação de modelos. Dentre algumas propostas para solucionar esse problema, destaca-se: a conversão para modelos UPPAAL (HU et al., 2015; JOHNSEN et al., 2012, ZHANG et al., 2011), ferramenta para verificar propriedades de lógica de árvore computacional (CTL) em autômatos temporais; para ACSR (SOKOLSKY; LEE; CLARKE, 2006), linguagem capaz de verificar propriedades não funcionais, como escalabilidade e tempo; e para NuSMV (BOZZANO et al., 2011), ferramenta para verificar propriedades CTL e de lógica linear temporal (LTL).

\subsection{Sistemas de Transição}

As seções a seguir sobre fundamentos de modelagem e verificação formal são baseadas em Baier e Katoen (2008).

O primeiro passo para a verificação de modelos, é fazer um modelo do sistema que é objeto de estudo. Sistemas de transição (TS) são modelos cujo objetivo é descrever o comportamento de sistemas. Eles são compostos por grafos direcionados, em que nós representam estados e setas representam transições, ou seja, mudanças de estado.

Def. Sistemas de transição (TS)

Define-se um TS pela tupla $(S, A c t, \rightarrow, I, A P, L)$, onde:

$S$ : Conjunto de estados;

Act: Conjunto de ações;

$\rightarrow \subseteq S \times$ Act $\times S:$ Relação de transição;

$I \subseteq S$ : Conjunto de estados iniciais;

$A P$ : Conjunto de proposições atômicas;

$L: S \rightarrow 2^{A P}$ : Função de rotulagem. 


\section{Máquina de Vendas de Bebidas}

O TS de exemplo, considerado um padrão no campo de cálculo de processos, é uma máquina de vendas de bebidas. O cliente pode escolher nessa máquina refrigerante (soda) ou cerveja (beer). As ações são inserir moeda (insert_coin), pegar refrigerante (get_soda) e pegar cerveja (get_beer).

Na figura 2 o conjunto de estados é representado por $S=\{$ pay, select, soda, beer $\}$, o conjunto de ações por Act $=\{$ insert_coin,get_soda,get_beer, $\tau\}$ e o conjunto de estados iniciais por $I=\{$ pay $\}$. Alguns exemplos de transições são pay $\stackrel{\text { insert }}{\longrightarrow}{ }^{\text {coin }}$ select $\mathrm{e}$ beer $\stackrel{\text { get_beer }}{\longrightarrow}$ pay.

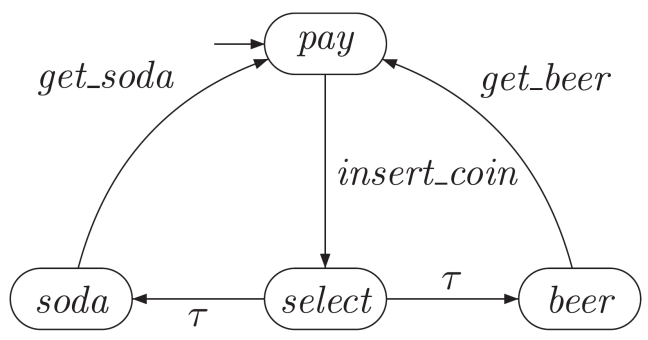

Figura 2 - TS para a máquina de vendas de bebidas - Retirado de Baier e Katoen (2008).

As proposições atômicas $(A P)$ dependem das propriedades em consideração. Um exemplo é ter a função de rotulagem como o nome do estado $(L(s)=\{s\})$ para a seguinte propriedade:

"A máquina de vendas apenas entrega uma bebida após receber uma moeda"

Teríamos então:

$A P=\{$ paid, drink $\}$ e $L($ pay $)=\varnothing, L($ soda $)=L($ beer $)=\{$ paid, drink $\}, L($ select $)=$ $\{$ paid $\}$.

\subsection{Propriedades de Tempo Linear}

Para fazer a verificação de um TS de interesse, é necessário especificar propriedades de Tempo Linear (LT). 


\section{Def. Propriedade LT}

Uma propriedade LT sobre o conjunto de proposições atômicas $A P$ é um subconjunto de $\left(2^{A P}\right)^{w}$.

Vale ressaltar que $\left(2^{A P}\right)^{w}$ indica o conjunto de palavras que vem da concatenação infinita de palavras de $2^{A P}$. Logo, uma propriedade LT é um conjunto de palavras infinitas sob o alfabeto $2^{A P}$.

Os traços (Traces) de um TS são palavras sobre o alfabeto $2^{A P}$.

Def. Relação de satisfação

Seja $P$ uma propriedade LT sobre $A P$ e $T S$ um sistema de transição. A relação de satisfação, indicada por $T S \vDash P$, é válida se e somente se $\operatorname{Traces}(T S) \subseteq P$.

Para estados $s \in S$, a relação de satisfação $s \vDash P$ é válida se e somente se $\operatorname{Traces}(s) \subseteq$ $P$.

\section{Sistema de semáforos}

O sistema de interesse é um cruzamento de ruas, em que há dois semáforos sincronizados que podem exibir uma das cores: verde (green) ou vermelho (red). A figura 3 mostra os TS do exemplo.
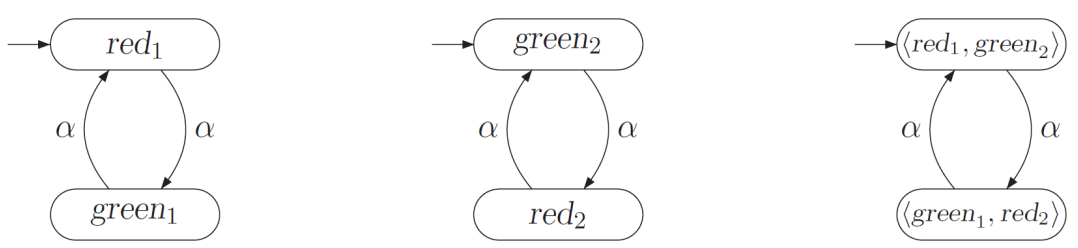

Figura 3 - TS para dois semáforos sincronizados e para sua composição paralela - Retirado de Baier e Katoen (2008).

Sejam as proposições de interesse:

$A P=\left\{\right.$ red $_{1}$, green $_{1}$, red $_{2}$, green $\left._{2}\right\}$

e seja a propriedade $\mathrm{P}$ definida por:

"O primeiro farol é por infinitas vezes verde". As seguintes palavras estariam contidas em $P$ :

$\{$ red 1, green 2$\}\{$ green 1, red 2$\}\{$ red 1, green 2$\}\{$ green 1, red 2$\} \ldots$

$\varnothing\{$ green 1$\} \varnothing\{$ green 1$\} \varnothing\{$ green 1$\} \varnothing\{$ green 1$\} \varnothing \ldots$

$\{$ red 1, green 1$\}\{$ red 1, green 1$\}\{$ red 1, green 1$\}\{$ red 1, green 1$\} \ldots$

\{green 1, green 2$\}\{$ green 1, green 2$\}\{$ green 1 , green 2$\}\{$ green 1, green 2$\} \ldots$

Porém, a seguinte palavra não estaria contida em $P$ :

$\{$ red 1, green 1$\}\{$ red 1, green 1$\} \varnothing \varnothing \varnothing \varnothing \ldots$

pois contém apenas ocorrências de green $_{1}$ em tempo finito.

A seguir, apresenta-se os diversos tipos de propriedades LT. 


\subsubsection{Deadlock}

Um deadlock ocorre se o sistema inteiro estiver em um estado terminal, mas pelo menos um componente estiver em um estado não terminal. Assim, não é possível que o sistema continue a operar.

\section{Deadlock para o sistema de semáforos}

A figura 4 demonstra uma situação de deadlock para o TS do exemplo do sistema de semáforos.

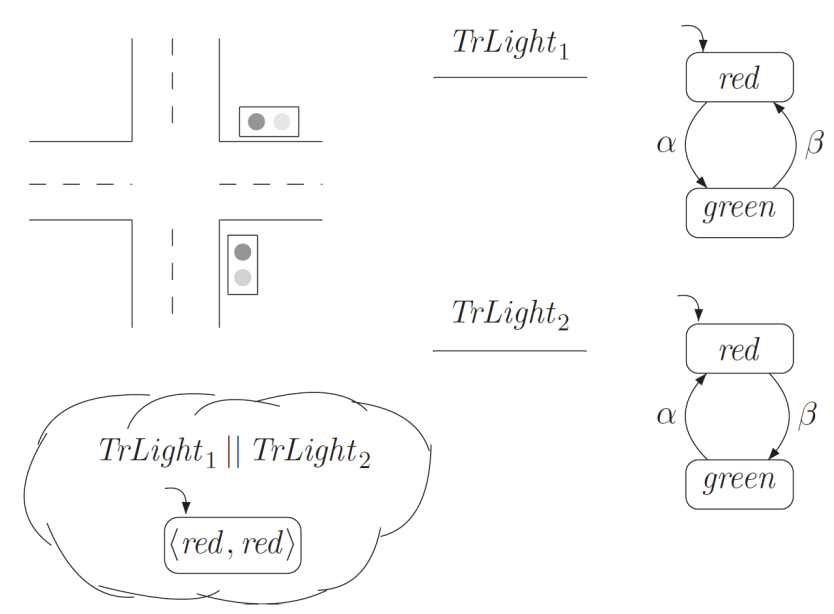

Figura 4 - Deadlock para o sistema de semáforos - Retirado de Baier e Katoen (2008).

Nesse exemplo simples, considera-se uma composição paralela (notação ||) de dois TS $\operatorname{Tr}$ Light $_{1} \| \operatorname{Tr}$ ight $_{2}$. O estado inicial seria composto por ambos os semáforos exibindo a cor vermelha $(r e d)$ e, logo, o sistema estaria inoperante e não poderia continuar.

\subsubsection{Segurança (Safety)}

As propriedades de segurança são caracterizadas pela frase:

"nada de ruim deve acontecer"

Considera-se que, em tempo finito, uma situação indesejável não ocorra.

Problema da exclusão mútua

O problema da exclusão mútua, que será utilizado como base para os exemplos a seguir, é caracterizado pelos processos $P_{1}$ e $P_{2}$ e seus respectivos grafos $P G_{1}$ e $P G_{2}$. Apenas um processo $P_{i}$ pode ter acesso à sua seção crítica por vez. As ações não-críticas podem ser executadas paralelamente ou com uma ação crítica do outro processo. Na figura 5 , ilustrase uma maneira de solucionar o problema com dois TS e um semáforo $y$, que indica se o processo $P_{i}$ pode ter acesso à sua seção crítica. 


$$
P G_{1}: \quad P G_{2} \text { : }
$$

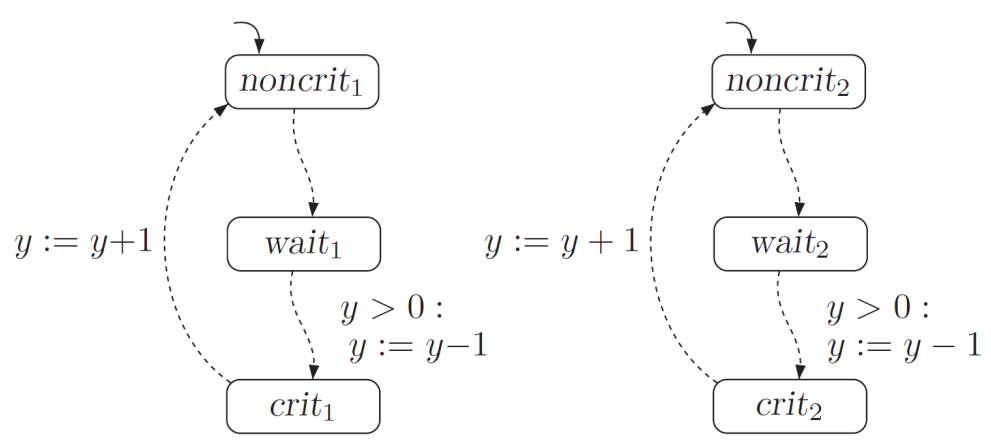

Figura 5 - Deadlock para o problema de exclusão mútua - Retirado de Baier e Katoen (2008).

Segurança para o problema da exclusão mútua

A propriedade de segurança relacionada ao problema do exemplo da exclusão mútua seria:

"Sempre no máximo um processo está na seção crítica"

\subsubsection{Vivacidade (Liveness)}

As propriedades de vivacidade são caracterizadas pela frase

"algo de bom irá acontecer no futuro"

Essas propriedades são complementares às de segurança, pois garantem que o sistema funcione como esperado no tempo infinito. As propriedades de vivacidade típicas podem ser classificadas em três níveis: eventualmente, repetido eventualmente e inanição (tradução de starvation).

\section{Vivacidade para o problema da exclusão mútua}

As propriedades de Vivacidade aplicadas ao problema do exemplo da exclusão mútua, divididas nas três classificações seriam, em descrição textual e matemática:

- Eventualmente: "Cada processo vai eventualmente entrar na sua seção crítica."

$$
\left(\exists j>0 . \text { crit }_{1} \in A_{j}\right) \wedge\left(\exists j>0 . \text { crit }_{2} \in A_{j}\right)
$$

- Repetido eventualmente: "Cada processo vai entrar na sua seção crítica infinitas vezes."

$$
\begin{gathered}
\left(\forall k \geq 0 . \exists j>k . \text { crit }_{1} \in A_{j}\right) \wedge(\forall k \geq 0 . \exists j>\text { k.crit } \\
\left.2 \in A_{j}\right) \\
\left(\stackrel{\infty}{E} j \geq 0 . \text {.rit }_{1} \in A_{j}\right) \wedge\left(\stackrel{\infty}{E} j \geq 0 . \text { crit }_{2} \in A_{j}\right)
\end{gathered}
$$


- Inanição: "Cada processo em espera vai eventualmente entrar na sua seção crítica." $\left(\forall j \geq 0 .\left(\right.\right.$ wait $_{1} \in A_{j} \Rightarrow\left(\exists k>j\right.$. crit $\left.\left._{1} \in A_{k}\right)\right) \wedge\left(\forall j \geq 0 .\left(\right.\right.$ wait $_{2} \in A_{j} \Rightarrow\left(\exists k>j\right.$. crit $\left.\left._{2} \in A_{k}\right)\right)$

\subsubsection{Imparcialidade (Fairness)}

As propriedades de imparcialidade são caracterizadas pelos caminhos em que as transições habilitadas são executadas de maneira imparcial. Elas são importantes para descartar comportamentos infinitos que são considerados irrealistas e necessárias para estabelecer propriedades de vivacidade. Em geral, uma execução imparcial requer o preenchimento de certas restrições:

\section{Imparcialidade para o problema da exclusão mútua}

As propriedades de imparcialidade aplicadas ao problema do exemplo da exclusão mútua, dadas as respectivas restrições, seriam:

- Incondicional: "Cada processo tem direito à sua vez por infinitas vezes."

$$
j \cdot \alpha_{j} \in A
$$

- Forte: "Cada processo que está habilitado por infinitas vezes tem direito à sua vez por infinitas vezes."

$$
\left(j . A c t\left(s_{j}\right) \cap A \neq \varnothing\right) \Rightarrow\left(j \cdot \alpha_{j} \in A\right)
$$

- Fraca: "Cada processo que está continuamente habilitado a partir de um certo instante de tempo tem direito à sua vez por infinitas vezes."

$$
\left(\stackrel{\infty}{\forall j . A c t}\left(s_{j}\right) \cap A \neq \varnothing\right) \Rightarrow\left(j . \alpha_{j} \in A\right)
$$

\subsubsection{Lógica Linear Temporal (LTL)}

A lógica temporal linear (LTL) é um formalismo que tem o objetivo de tratar aspectos de execução do sistema e questões de imparcialidade. É baseada em uma notação intuitiva e matematicamente precisa e estende a lógica proposicional ou de predicado.

O domínio temporal da LTL é o tempo discreto, sendo que a natureza do tempo na LTL é linear, ou seja, há apenas um sucessor a cada estado. A lógica de árvore computacional (CTL), por sua vez, conta com uma estrutura de árvore, ou seja, há um nó principal e diversas ramificações. A CTL é baseada no tempo ramificado.

A notação básica utilizada na LTL é apresentada na Tabela 2 , com os símbolos correspondentes e os agrupamentos:.

Algumas propriedades LT, utilizando-se as notações LTL, aplicadas ao problema do exemplo da exclusão mútua são apresentadas a seguir: 
Tabela 2 - Notação LTL em forma de símbolos.

\begin{tabular}{|c|c|}
\hline Símbolo & Operação \\
\hline$\square$ & sempre \\
$\diamond$ & eventualmente \\
$\wedge$ & conjunção \\
$\vee$ & disjunção \\
$\neg$ & negação \\
$\rightarrow$ & implicação \\
$\leftrightarrow$ & equivalência \\
$\oplus$ & OU exclusivo \\
$\bigcirc$ & próximo \\
$\cup$ & até que \\
$\square \diamond$ & por infinitas vezes \\
$\diamond \square$ & eventualmente para sempre \\
\hline
\end{tabular}

LTL para o problema da exclusão mútua

- Segurança: P1 e P2 nunca devem ter acesso simultaneamente às suas seções críticas

$$
\square\left(\neg \text { crit }_{1} \vee \neg \text { crit }_{2}\right)
$$

- Vivacidade: cada processo Pi está em sua seção crítica por infinitas vezes

$$
\left(\square \diamond \text { crit }_{1} \vee \square \diamond \text { crit }_{2}\right)
$$

- Solução do problema utilizando um semáforo binário y

$$
\square\left((y=0) \rightarrow \text { crit }_{1} \vee \text { crit }_{2}\right)
$$

\subsection{Verificação de modelos LTL baseada em autômatos}

Sendo um TS finito, sem estados terminais, e uma fórmula LTL $\varphi$ que formaliza um requisito de TS. Verifica-se se $T S \models \varphi$. Caso $T S \not \models \varphi$, é apresentado um contraexemplo: prefixo finito de um caminho infinito em $T S$ onde $\varphi$ não é válido.

A verificação de modelos LTL baseada em autômatos é feita pelo algoritmo baseado em Vardi e Wolper (1986), do seguinte modo: cada fórmula LTL $\varphi$ pode ser representada por um autômato não determinístico de Büchi (NBA) e a ideia básica é tentar refutar $T S \models \varphi$, procurando por um caminho $\pi$ em que $\pi \not \models \varphi$. Para checar se a propriedade $\varphi$ é válida, constroi-se um NBA para a negação de $\varphi$ e aplica-se técnicas de interseção.

Def. Autômato de Büchi:

O autômato de Büchi é definido pela tupla $\langle S, I, \delta, F\rangle$, onde:

$S$ : conjunto de estados;

$I \subseteq S:$ conjunto de estados iniciais;

$\delta \subseteq S \times S:$ relação de transição; 
$F \subseteq S:$ conjunto de estados de aceitação.

Um autômato de Büchi aceita traços infinitos, sendo que uma sequência infinita de estados é aceita se e somente se ela contém estados de aceitação por infinitas vezes.

\section{Aceitação por Autômato de Büchi}

As seguintes palavras seriam aceitam pelo autômato da Figura 6, pois o estado $S_{2}$ é sempre alcançado no infinito:

$$
\begin{aligned}
& \sigma_{1}=S_{0} S_{1} S_{2} S_{2} S_{2} S_{2} \ldots \\
& \sigma_{2}=S_{0} S_{1} S_{2} S_{1} S_{2} S_{1} \ldots
\end{aligned}
$$

A seguinte palavra, no entanto, não seria aceita pela razão inversa:

$\sigma_{3}=S_{0} S_{1} S_{2} S_{1} S_{1} S_{1} \ldots$

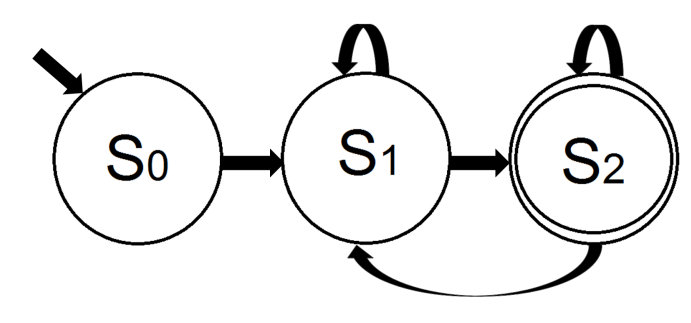

Figura 6 - Modelo de autômato de Büchi.

\subsection{Lógica de Árvore Computacional (CTL)}

Enquanto a LTL baseia-se na noção linear do tempo, representada por um TS com uma sequência infinita de estados, a lógica de árvore computacional (CTL) baseia-se na noção ramificada de tempo, que é representada por uma árvore infinita de estados. A noção ramificada de tempo define que, a cada momento, deve haver diversos estados futuros possíveis, o que define uma árvore de estados.

A notação utilizada na CTL permite que as propriedades sejam expressas para algumas ou todas as computações, sendo assim:

Def. Notação da CTL

$\exists$ quantificador de caminho existencial

$\forall$ quantificador de caminho universal

A simbologia adotada por Baier e Katoen (2008) não é usual na descrição textual. Por isso, para descrever modelos CTL em modelos textuais, normalmente se utiliza a nomenclatura da Tabela 3 .

A Figura 7 mostra um exemplo visual de fórmulas CTL básicas. 
Tabela 3 - Notação CTL em forma de símbolos e em forma textual.

\begin{tabular}{|c|c|c|}
\hline Símbolo & Texto & Operação \\
\hline$\exists$ & $\mathrm{E}$ & existe \\
$\forall$ & $\mathrm{A}$ & para todo \\
$\neg$ & ! & negação \\
$\bigcirc$ & $\mathrm{X}$ & próximo \\
$\cup$ & $\mathrm{U}$ & até que \\
$\square$ & $\mathrm{G}$ & globalmente \\
$\diamond$ & $\mathrm{F}$ & finalmente \\
\hline
\end{tabular}

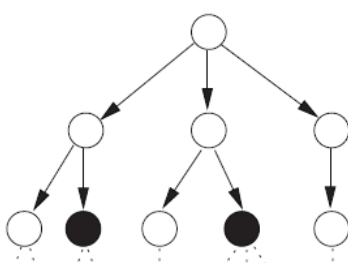

$\exists \triangleright$ black

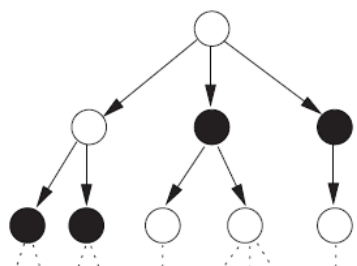

$\forall \triangleright$ black

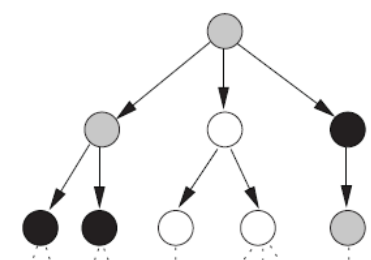

$\exists($ gray $\cup$ black $)$

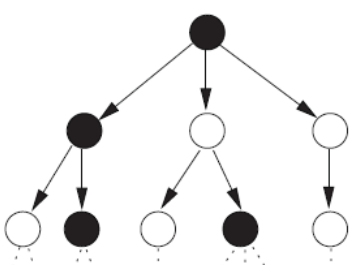

$\exists \square$ black

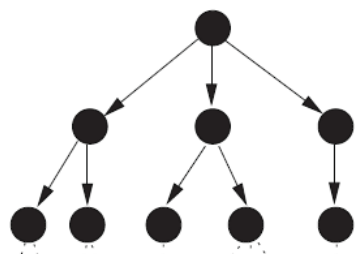

$\forall \square$ black

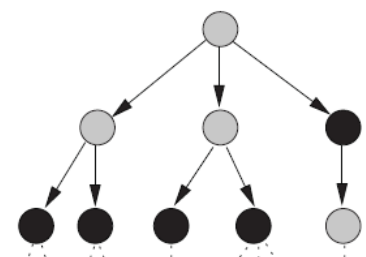

$\forall($ gray $\mathrm{U}$ black $)$

Figura 7 - Visualização da semântica de algumas fórmulas CTL básicas - Retirado de Baier e Katoen (2008).

Há particularidades tanto em LTL quanto em CTL, porém há casos em que as propriedades podem ser derivadas em ambas as lógicas, como observado na Tabela 4 .

Tabela 4 - Derivação de propriedades LTL em CTL.

\begin{tabular}{|l|cc|}
\hline & Fórmula LTL & Fórmula CTL \\
\hline eventualmente: & $\exists \triangleright \phi$ & $\exists($ trueU $\phi)$ \\
& $\forall \diamond \phi$ & $\forall($ trueU $\phi)$ \\
\hline sempre: & $\exists \square \phi$ & $\neg \forall \diamond \neg \phi$ \\
& $\forall \square \phi$ & $\neg \exists \diamond \neg \phi$ \\
\hline
\end{tabular}





\section{Sistemas de Tráfego Aéreo}

\subsection{Descrição}

O objetivo dessa seção é descrever o funcionamento de sistemas de tráfego aéreo, utilizando como base os trabalhos relacionados e identificar os tipos de propriedades relevantes para se fazer a verificação formal.

Os sistemas de tráfego aéreo podem ser considerados sistemas críticos, já que o controle do espaço aéreo é uma atividade que convive frequentemente com o risco de graves acidentes. São considerados também sistemas de tempo real, pois dependem de respostas em períodos de tempos bem definidos. Segundo Bessam e Kimour (2008), uma tarefa de tempo real é caracterizada por ter um agendamento para sua execução, e pode ser periódica ou aperiódica, ativada por uma interrupção externa. Sistemas de tempo real devem completar suas rotinas dentro de prazos bem determinados, para garantir a segurança da sua execução.

Segundo ICAO (2008), o sistema de Gerenciamento do Tráfego Aéreo (ATM) é uma integração de diversos itens de diferentes categorias, incluindo humanos, informação, serviços e tecnologia. A tarefa do sistema de ATM é "manter o tráfego aéreo global organizado, interoperável, confiável, eficiente e seguro" (AZZOPARDI, 2015). O ATM é composto tanto pelo Controle de Tráfego Aéreo (ATC), quanto pelo Gerenciamento de Fluxo de Tráfego Aéreo (ATFM). O sistema ATC em operação atualmente é um sistema distribuído por construção, já que o espaço aéreo é divido em áreas e setores de controle, cada um com poder de decisão em sua área. A Figura 8 ilustra a divisão do espaço aéreo brasileiro em 5 regiões de informação de voo (FIR). Cada FIR é dividida em diversos setores e cada controlador de voo é responsável por um setor, que comporta aproximadamente 15 aeronaves (ERZBERGER, 2004).

Segundo Oliveira (2007), a estrutura básica dos sistemas de tráfego aéreo não evoluiu muito desde os anos 60, quando se introduziu a tecnologia Radar. Os sistemas de tráfego aéreo atuais atuam como uma ferramenta de suporte à decisão e seus principais usuários são os controladores de voo. A automação nesses sistemas ainda é considerada secundária, porém se torna cada vez mais relevante, uma vez que possibilita que as aeronaves voem com uma distância menor entre elas, permitindo assim uma melhor utilização do espaço aéreo. Eventuais falhas de sistema podem influenciar apenas na capacidade e na eficiência, mas não na segurança da operação. Quando há alguma falha e os sistemas estão indisponíveis (modo degradado), os controladores devem ser capazes de gerenciar o tráfego aéreo sem utilizar o software como auxílio (PIZZO, 2008).

Segundo Pizzo (2008), o controle de tráfego aéreo pode ser dividido em quatro mo- 


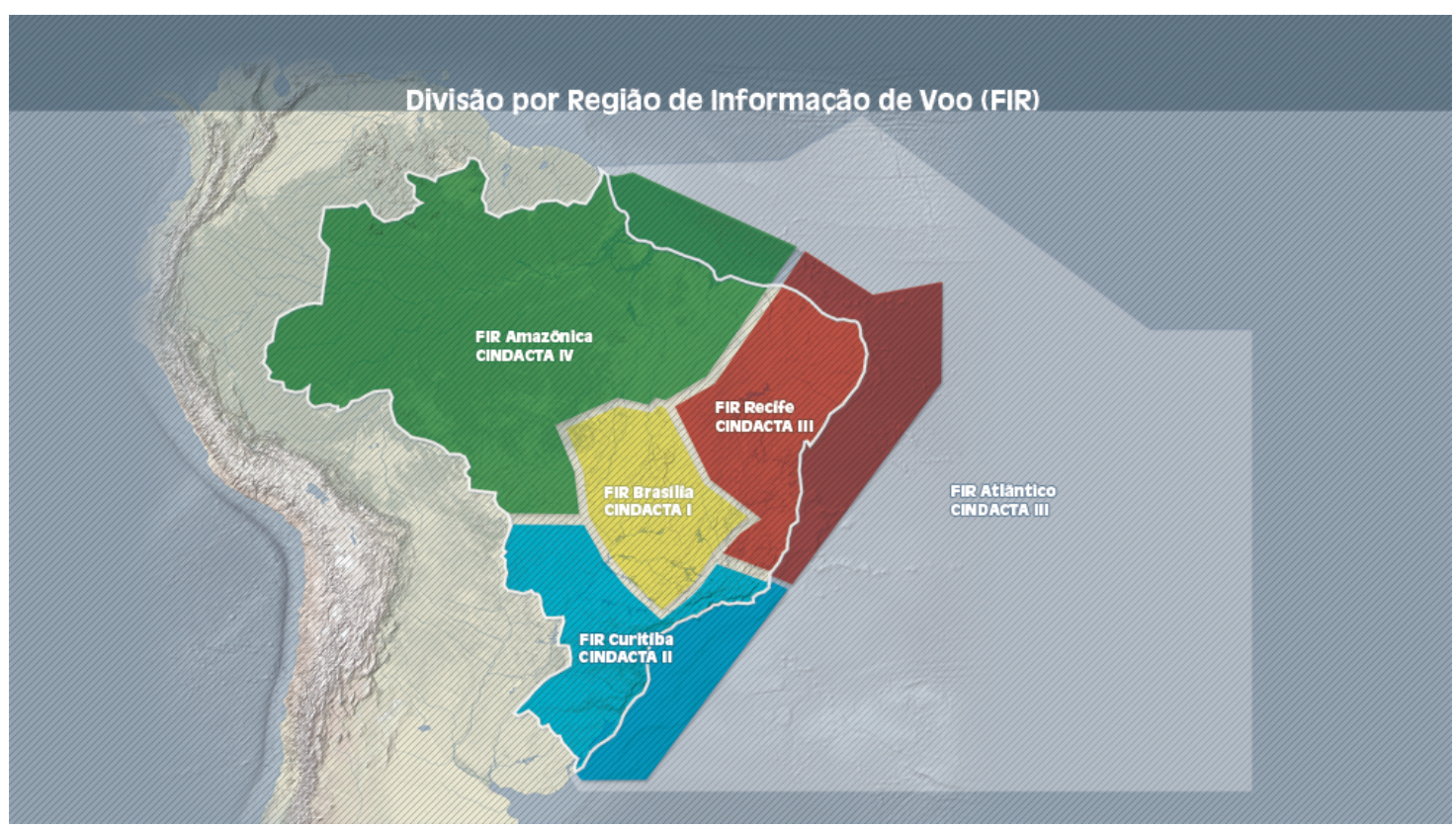

Figura 8 - Divisão do espaço aéreo brasileiro em 5 FIR - Retirado de DECEA (2018).

mentos distintos:

i. Torre de controle (TWR): responsável pelo gerenciamento de pousos e decolagens de aeronaves. Escala temporal - segundos a minutos;

ii. Controle de aproximação (APP): responsável pelo gerenciamento do tráfego nas áreas terminais (próximas a grandes aeroportos), desde o pouso ou a decolagem até a fase em rota. Escala temporal - minutos a segundos;

iii. Centro de Controle em Área (ACC): responsável pelo gerenciamento de aeronaves em rota. Escala temporal - horas;

iv. Gerenciamento de fluxo de tráfego aéreo (ATFM): responsável pela otimização do fluxo de tráfego aéreo, tarefa anterior ao controle, também responsável pela decisão de médio e longo prazo. Escala temporal - dias a meses.

O trajeto convencional de uma aeronave se inicia em um aeroporto, com a autorização para decolagem da TWR. Então, a subida da aeronave é conduzida pelo APP até o nível correspondente da aerovia e, em seguida, é controlada pelos diversos ACC em sua rota (PIZZO, 2008). A Figura 9 ilustra a variação temporal de uma aeronave, como descrito anteriormente, e relaciona-se a quem é responsável pelo seu controle. 


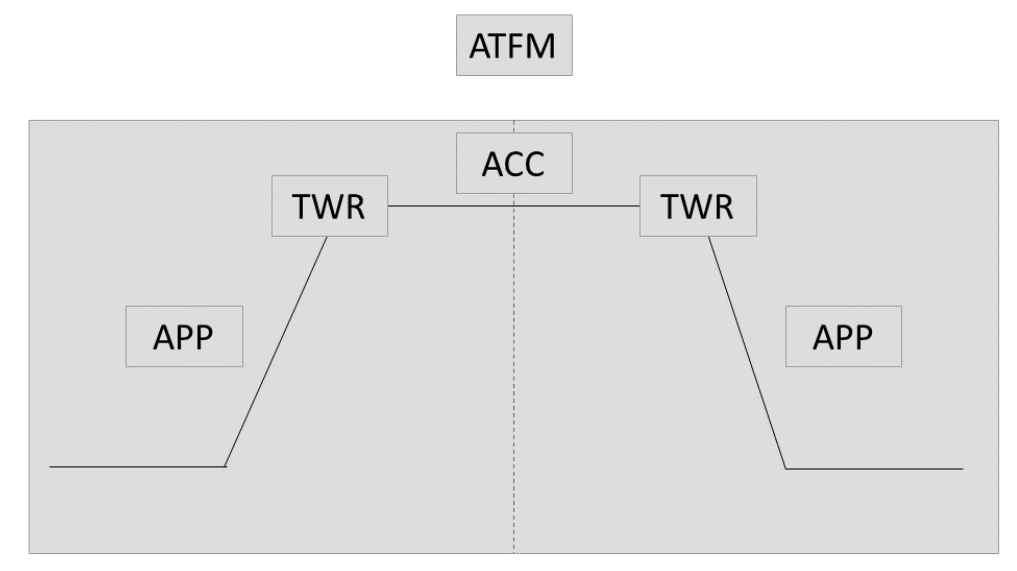

Figura 9 - Evolução temporal do controle de uma aeronave.

\subsection{Conceitos básicos}

Pista Radar ou apenas pista (Figura 10) é o nome dado para o conjunto de informações que tem origem em uma deteç̧ão de uma aeronave por um radar (ou em uma fusão de várias detecções). Cada pista contém informações de posição, altitude, velocidade, código de identificação (denominado indicativo da aeronave/callsign), entre outras, e é enviada aos Centros de Controle para composição de uma síntese da situação aérea, que é apresentada aos controladores de voo (PIZZO, 2008). Faz-se também um cálculo de extrapolação para prever a posição da aeronave em alguns minutos, levando-se em conta seu rumo (ou sentido) e sua velocidade. Algumas aplicações são por exemplo prevenção de colisões e transferência de planos de voo.

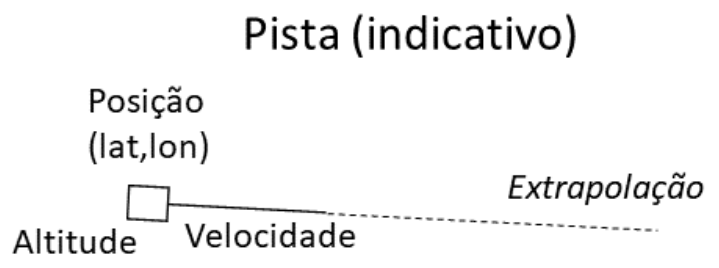

Figura 10 - Elementos de representação de uma Pista.

A forma de vigilância mais comum atualmente é a vigilância por radar. Há dois tipos de radares que são utilizados, o radar primário e o radar secundário NAVARRETE, 2006). O radar primário é considerado um tipo de vigilância passiva, em que sinais são emitidos a cada ciclo de geralmente 4 a 10 segundos e depois são recebidos após reflexão na aeronave, a qual não oferece nenhum tipo de resposta. Uma desvantagem é a ausência de algumas informações da aeronave, como sua identificação e sua altitude, por exemplo. O radar secundário é considerado um tipo de vigilância independente, em que, a cada ciclo, os sinais são enviados à aeronave e um equipamento chamado transponder envia uma 
resposta, contendo além de informações da posição da aeronave, informações de altitude, velocidade e indicativo.

O plano de voo (FPL, representado na Figura 11) é um documento anterior ao voo submetido à autoridade responsável pela Aviação Civil e, em linhas gerais, contém informações de identificação da aeronave (por exemplo, código de identificação, modelo da aeronave), de equipamentos presentes na aeronave, de partida (por exemplo, local e horário de partida), de rota (ou seja, por quais pontos - também chamados de aeródromos a aeronave deverá passar) e de destino (por exemplo, local e horário da chegada) (ICAO, 2007a).

\subsection{Arquitetura}

\subsubsection{Gerenciamento do Tráfego Aéreo (ATM)}

Segundo ICAO (2008), o sistema deve "ser capaz de coletar e integrar informação de diversas fontes para produzir uma visão completa e acurada do estado do sistema ATM", também especificado como o fornecimento de "uma consciência situacional compreensiva e gerenciamento de conflitos", além de "reunir a figura integrada da melhor maneira possível da situação do sistema ATM, seja em um estado histórico, em tempo real ou planejado/esperado ".

As definições a seguir são propostas por Azzopardi (2015). O esforço de pesquisa na área de tráfego aéreo pode ser dividido tem três categorias:

- Tipo I, alinhado com o modelo atual de ATM. Propõe-se a criação de novas ferramentas para ajudar na tarefa de controle de fluxo e na separação de aeronaves, com o objetivo de aumentar a produtividade, reduzir custos operacionais e aplicar conceitos de redes de segurança ("safety-nets");

- Tipo II, que propõe uma reformulação no modelo de ATM. Essas pesquisas estão alinhadas com os projetos de cooperação internacional SESAR (Europa), NextGen (Estados Unidos), CARATS (Japão) e SIRIUS (Brasil), que propõem a adoção de uma nova rede de compartilhamento de informações (o chamado "SWIM") e de um novo paradigma para movimentação de aeronaves (operações baseadas em trajetórias $4 \mathrm{D}$ e voo livre).

- Tipo III, que propõe uma revisão do problema de ATM, no nível de fundamentos. Ao ser concedido um alto grau de autonomia às aeronaves e ao serem adotadas soluções tecnológicas automatizadas, deseja-se alcançar novos níveis em segurança, em quantidade de aeronaves atendidas e em eficiência na gestão de voos, garantindo uma maior robustez aos sistemas, um consumo reduzido de combustível nas aeronaves e um menor impacto ao meio ambiente. 


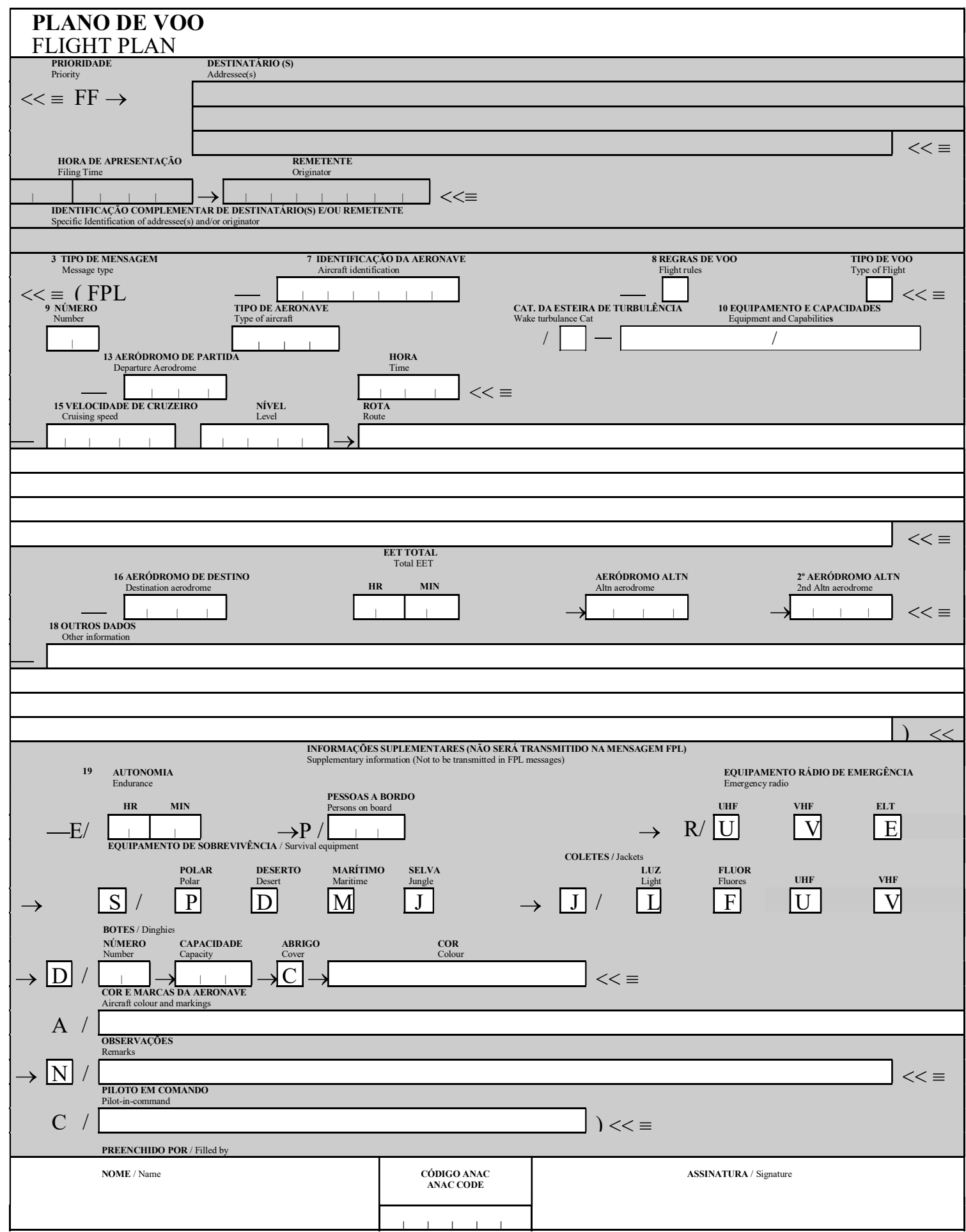

Figura 11 - Exemplo de formulário de plano de voo - Retirado de ICAO (2007a).

O presente trabalho está inserido no contexto do Tipo II, já que pretende-se aplicar a modelagem e verificação formal aos sistemas distribuídos, visando sua inserção em um futuro próximo. Essa abordagem não é aplicada nos sistemas atuais - a verificação de corretude é feita utilizando-se principalmente a abordagem de testes.

A arquitetura do sistema ATM atual é centralizada. Esse sistema é resultado de um 
conjunto de subsistemas fortemente acoplados, modelados incorretamente e é altamente não determinístico. A robustez do sistema é alcançada pela adoção desse parâmetro alto para a distância de separação mínima entre as aeronaves, o que permite certa tolerância para manobras evasivas. A tarefa principal do ATM é facilitar o controle aéreo (ATC), ao eliminar as possíveis incertezas.

O ATM não pode ser adequadamente modelado, analisado, simulado, otimizado ou controlado com segurança utilizando-se técnicas clássicas de tempo discreto ou contínuo. Ele pode ser modelado hierarquicamente como uma máquina de estados finitos, em que as mudanças de estado dependem de variáveis contínuas, que podem sofrer mudanças dinamicamente, de acordo com equações diferenciais. Algumas modelagens bem sucedidas basearam-se em modelos de autômatos híbridos, capazes de prever uma dinâmica não muito precisa, perturbações externas não determinísticas e falhas aleatórias, considerando simultaneamente as diversas interações entre estados discretos e contínuos do sistema.

Azzopardi (2015) propõe uma nova abordagem para o ATM, chamado de Gerenciamento de Tráfego Aéreo Computacional (CATM). Segundo essa nova abordagem, o ATM seria totalmente automatizado, diferentemente do ATM atual, que tem como pilar central a atividade humana.A adoção de um parâmetro de separação mínima para aeronaves com valor alto garante a segurança, mas se traduz em uma restrição na capacidade do tráfego aéreo. Para o futuro, pretende-se adotar ao menos parcialmente o conceito de voo livre, em que o piloto tem mais liberdade para conduzir o seu voo, baseando-se nos sensores presentes na própria aeronave. Esse conceito difere do conceito vigente atualmente, que possui como personagem principal o controlador de voo. A principal vantagem da adoção desse conceito é permitir uma distância de separação entre as aeronaves menor e, assim, uma melhor distribuição e uma maior intensidade de tráfego aéreo.

A arquitetura proposta para o cenário futuro considera cada uma das aeronaves como um centro de controle, que possui a capacidade de cooperar tanto com as informações presentes na própria aeronave, quanto com as informações recebidas de aeronaves adjacentes. Propõe-se a utilização de uma nova infraestrutura de comunicação, construída com datalinks ponto a ponto (p2p). A Figura 12 mostra uma visão esquemática da arquitetura do CATM. 


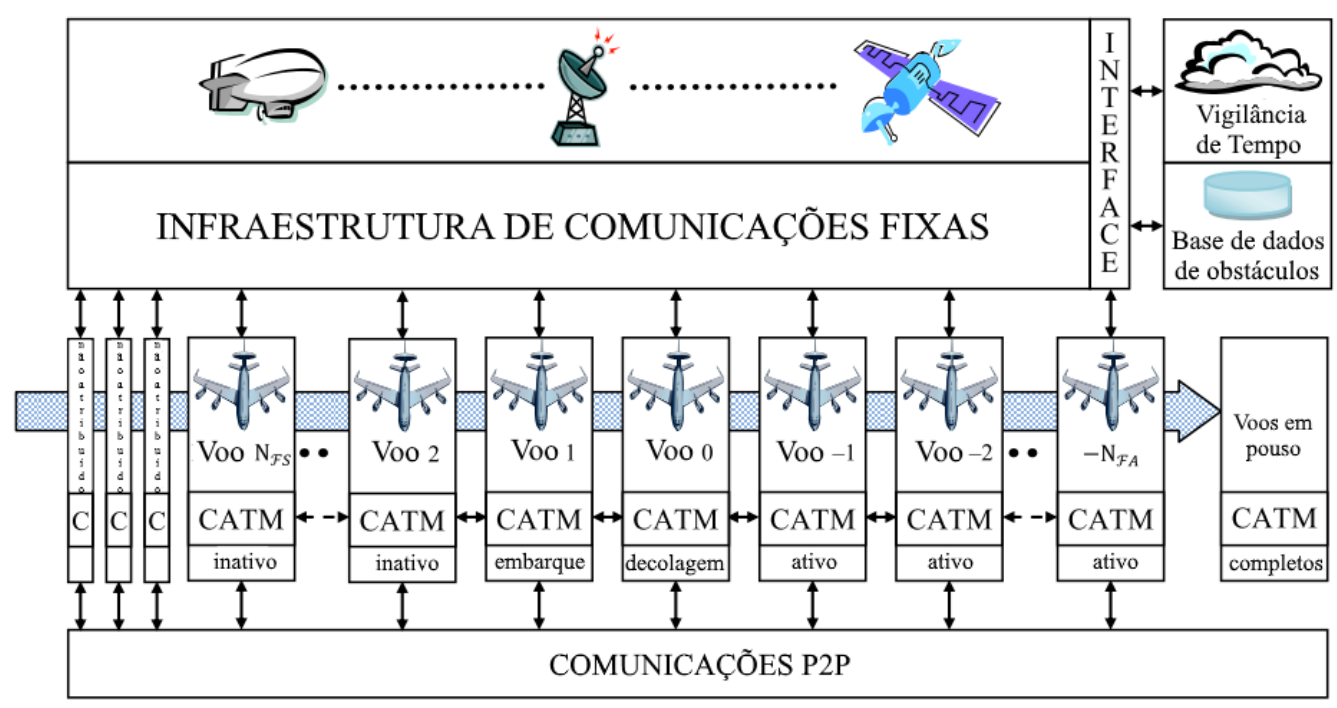

Figura 12 - Arquitetura do CATM - Adaptado de Azzopardi (2015).

\subsubsection{Controle de Tráfego Aéreo (ATC)}

Tipicamente, os sistemas ATC possuem as seguintes interfaces: recebimento de dados de aeronaves em tempo real, coletados através de sensores radar; recebimento de dados meteorológicos; troca de informações de plano de voo; troca de mensagens entre os centros de controle (APP e ACC) e as torres de controle (TWR) (mensagens de coordenação, mensagens relativas a planos de voo). O sistema computacional é composto pelos servidores que processam essas informações recebidas, por visualizadores (para visualização de informação condensada, em apoio à tomada de decisão do controlador) e por bancos de dados (para armazenamento de informações de aeronaves, de planos de voo e de delimitações de áreas do espaço aéreo, além de informações sobre as decisões tomadas pelos controladores) (PIZZO, 2008; ROSSI; KANASHIRO, 2010). Um diagrama simplificado dessas interfaces é apresentado na Figura 13. 


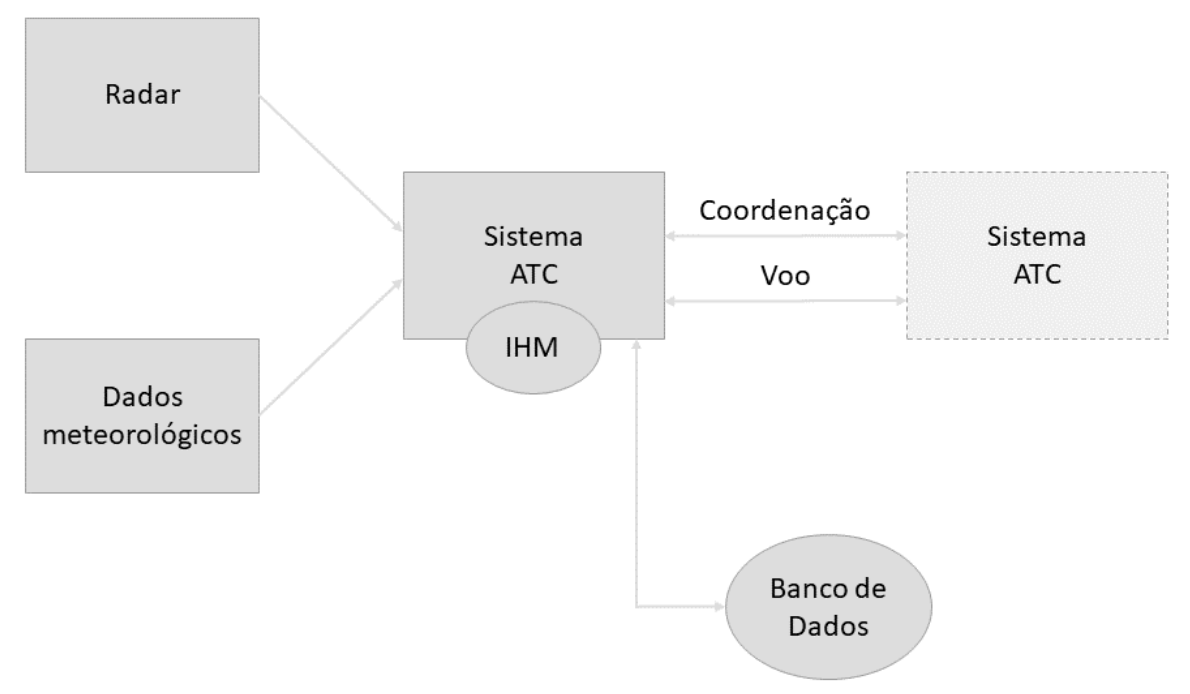

Figura 13 - Diagrama simplificado de interfaces de um sistema ATC.

A Figura 14 representa a arquitetura do sistema ATC americand ${ }^{1}$ uma visão detalhada da arquitetura da Figura 13, em que as interfaces são representadas pela parte de vigilância, que incorpora radares e outros sensores, como Automatic dependent surveillance - broadcast (ADS-B), pela parte de meteorologia e pela troca de mensagens com outros sistemas (Torre de controle e centros de controle APP e ATCSCC). Dentre as funções do sistema, destaca-se o processamento e a exibição de informações críticas relacionadas a missões e, como apresentado anteriormente, também navegação, vigilância, comunicação e funções de meteorologia. Esse sistema é um sistema crítico em segurança, que continuamente faz trocas de dados em tempo real.

O sistema ATC americano foi modernizado em Stillman (1997) com o objetivo de se adequar ao aumento da densidade do tráfego de aeronaves, garantindo-se segurança e eficiência.

\subsection{Requisitos}

Para se fazer um trabalho de modelagem e verificação formal, é necessário fazer um levantamento de requisitos de negócio, que em seguida devem ser traduzidos a requisitos de sistema, para então se identificar as propriedades de interesse. Para o domínio de tráfego aéreo, os requisitos normalmente são muito genéricos ou vagos, a ponto de não ser possível traduzir o requisito como uma propriedade verificável. Nessa seção, reúne-se os requisitos mais importantes afim de se compreender qual o foco principal para a verificação formal.

Segundo Barbacci et al. (1995), os sistemas críticos possuem características bem específicas, dentre as quais: operação contínua ou quase sem paradas, integração com os mais

1 Para o significado das siglas, consultar Stillman (1997). 


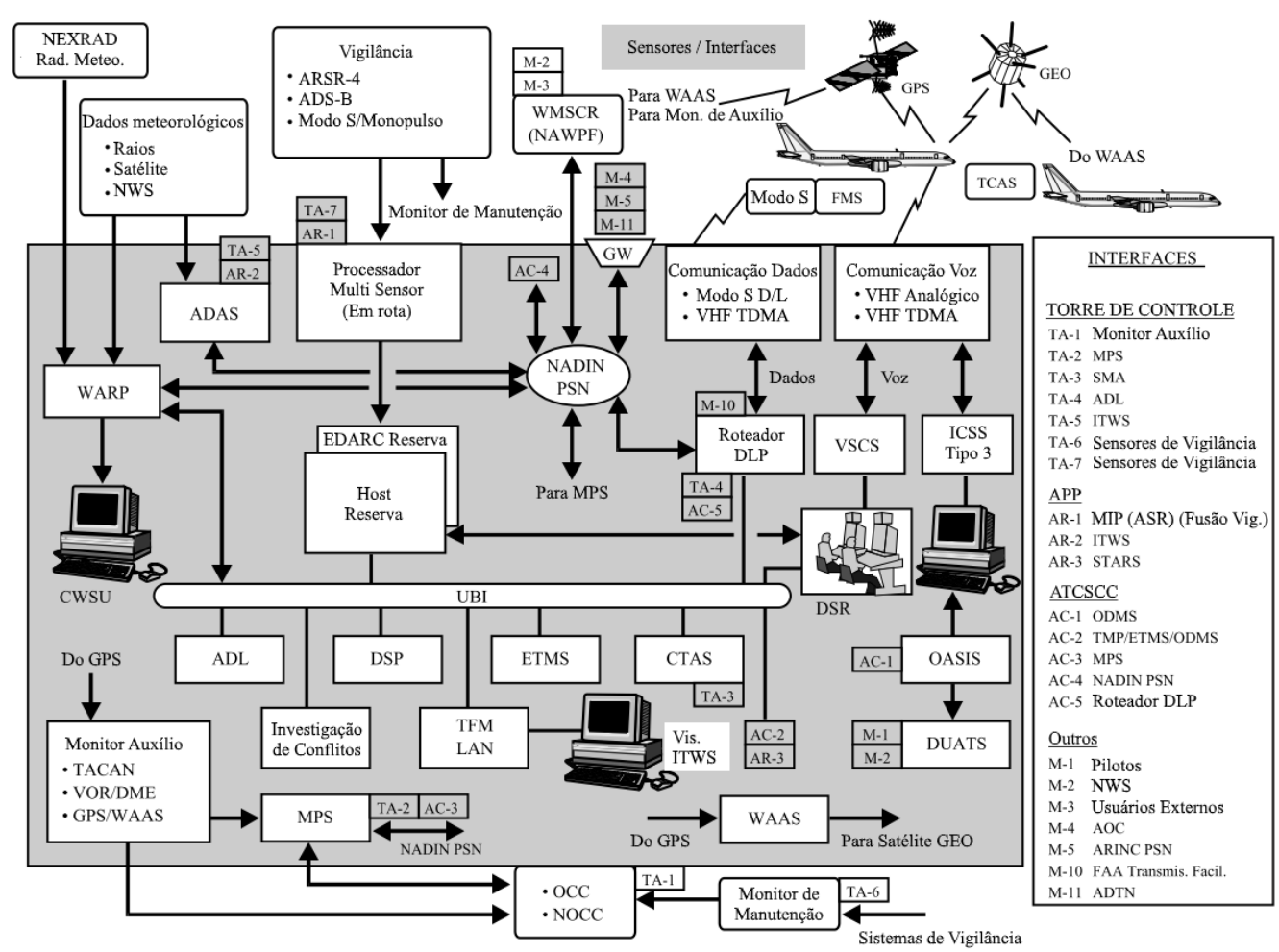

Figura 14 - Arquitetura do sistema ATC americano - Adaptado de (STILLMAN, 1997).

diversos tipos de Hardware e também necessidade de se satisfazer atributos particulares que garantam a qualidade do sistema de software.

A International Civil Aviation Organization (ICAO) define 11 áreas chave de desempenho (KPAs) para o ATM, juntamente com seus indicadores chave de desempenho (KPIs) como princípios básicos. Segundo Azzopardi (2015), porém, esses requisitos são muito genéricos, então seu trabalho propõe outros KPAs em nível de sistema:

- Escalabilidade;

- Robustez, sem ponto único de falha. Esse requisito pode ser alcançado ao se embarcar o ATM nas aeronaves;

- Otimização Multi-Objetivos, em diversas variáveis;

- Proteção ambiental;

- Controle de estados do voo em tempo real, levando-se em conta a trajetória ótima;

- Balanceamento de recursos, visando maximizar a utilização do espaço aéreo;

- Adaptabilidade contínua. Leva-se em conta que há diversos fatores que não podem ser controlados, assim, o ATM deve utilizar todos os recursos disponíveis para se adaptar; 
- Resiliência, com uma reorganização rápida no caso de interferências externas;

- Priorização. Possibilidade de uma companhia aérea solicitar um nível diferente de prioridade para voos específicos;

- Dispersão de Penalidades. Em eventuais cenários de eventos inesperados, os efeitos devem ser dispersos entre todos os membros do espaço aéreo;

- Interoperabilidade com ferramentas de informação geográfica (GIS), de dados meteorológicos, por exemplo e com diversos outros bancos de dados;

- Habilidade preditiva para estados futuros do tráfego aéreo.

No documento ICAO (2008), define-se os requisitos do ATM, de modo geral. Destaca-se a seguir um exemplo dos requisitos mais relevantes ao presente trabalho, exemplificando a forma que eles são tratados no documento:

- Segurança: o princípio da segurança é baseado em evidências, logo todos os dados de segurança devem ser gravados, processados e analisados conforme o local de interesse;

- Capacidade: é necessário fornecer ao sistema o nível acordado colaborativamente de capacidade;

- Serviços de Informação: é necessário implementar o gerenciamento de informações em nível global do sistema; deve-se estabelecer protocolos de troca de informações para garantir que o desempenho apropriado seja alcançada dentro das regras acordadas;

- Design e engenharia de sistemas: deve ser baseado em padrões globais e procedimentos comuns;

- Design humano e automação: é desejável fazer análises de segurança acompanhadas do design do sistema; a automação deve ser usada colaborativamente onde apropriado para garantir o desempenho adequado do sistema.

O trabalho de Bass, Clements e Kazman (2003) apresenta como estudo de caso o projeto do Initial Sector Suite System (ISSS), um sistema de software e hardware que fazia parte da modernização do sistema de tráfego aéreo americano, administrado pela Administração da Aviação Federal (FAA) americana. Esse sistema foi descontinuado, porém a arquitetura concebida inspirou o sistema de ATC utilizado atualmente em território americano. Diferentemente dos documentos feitos pela ICAO, esse trabalho apresenta alguns requisitos quantitativos e não só qualitativos. Dentre os requisitos solicitados pela FAA, destaca-se: 
- Alta disponibilidade, de valor 0.99999, o que significa que o sistema pode ficar indisponível por no máximo 5 minutos por ano;

- Alto desempenho. O sistema deve ser capaz de gerenciar até 2440 aeronaves, sem perdas. Esse requisito está relacionado tanto ao processamento do sistema, quanto à carga de comunicação via rede;

- Flexibilidade para incorporar componentes desenvolvidos por terceiros;

- Habilidade para desabilitar subcomponentes do sistema;

- Habilidade para fazer modificações na funcionalidade do software e eventuais atualizações ou adições de hardware;

- Habilidade de operar com uma vasta gama de sistemas externos, tanto legados quanto eventualmente não implementados.

Lista-se outros requisitos quantitativos do sistema:

- 210 consoles por ATC. Atualmente, é possível se utilizar de virtualização ou de soluções em nuvem para esse fim (FICCO et al., 2014);

- Cada ATC pode ter de 60 a 90 posições de controle (cada com um ou mais consoles);

- Cada ATC pode controlar de 400 a 2440 aeronaves;

- Cada ATC deve suportar de 16 a 40 radares.

Baseando-se nos trabalhos relacionados e nos documentos de especificação de requisitos, não foi possível definir especificamente as propriedades a serem verificadas formalmente. Porém, levando-se em conta a escolha da linguagem SMV e das lógicas LTL/CTL e o que elas são capazes de verificar, definiu-se que o foco será em requisitos do tipo Segurança e Vivacidade. A escolha de requisitos de Segurança se justifica por se tratar de um sistema crítico e principalmente pelo enfoque dado nessa questão pelos órgãos responsáveis. A escolha de requisitos de Vivacidade se justifica pela necessidade de fluidez do sistema, para que as tarefas possam ser realizadas sem eventuais travamentos indesejados.

\subsection{Iniciativas de Modelagem e Verificação Formal em Sistemas de Tráfego Aéreo}

Nessa seção, apresenta-se o que se pode encontrar de mais atual nas áreas de modelagem e verificação formal e em sistemas de tráfego aéreo, que são o foco principal do presente trabalho. 
O trabalho de Zhao e Rozier (2014) trata o problema de perda de separação de aeronaves, ou seja, quando as aeronaves estão se aproximando e há uma possibilidade de colisão futura. Esse cenário pode ser dividido em três fases conforme o tempo que falta para a colisão. As aeronaves podem ser divididas conforme o tipo de equipamento que possuem: as aeronaves comuns que precisam necessariamente de comandos do ATC em solo para operar, aeronaves que possuem sensores para envio de sua posição e recebimento da posição de outras aeronaves e por isso é capaz de fazer o controle autônomo. A modelagem é feita na ferramenta NuSMV e as propriedades a serem verificadas são feitas em LTL/CTL. O motivo para a escolha do NuSMV (e cita-se também outra ferramenta chamada CadenceSMV) é o fato de ser uma plataforma livre, frequentemente utilizada na indústria.

Esse trabalho está inserido no contexto do NextGen e faz parte de uma iniciativa da NASA. Ele propõe um método que vai desde a descrição do sistema de interesse, passando pela modelagem e verificação formal, incluindo recomendações de reformulação do modelo e/ou da propriedade de interesse quando a verificação falha e é gerado um contraexemplo.

O trabalho de Muñoz, Dowek e Carreño (2004) trata de modelagem e verificação formal da operação de um centro de controle remoto automatizado. Em linhas gerais, o modelo trata as diversas posições por que uma aeronave passa desde o momento em que chega em uma região próxima ao aeroporto até o momento do seu pouso em solo ou vice-versa - do momento em que sai do solo para a decolagem até o momento em que sai dessa aérea limite do aeroporto. O modelo foi escrito na linguagem PVS (Sistema de Verificação de Protótipos), que é adequada para provador de teoremas, e foi verificado usando um algoritmo de exploração de estados explícito.

Tanto o trabalho de Zhao e Rozier (2014) quanto o de Muñoz, Dowek e Carreño (2004) tratam de modelagem de comportamento de sistemas relacionados ao domínio de tráfego aéreo. Porém não tratam de funções específicas do sistema de software implementado para ATC, por exemplo, mas sim de validação de cenários para auxiliar na tomada de decisão em um nível mais alto. O objetivo do presente trabalho é chegar em um nível mais próximo ao comportamento do software.

Define-se alto nível de abstração para a validação de regras e conceitos operacionais, como por exemplo no trabalho de Zhao e Rozier (2014), em que o foco é em modelar o comportamento esperado para o cenário de perda de separação de aeronaves. Definese baixo nível de abstração para a validação do funcionamento de módulos de software, como por exemplo no estudo de caso do presente trabalho, em que o foco é em modelar o comportamento esperado para alguns módulos do sistema de software, responsáveis por funções bem específicas.

O trabalho de Assis (2009) não trata especificamente de sistemas de tráfego aéreo. O seu foco é em sistemas de controle de veículos submarinos, que são sistemas multitarefa de tempo real, caracterizados pela concorrência de processos e comunicação em 
rede, características essas também desejáveis aos sistemas de tráfego aéreo. Ele propõe um método de modelagem e verificação formal baseado em CSP e Object-Z ("foco em processos"), posteriormente convertido manualmente ao nível de implementação para a linguagem SPARK ("foco em dados"). Não são feitas especificações formais de propriedades nesse trabalho, apenas as verificações genéricas do FDR (ferramenta que verifica deadlocks, livelocks e determinismos em CSP) e SPARK examiner (ferramenta que verifica através de anotações se há erros no fluxo de dados em SPARK) são abordadas. O código é então compilado e testado em VxWorks.

Kanoun et al. (1999) define uma nova arquitetura para o Sistema de controle automatizado do tráfego aéreo (CAUTRA) francês, um sistema de tempo real distribuído, tolerante a falhas e que demanda um alto grau de disponibilidade. O CAUTRA é responsável pelo gerenciamento de planos de voo (Processamento de Planos de Voo - FPP) e de dados de radar (Processamento de Dados Radar - RDP). A arquitetura atual do sistema é composta de dois computadores gerais de dados redundantes (DG1 e DG2). O software de cada aplicação é replicado em quatro nós: dois principais (RDPpal, FPPpal) e dois secundários (RDPsec, FPPsec). Um desenho esquemático da arquitetura é apresentado na Figura 15.

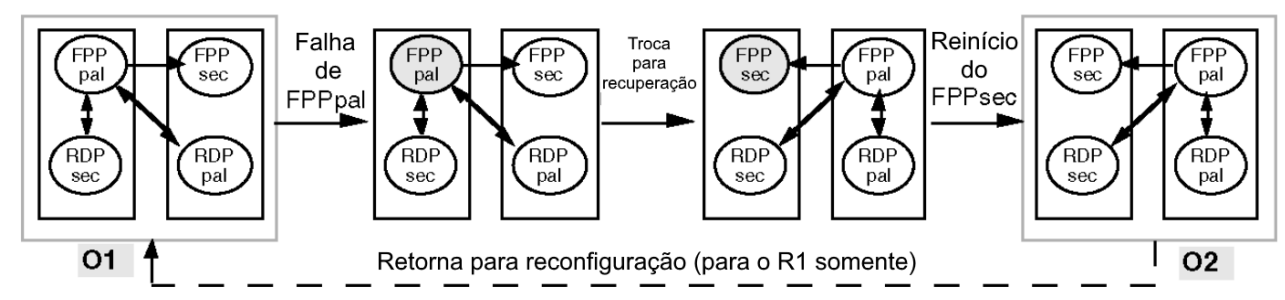

Figura 15 - Arquitetura do CAUTRA - Adaptado de Rugina et al. (2008).

São propostas algumas alternativas de arquitetura, levando-se em conta estratégias de reconfiguração e de tolerância a falha, utilizando-se Redes de Petri Estocásticas Generalizadas (GSPNs). Examina-se algumas modificações na arquitetura, como a quantidade de computadores ou a distribuição de nós, visando-se principalmente garantir a disponibilidade do sistema.

Uma evolução desse trabalho é proposta por Rugina et al. 2008 com a utilização da AADL, uma linguagem que funciona como base para realização de diversos tipos de análises, como explicado brevemente na seção 2.1. O foco do trabalho de Rugina et al. (2008) é o controlador que analisa os nós redundantes e faz a alternância entre os nós principais e os secundários em caso de falha. Três tipos de padrões de tolerância a falhas são considerados para o controlador:

- por observação simples: o componente secundário pode decidir assumir o controle, dependendo da entrada do componente primário. Há dois modos globais de operação: 
quando o componente1 é o nó primário e quando o componente2 é o nó primário;

- por observação mútua: o componente é auto-gerenciável e possui a capacidade de reinicialização em caso de falha. Há três modos particulares de operação: componente1/componente2 em modo primário, em modo de reinicialização ou em espera;

- independente: o controlador é um componente independente, que tem a tarefa de alternar entre os componentes caso detecte uma falha. Há dois modos particulares de operação: componente1/componente2 em modo primário ou em espera.

O estudo de caso é uma aplicação do controlador por observação simples para o sistema CAUTRA. Esse trabalho possui um foco muito específico (tolerância a falhas), logo, o nível de abstração abordado é alto, ou seja, não há nenhum detalhamento de módulos ou funções específicas do sistema de tráfego aéreo.

Dentre outros trabalhos relacionados, o trabalho de Coimbra et al. (2007) trata da modelagem em alto nível de um sistema ATC, porém não se utiliza a verificação formal. As decisões de arquitetura são descritas informalmente, não sendo possível dessa forma utilizar técnicas de validação automática. Assim, a enumeração de riscos necessita da análise de um profundo conhecedor do sistema de interesse, para que estejam alinhados com a realidade. Esses riscos também são de difícil detecção. O foco principal do trabalho é na simulação das possíveis soluções apontadas para resolução dos problemas enumerados.

O presente trabalho propõe um método de modelagem e verificação formal para sistemas críticos com aplicação ao domínio de tráfego aéreo, sendo parte baseada no trabalho de Assis (2009), que também propõe um método de modelagem e verificação formal, porém utilizando CSP e Object-Z e, em seguida, convertido manualmente ao nível de implementação para a linguagem SPARK, com aplicação a sistemas de controle de veículos submarinos. O trabalho de Assis (2009), porém, não propõe especificação formal de propriedades específicas, aplicando apenas as verificações genéricas do FDR, enquanto no presente trabalho as especificações são feitas em CTL e verificadas com a ferramenta NuSMV. O trabalho de Assis (2009) avança um passo no método ao se fazer a conversão a nível de implementação, enquanto o presente trabalho vai apenas ao nível anterior de modelagem e verificação formal. O método proposto no presente trabalho será abordado no capítulo 4 .

Em comparação com o presente trabalho, o trabalho de Zhao e Rozier (2014), como citado anteriormente, também trata de um sistema de tráfego aéreo, sendo abordado o problema específico de separação de aeronaves. A modelagem também é feita na ferramenta NuSMV e as propriedades a serem verificadas são feitas em LTL/CTL. A análise de contraexemplos, porém, é abordada de maneira genérica, sem entrar em detalhes de codificação e da identificação de problemas, como faz o presente trabalho. O presente trabalho apresenta um ineditismo na seleção do sistema: módulos baseados em sistemas ATC em baixo nível de abstração, com modelagem de comportamento em nível de módu- 
los do sistema de software, enquanto o sistema de Zhao e Rozier (2014) aborda um nível de abstração mais alto, com modelagem em nível de regras e conceitos operacionais do sistema. 



\section{Metodologia}

Para o presente trabalho, idealizou-se um método de modelagem e verificação formal de sistemas críticos (Figura 16), baseado em outros trabalhos de referência (POHL, 2015, ASSIS, 2009:ZHAO; ROZIER, 2014). O trabalho de Pohl (2015) tem como objetivo prover os fundamentos da engenharia de requisitos, para fins de certificação. Além de apresentar definições para o desenvolvimento de projetos de engenharia, é feita uma análise das fontes principais da definição de requisitos, inclusive das partes interessadas em cada fase de projeto. Os trabalhos de Assis (2009), Zhao e Rozier (2014) foram descritos na seção 3.5.

A definição de um requisito, segundo Pohl (2015), é "uma condição ou capacidade necessitada por um usuário para resolver um problema ou alcançar um objetivo". A definição do problema é definida como um pré-requisito e está fora do escopo do método.

Para a aplicação do método, são necessários três papéis distintos: o idealizador do sistema, que é geralmente o responsável pela equipe que vai utilizar o sistema, com apoio do usuário; o arquiteto de sistemas, responsável pelo desenho teórico da arquitetura do sistema; engenheiro de sistemas, responsável pela modelagem do sistema e pela especificação de propriedades para sua verificação.

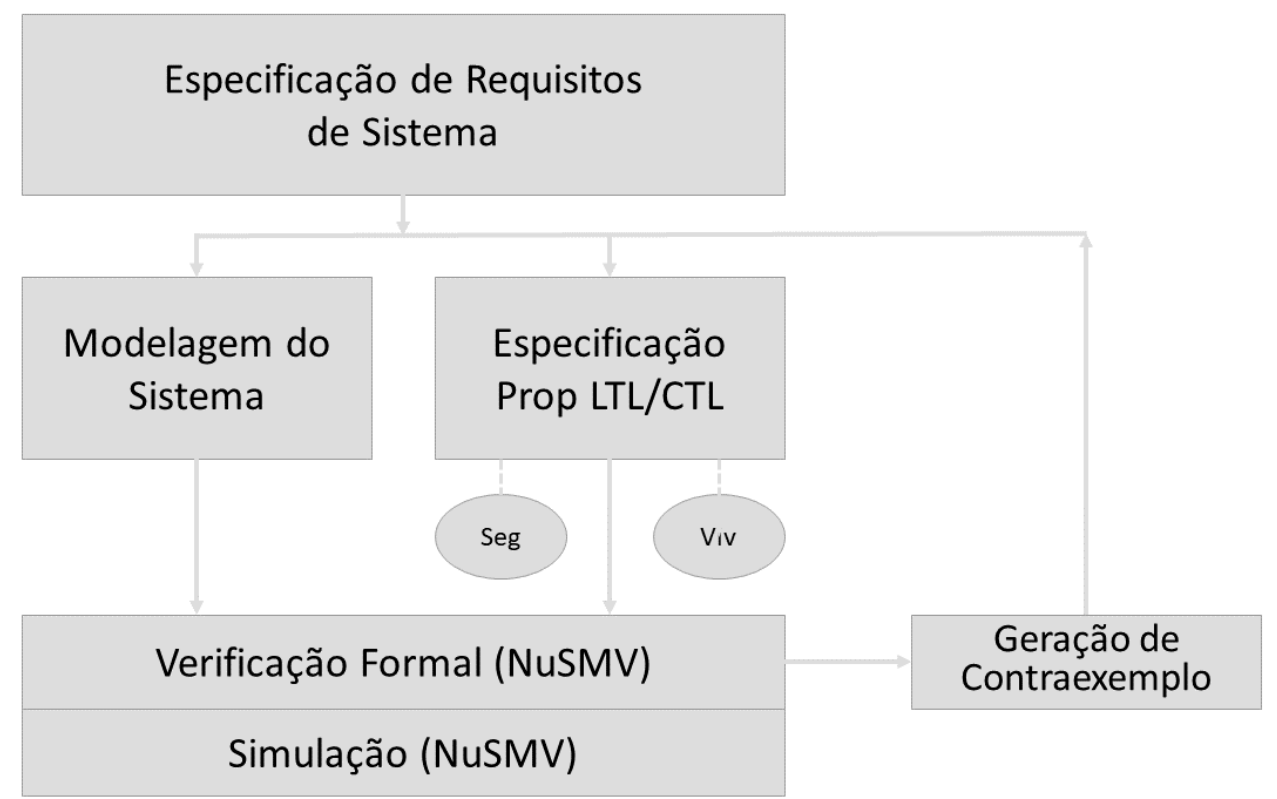

Figura 16 - Método proposto para verificação formal. 
Inicialmente, é feita a especificação de requisitos de sistema pelo idealizador, geralmente em conjunto com o arquiteto de sistemas. Nessa fase, é necessário delimitar o domínio de aplicação e também definir o escopo do desenvolvimento, ou seja, define-se os subsistemas de interesse, as entradas e saídas do sistema, as interfaces e a forma de comunicação com os elementos externos e a descrição do hardware utilizado. O foco no presente trabalho é o sistema de software, logo ao ser utilizada a palavra "sistema", subentende-se que seja de software.

Em seguida, o engenheiro de sistemas faz a modelagem do sistema em paralelo com a especificação de propriedades LTL/CTL, que na Figura 16 representam requisitos de Segurança e Vivacidade.

Então, faz-se a verificação formal utilizando a ferramenta NuSMV, com o objetivo de assegurar que o sistema modelado está de acordo com os requisitos especificados no início. Idealmente, a Especificação de Requisitos deve ser verificada com o idealizador, para que todas as partes estejam de acordo que as propriedades especificadas representam todos os requisitos especificados.

Por fim, tanto o modelo quanto as propriedades projetadas passam por uma fase de evolução. Esse aperfeiçoamento do modelo inicial e das propriedades se dá de uma forma iterativa, aplicando-se a verificação formal e fazendo as modificações que forem necessárias.

Como descrito por Zhao e Rozier (2014), a utilização do NuSMV com a especificação de propriedades utilizando-se lógicas LTL/CTL se justifica por ser uma plataforma livre e frequentemente utilizada na indústria. Adiciona-se a isso a facilidade de se realizar a verificação formal, feita através da execução de um arquivo binário e também a facilidade de geração e compreensão de contraexemplos, se comparado a outras ferramentas, como SPARK Examiner por exemplo. Há ainda a possibilidade de se fazer simulação pela entrada de dados específicos no programa para verificar manualmente a progressão de estados do modelo.

A aplicação do método no presente trabalho é feita em sistemas de tráfego aéreo, mas ela também poderia ser feita em um contexto mais geral. Dentre as limitações do trabalho, tem-se que os requisitos do sistema de interesse já foram previamente especificados e não é possível obter nenhum tipo de feedback do idealizador do sistema.

O diagrama da Figura 17 representa o método que abrange o ciclo completo da construção do sistema, desde sua concepção e especificação até sua codificação propriamente dita, passando pela modelagem e verificação formal. O ponto inicial desse processo é a idealização de um sistema de interesse e o resultado é o sistema propriamente dito, como utilizado pelo usuário final. 


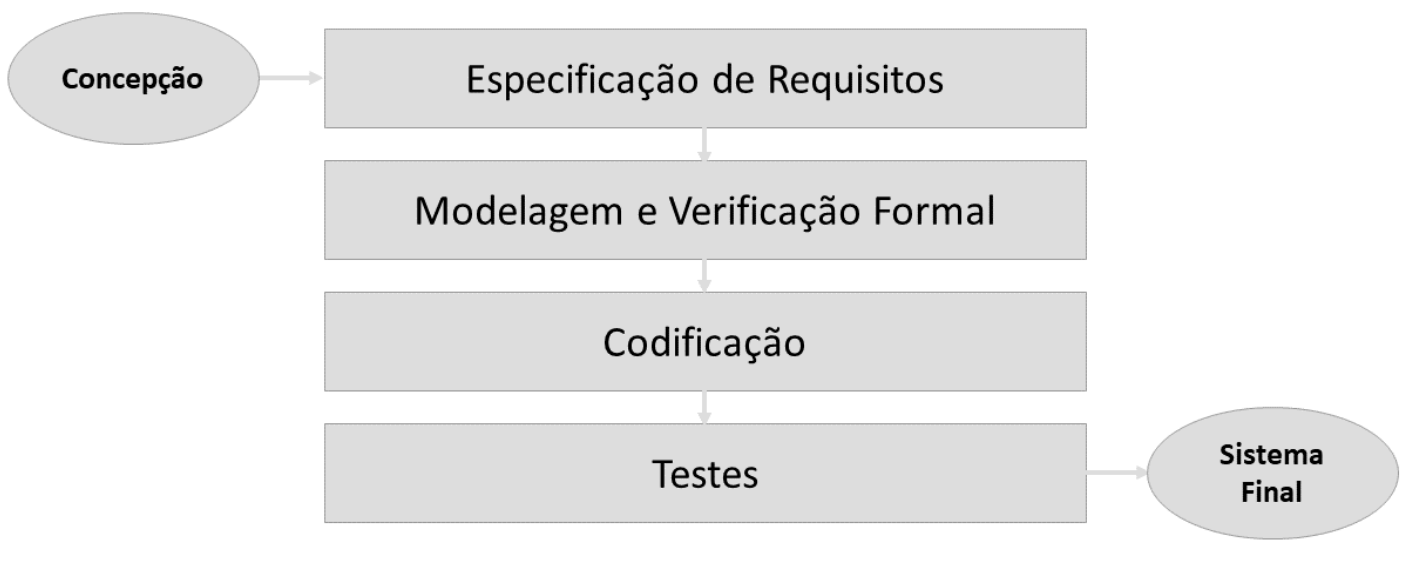

Figura 17 - Ciclo completo da construção de um sistema.

O diagrama da Figura 18 representa o método ideal, em que as fases manuais de codificação e de testes são substituídas pela geração de código a partir do modelo verificado formalmente na etapa anterior. O diagrama da Figura 19 representa um recorte da fase de Modelagem e Verificação Formal. Divide-se essa fase em duas partes: a modelagem de comportamento em LTL/CTL e a codificação em SPARK. A conversão do modelo LTL/CTL para o código em SPARK pode ser feita por mapeamento manual (utilizando-se um método análogo ao proposto por Assis (2009)) ou idealmente por geração automática de código.

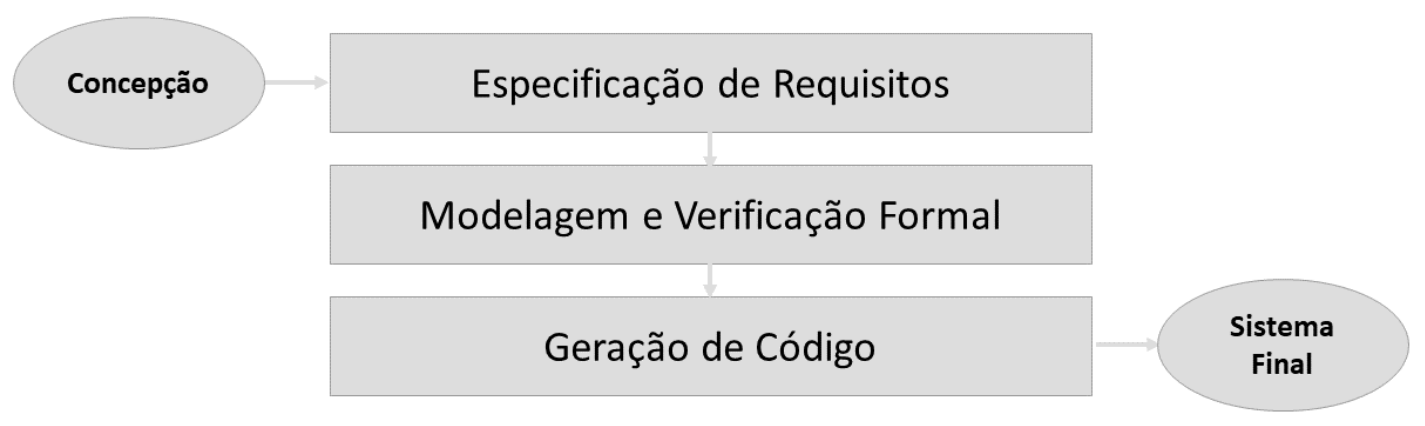

Figura 18 - Ciclo completo ideal da construção de um sistema.

Para a modelagem de comportamento, algumas opções foram analisadas, tais como AADL, Object Z e CSP, além de LTL/CTL. Para a parte de codificação, algumas linguagens que oferecem a possibilidade de verificação formal são SPARK, Frama C e Java. Alguns testes foram feitos em AADL e em SPARK, porém não foram bem sucedidos e não fazem parte do trabalho final. A vantagem principal da AADL é possuir uma representação mais genérica, com a possibilidade de tradução para modelos mais específicos conforme a necessidade de verificação, como proposto, por exemplo, em outros trabalhos citados na seção 3.5. SPARK é um subconjunto da linguagem de programação Ada, com uma extensão para possibilitar realizar verificação formal em forma de pré e pós condições em cada função declarada. 


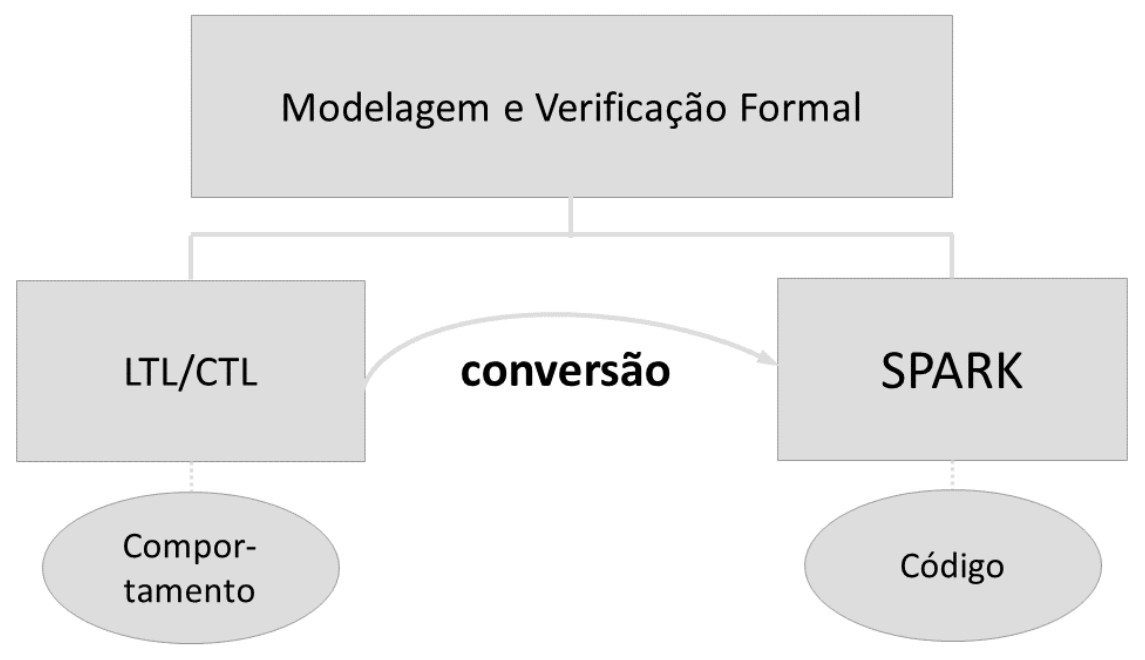

Figura 19 - Método proposto para modelagem e verificação formal.

O foco para o presente trabalho é na modelagem de comportamento, como detalhado na Figura 16. Em resumo, a descrição do sistema de interesse será apresentada na seção 5.1, a especificação de requisitos desse sistema será apresentada na seção 5.2, a modelagem em SMV será apresentada na seção 5.3 , a especificação de requisitos CTL será apresentada na seção 5.4, as diretivas para elaboração do modelo de máquinas de estados em SMV serão apresentadas na seção 5.5.1 e as diretivas para aplicação do método pela utilização do contraexemplo serão apresentadas no capítulo 5.5.2. A parte de conversão de código não será abordada. 


\section{Estudo de caso}

O estudo de caso representa uma continuidade do trabalho proposto em Aguchiku et al. (2015), que será descrito a seguir. O trabalho trata da modelagem e verificação de uma versão simplificada do Processador de Dados de Voo (FDP), um dos módulos sugeridos pela ICAO e também presente no sistema ATC brasileiro. Em linhas gerais, a tarefa do FDP é gerenciar dados de voos em uma região específica, seguindo uma série de protocolos preestabelecidos. A estrutura dos dados de voo é representada pelo plano de voo, que pode adquirir um dos seguintes estados: Inativo, Pré-Ativo, Ativo, Terminado e Arquivado. O estado Ativo é dividido em subestados, que são particularmente importantes para a operação de transferência do controle de um plano de voo entre ATCs. Essa operação de transferência baseia-se na troca de mensagens de coordenação entre os controladores de voo dos ATCs e na consequente alteração de estados do plano de voo.

Após uma simplificação, o estudo de caso proposto em Aguchiku et al. (2015) levou em conta quatro estados: Pré-Ativo, Ativo não controlado, Ativo controlado e Ativo em proposição de transferência. Para a operação de transferência entre dois ATCs, haverá duas instâncias do plano de voo, sendo uma ativa no ATC doador e uma inativa no ATC receptor. Não é permitido que dois planos de voo estejam no estado Ativo ao mesmo tempo em dois ATCs diferentes.

Resumidamente, o plano de voo inicia no estado Pré-Ativo em ambos ATCs e em seguida é ativado no ATC doador. Um contador regressivo é inicializado para simbolizar o tempo até a aeronave chegar na fronteira entre os ATCs. O processo de transferência se inicia no envio de uma mensagem do ATC doador para o ATC receptor ou automaticamente quando o contador alcança 3 unidades de tempo (requisito funcional do sistema). Então o ATC doador passa para o estado Ativo proposição de transferência. Uma mensagem de aceitação deve ser enviada do ATC receptor para o ATC doador, que passa para o estado Ativo controlado, enquanto o ATC doador passa para o estado Ativo não controlado. O foco desse estudo foi a verificação de requisitos de segurança. Utilizou-se a ferramenta AutoFocus3, com a verificação de propriedades LTL/CTL através de um plugin que faz a conversão para se utilizar a ferramenta NuSMV. A Figura 20 mostra a simulação da tarefa descrita, com as máquinas de estados dos dois ATCs e um painel de exemplo para envio de mensagens. 


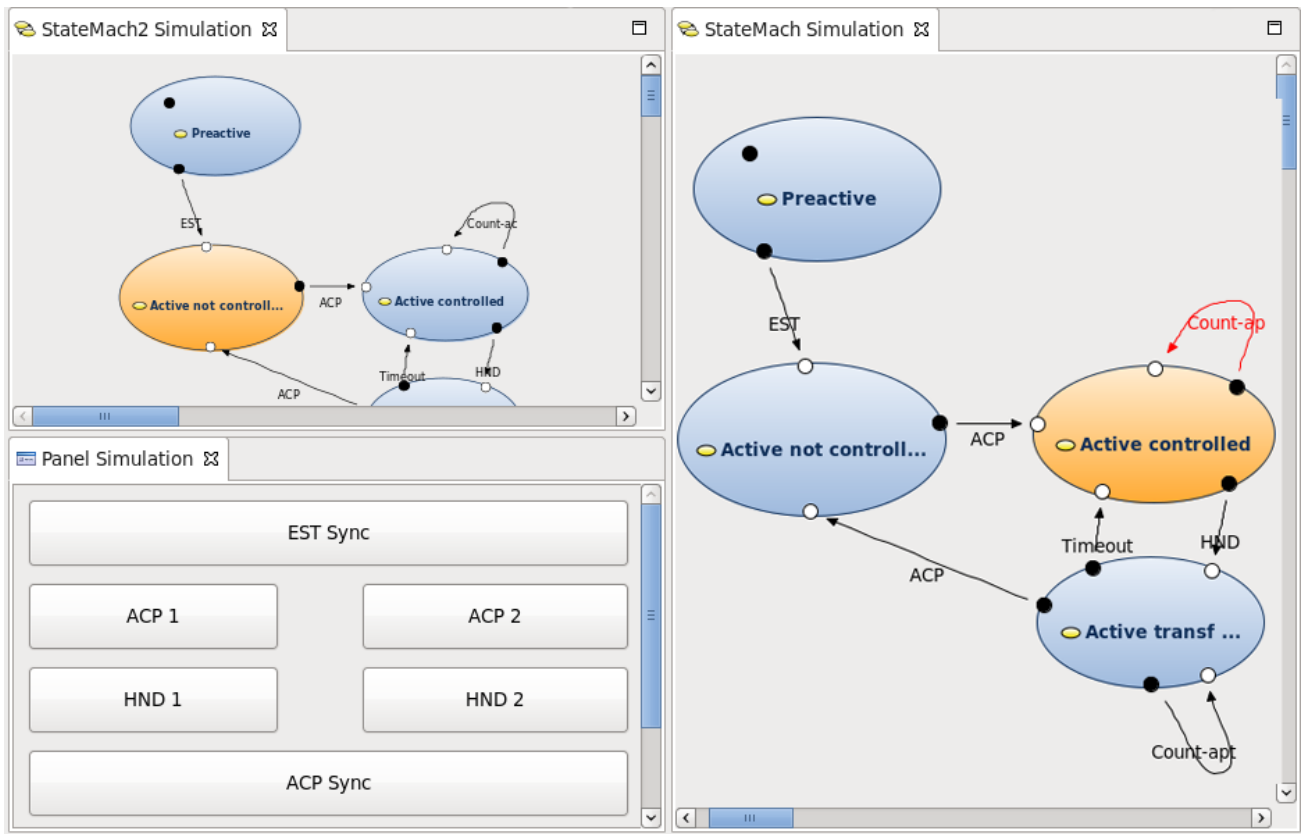

Figura 20 - Simulação do estudo de caso: transferência de um plano de voo entre ATCs - Retirado de Aguchiku et al. (2015).

\subsection{Descrição do sistema}

Os sistemas de tráfego aéreo, como apresentados no capítulo 3, são sistemas de consciência situacional, ou seja, seu objetivo é coletar informações de diversas fontes pertinentes, como radares, estações meteorológicas etc, e reuni-las da melhor forma possível para fornecer ao controlador uma visão da situação aérea atual, auxiliando-o na sua rápida tomada de decisão. Para isso, diversos algoritmos são empregados nas tarefas de, por exemplo, fusionar diferentes detecções de vários radares para exibir a posição aproximada de uma aeronave, realizar a correlação de planos de voo com as aeronaves que foram previamente detectadas e coordenar o envio e a recepção de mensagens entre centros para garantir que todo o ciclo de vida de um plano de voo seja percorrido. Para o presente trabalho, o foco será no sistema de software, em especial em três módulos relacionados: o módulo de vigilância e detecção de aeronaves (DET), o módulo de recepção e difusão de planos de voo (REC) e o módulo de correlação de planos de voo e pistas (CORR). O foco da verificação formal será na garantia de funcionamento do sistema como um todo, sendo que seus módulos funcionam em paralelo e possuem dependências entre si. Foram especificadas propriedades de vivacidade (liveness) e segurança (safety) em CTL.

O módulo identificado como REC no presente trabalho é o equivalente do módulo FDP proposto em Aguchiku et al. (2015), com a diferença de que em Aguchiku et al. (2015) o foco foi dado especificamente na função de transferência de planos de voo entre ATCs. 
O esquema da Figura 21 representa o estudo de caso, sendo:

- Sistema de interesse: representado pelo círculo;

- DET: representado pelo lado esquerdo da figura, com a recepção de pistas do Radar;

- REC: representado pelo lado direito da figura, com a recepção de mensagens de planos de voo de centros externos ao sistema;

- CORR: representado no interior da figura pela correlação entre pista e plano.

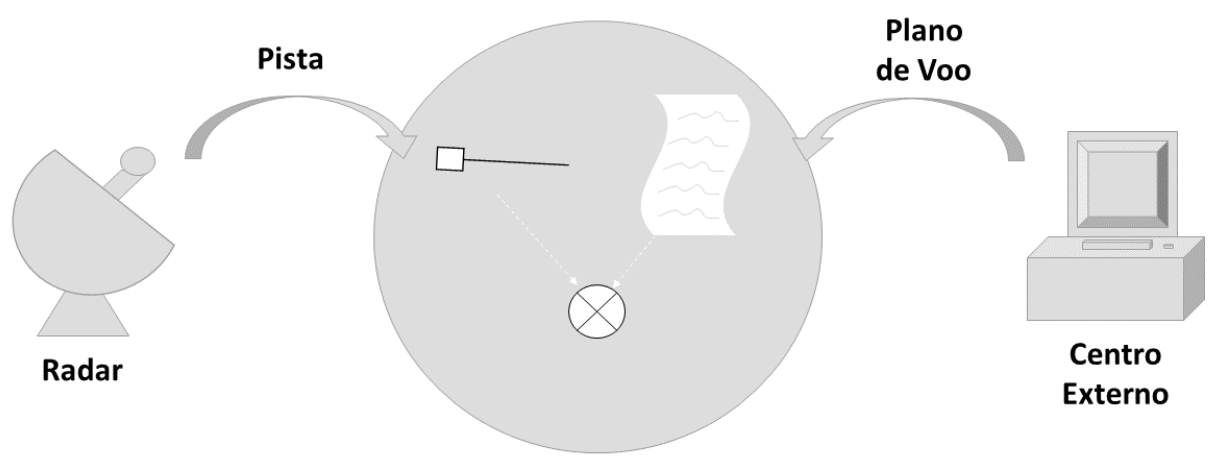

\section{Sistema}

Figura 21 - Desenho esquemático do estudo de caso e de seus componentes.

A principal tarefa do DET é receber, processar e armazenar no banco de dados as detecções de pistas provenientes do Radar, representado na Figura 22 como um sensor externo ao sistema. A máquina de estados referente ao DET é apresentada na Figura 24.

A principal tarefa do REC é receber e processar as mensagens de planos de voo do tipo AIDC (ICAO, 2007b) e armazenar no banco de dados novos planos de voo e alterações nos planos já existentes. Essas mensagens são provenientes de outros centros de controle (de tráfego aéreo), como representado na Figura 22. A máquina de estados referente ao REC é apresentada na Figura 25.

O AIDC (Comunicação de dados de interface ATS) suporta trocas de informações entre aplicações ATC em sistemas automatizados, localizados em diferentes centros de controle. As funções suportadas são as de Notificação, Coordenação e Transferência de Comunicação e Controle ICAO (2007b).

A principal tarefa do CORR é fazer a correlação entre pistas e planos de voo que apresentam o mesmo indicativo, que é um campo comum a ambas as estruturas, como apresentado na seção 3.2 . Este módulo é representado na Figura 22 como um módulo 
interno ao sistema, que não interage com o meio externo, porém utiliza-se dos dados guardados em banco para realizar a correlação. O módulo CORR não possui uma máquina de estados associada - sua tarefa é descrita através de operações feitas diretamente na linguagem SMV.

O CORR funciona de maneira assíncrona, ou seja, é acionado a cada nova rodada de pistas enviadas pelo Radar ou a cada recepção de um novo plano de voo.

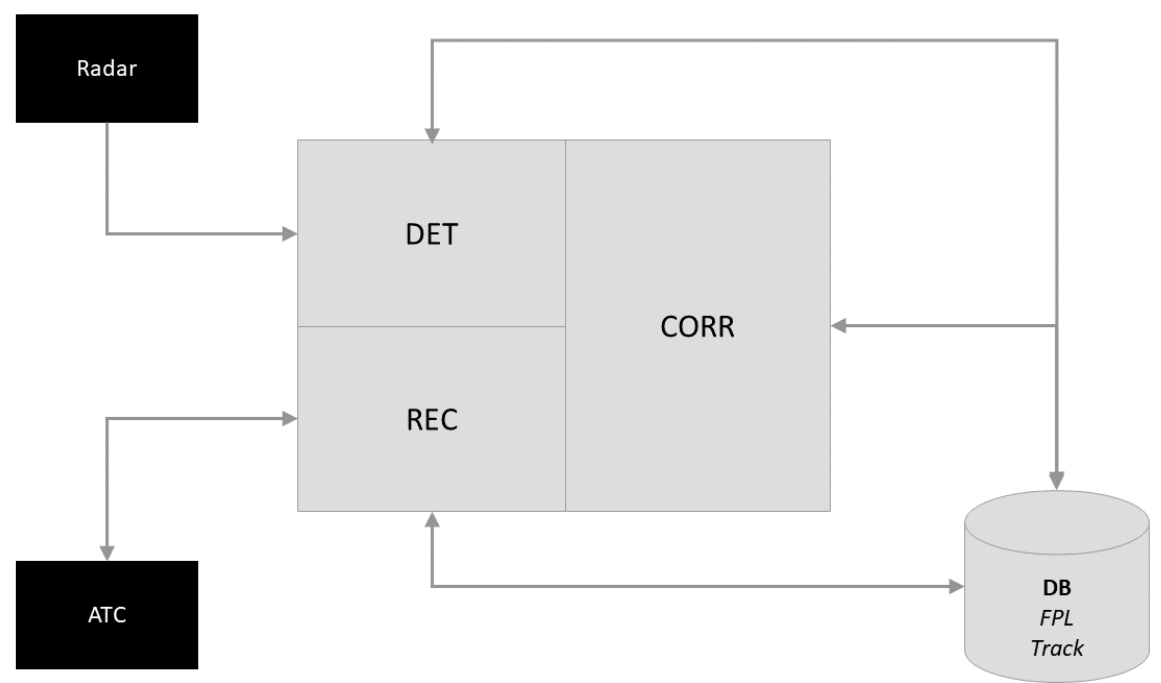

Figura 22 - Diagrama representativo do modelo do sistema de tráfego aéreo utilizado para o estudo de caso.

\subsection{Requisitos de sistema}

Em termos gerais, os requisitos mais relevantes para modelagem e verificação formal desses módulos são os seguintes:

\subsubsection{Módulo de vigilância e detecção de aeronaves (DET)}

A função principal desse módulo é a recepção de dados de aeronaves (pistas). A fonte das detecções recebidas pode ser um dos seguintes sensores: Radar, ADS (envio de dados onboard de navegação diretamente pela aeronave via comunicação por datalink) ou ainda via comunicação com outros centros de controle (ACC ou APP).

Outra função desse módulo, mas que está fora do escopo do presente trabalho, é realizar a fusão de dados de sensores, ou seja, a partir de dados provenientes de diversos sensores (que podem ser dois ou mais sensores de um dos tipos mencionados, ou mesmo dois radares por exemplo) consolida-se a informação da localização da aeronave, de modo que seja a mais confiável possível. Em termos gerais, cada sensor tem um peso na qualidade da informação: por exemplo, para radares pode haver recepção de pistas primárias 
(rastreamento via envio e recepção de sinais de rádio, sem resposta da aeronave) ou de pistas secundárias (rastreamento via envio e recepção de sinais de rádio, mas com recebimento em retorno de informações enviadas pela aeronave). Também leva-se em conta a proximidade do radar e a área de cobertura, que pode ser limitada por obstáculos, como prédios, montanhas e pelo alcance do sinal.

Requisitos

- Criação de pista: uma nova pista é criada ao receber novas informações que não correspondem a nenhuma pista, de qualquer que seja o sensor.

- Atualização de pista: uma nova pista sofre alterações quando recebe novas informações de algum sensor.

- Tratamento de pistas: quando se recebe uma informação de algum sensor, processase a informação e constroi-se a situação aérea atual, composta por todas as pistas presentes em determinada região.

- Rastreamento de alvos: O processo completo engloba as seguintes fases - Criação, atualização, extrapolação/envelhecimento (cálculo de posições futuras durante alguns ciclos) e, por fim, supressão da pista.

Para o presente trabalho, é feita uma simplificação - ignora-se o recebimento preliminar de detecções (processo anterior à consolidação de informações que irão fazer parte de uma pista), tal como a origem da informação de pista e simplifica-se a função desse módulo para a seguinte: recepção e armazenamento de pistas no banco de dados. Logo, o processo que é levado em conta é apenas a criação da pista. A informação da pista que é levada em conta é apenas seu indicativo (callsign), que é informação suficiente para realizar a Correlação.

\subsubsection{Módulo de recepção e difusão de planos de voo (REC)}

Cada plano de voo possui uma identificação única, representada por três elementos: um identificador, denominado indicativo (callsign), pelo local de partida e pelo horário estimado de decolagem. O plano de voo é apresentado ao controlador na forma de "strip" eletrônica (na Figura 23), que exibe, nessa ordem: informações de local de partida/chegada (ex: TUSET) e horários estimados (ex: 09:35); informação de nível de voo (ex: 160); informações gerais do plano, como modelo da aeronave (ex: AT45), indicativo (ex: AFR201), código da companhia aérea (ex: AIRFRANS), SSR (ex: A4004) e outras informações sobre a rota, como horários estimados (ex: 09:50) de passagem nos pontos de rota (ex: OBR). 


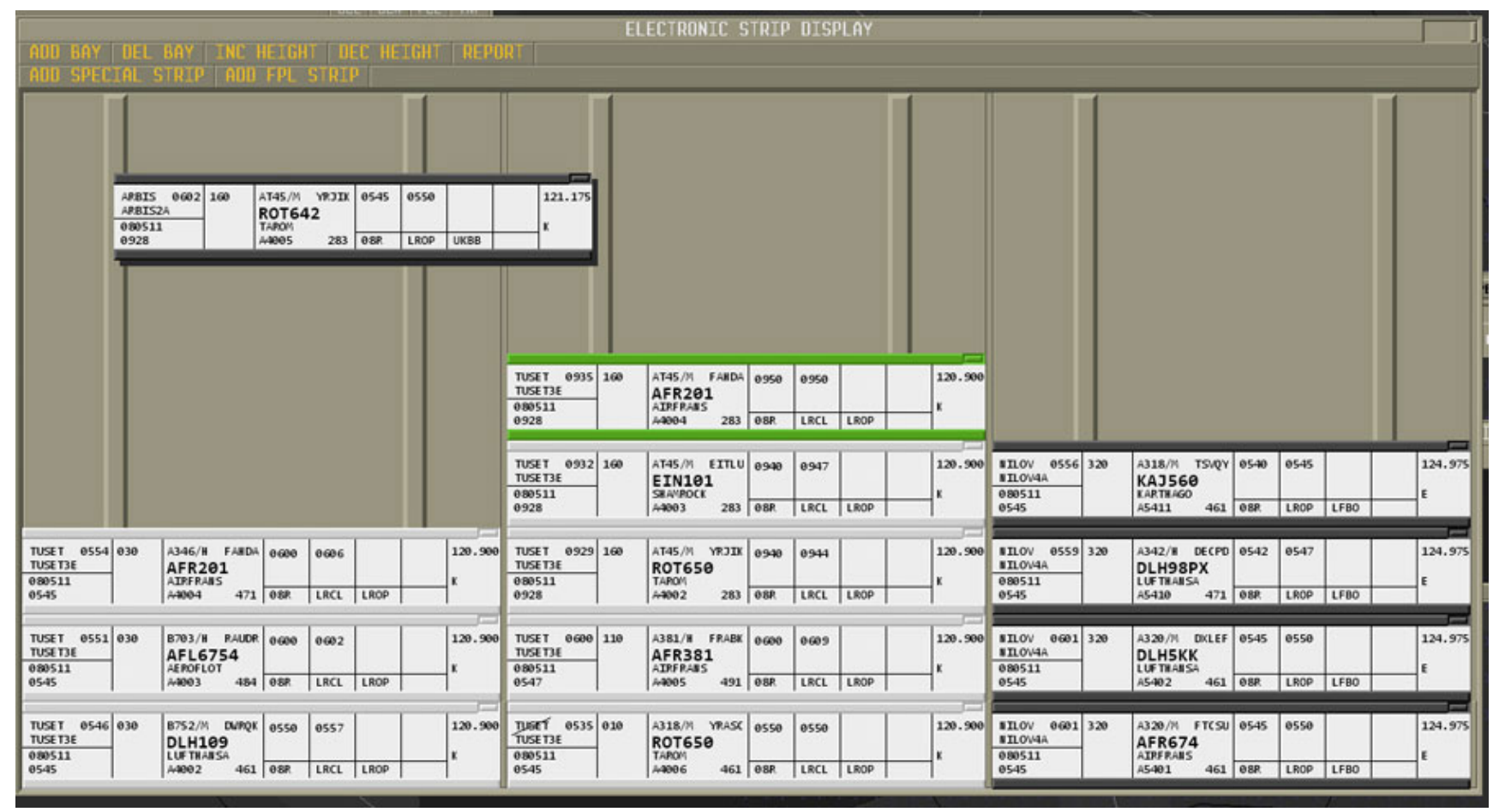

Figura 23 - Representação de uma strip eletrônica - Retirado de SimSoft (2018).

Requisitos de planos de voo

- O sistema deve criar um plano máquina para cada plano de voo recebido. Para o presente trabalho, é feita uma simplificação: a informação do plano de voo que é levada em conta é apenas seu indicativo (callsign), que é informação suficiente para realizar a Correlação.

O processo de criação de um plano de voo passa pelas seguintes etapas:

i. Validação dos campos

ii. Extração da rota (sequência de pontos que definem a trajetória da aeronave dentro da área controlada)

iii. Determinação das partes envolvidas (setores e centros de controle) e compartilhamento

Requisitos de mensagens AIDC (ICAO, 2007b)

- Deve haver uma verificação de identificadores de mensagens duplicados: podem ir de 0 a 999999.

- Deve haver um tempo de expiração (Timeout) de mensagens de 180 segundos 


\subsubsection{Módulo de correlação de planos de voo e pistas (CORR)}

\section{Requisitos}

- A correlação de pistas com planos de voo deve ser feita automaticamente quando possuírem o código do equipamento transponder (SSR) ou matrículas da aeronave idênticos. A atribuição de códigos SSR permite uma correlação única entre o plano de voo e a pista.

\subsection{Modelagem}

\subsubsection{Modelo desenvolvido em SMV}

A partir dos requisitos de sistema apresentados na seção 5.2 foram idealizadas as máquinas de estados das Figuras 24 e 25. Essas máquinas de estados foram implementadas em SMV e funcionam paralelamente e independentemente.

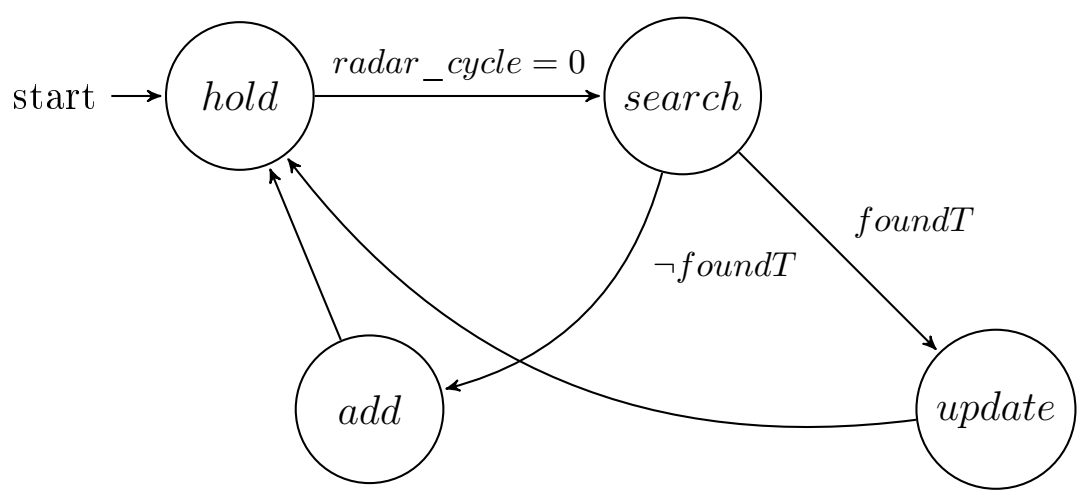

Figura 24 - Máquina de estados representativa do modelo do DET.

A representação das estruturas em geral é feita através de variáveis do tipo enum. As seguintes variáveis são declaradas como globais:

- FPL: vetor do tipo enum com três posições disponíveis para representar o banco de dados de plano de voos. Cada posição do enum é capaz de representar três valores de indicativo para um plano de voo ou o valor nulo (none);

- track1..3: as pistas foram declaradas como módulos independentes, com indicativo $(C S N)$ e número de pista. No SMV, são declaradas como tipo process para que possuam suas máquinas de estados independentes; 


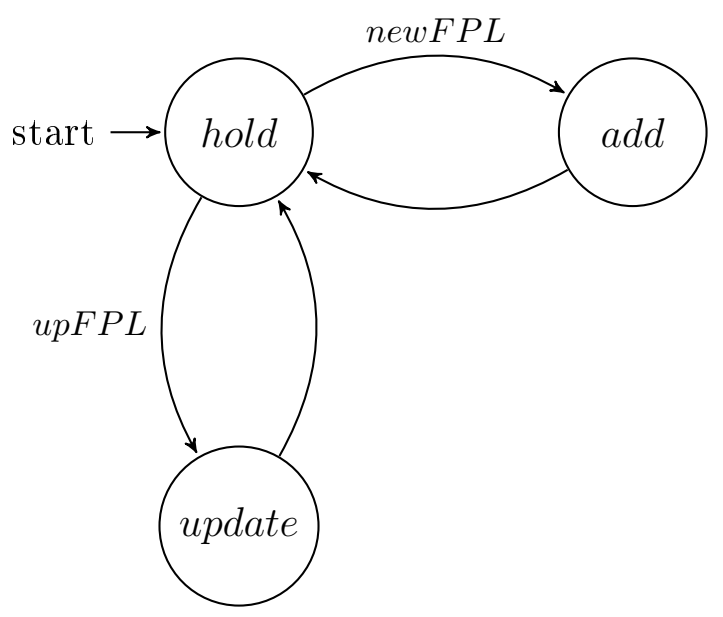

Figura 25 - Máquina de estados representativa do modelo do REC.

- $C R$ : vetor do tipo boolean com três posições disponíveis para representar um plano correlacionado, ou seja, se TRUE, há uma correlação daquele plano, se $F A L S E$, não há nenhuma correlação para aquele plano;

- radar_cycle: enum que vai de 0 a 3 para indicar o ciclo de um radar de 4 unidades de tempo.

As seguintes variáveis são declaradas no módulo DET:

- new_track: enum que representa o indicativo de uma nova pista;

- found_track: boolean que representa que uma pista foi encontrada no banco de dados track.

As seguintes variáveis são declaradas no módulo REC:

- new_FPL: enum que representa o recebimento de um plano de voo;

- new_FPL_message: boolean que representa a recepção de uma mensagem de novo plano de voo;

- update_FPL_message: boolean que representa a recepção de uma mensagem de atualização de plano de voo.

As seguintes operações são declaradas no módulo DET:

- Gravação de pistas no banco de dados: a pista será gravada no banco de dados caso não seja encontrada anteriormente e a operação será realizada sequencialmente até preencher completamente o banco de dados track.

- Recepção de novas pistas: no início de cada ciclo, a pista identificada por new_track pode mudar de valor do indicativo, o que, em um cenário real, representa que o radar identificou uma nova pista nesse instante. 
As seguintes operações são declaradas no módulo REC:

- Gravação de planos no banco de dados: o plano de voo será gravado no banco de dados caso a mensagem seja identificada como novo plano de voo. A operação funciona de modo similar à operação de gravação de pistas.

- Recepção de novos planos e de novas mensagens: o plano de voo identificado por $n e w_{\text {_ }} F P L$ pode mudar de valor de identificação.

A seguinte operação é declarada no módulo CORR:

- Correlação de pista e plano de voo: o recebimento de pistas pelo módulo REC funciona como um gatilho para o módulo CORR tentar fazer a correlação entre os planos recebidos e as pistas guardadas no banco de dados. Logo, essa operação é teoricamente assíncrona, com o acionamento através de um gatilho. Porém, tornase síncrona no presente caso de estudo, em que por simplificação se desconsidera o eventual recebimento de um novo plano como gatilho, situação que pode ocorrer no sistema real, e leva em conta apenas o recebimento de pistas, que ocorre periodicamente.

Como pré-requisito, estabeleceu-se que deveria haver dependência entre os módulos e funcionamento em paralelo de suas máquinas de estados. A Figura 26 mostra uma visão geral dos módulos apresentados, destacando-se as dependências entre eles.

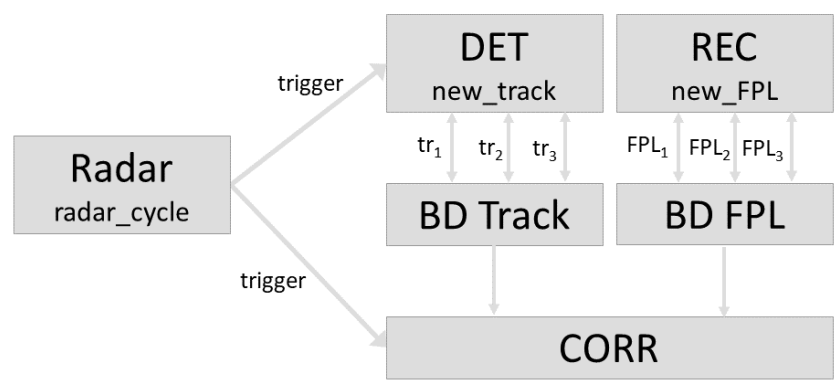

Figura 26 - Dependências entre os módulos do estudo de caso.

O módulo Radar atua como gatilho das respectivas funções dos módulos DET e CORR (através da variável cíclica radar_cycle). O módulo DET lê e escreve no banco de pistas (track1, track2 e track3). O módulo REC lê e escreve no banco de planos (FPL[1], FPL[2] e FPL[3]). O módulo CORR lê dos bancos de pistas (track1, track2 e track3) e de planos (FPL[1], FPL[2] e FPL[3]).

O Anexo A contém as Listagens SMV dos modelos, sendo que as variáveis globais estão identificadas na Listagem A.1 e as inicializações na Listagem A.2. 


\subsection{Especificação de propriedades}

As propriedades de vivacidade e segurança que foram especificadas são apresentadas nessa seção, acompanhadas de sua equação descrita em símbolos, como apresentado na seção 2.5 e de sua descrição em linguagem natural.

\subsubsection{Recepção de planos de voo}

Vivacidade: Quando o módulo de Recepção está no estado de espera (estado hold) e recebe-se uma mensagem de novo plano de voo, indicado pelo indicativo AAA, sempre ele será adicionado ao banco de dados, em alguma das posições. A propriedade exemplificada (Propriedade 5.1) é parcial, sendo que a propriedade completa contempla todos os tipos de planos (AAA, BBB e CCC).

$$
\begin{array}{r}
\forall \square\left(\left(s . R E C=\text { hold \& } R E C \text { _run.new_FP_message \& } R E C_{-} \text {run.new_FP=AAA) } \rightarrow\right.\right. \\
\forall \diamond(s . F P[1]=A A A \mid \text { s.FP[2] }=A A A \mid s . F P[3]=A A A))
\end{array}
$$

\subsubsection{Detecção de pista}

Vivacidade: Quando o módulo de Detecção está no estado de espera (estado hold), o ciclo do radar se inicia e recebe-se uma nova pista, eventualmente ela será adicionada ao banco de dados, em alguma das posições. A propriedade exemplificada (Propriedade 5.2 é parcial, sendo que a propriedade completa contempla todos os tipos de pistas (AAA, $\mathrm{BBB}$ e $\mathrm{CCC})$.

$$
\begin{array}{r}
\forall \square\left(\left(\text { s.DET }=\text { hold \& s.radar cycle }=0 \& D E T \_ \text {run.new_track }=A A A\right) \rightarrow\right. \\
\exists \triangleright(\text { s.track1.csn }=A A A \mid \text { s.track2.csn }=A A A \mid \text { s.track3.csn }=A A A))
\end{array}
$$

Uma propriedade mais forte seria considerar que a pista sempre seria adicionada. Porém, essa propriedade não se sustenta, já que no modelo foram separadas as ações de adicionar e de atualizar, sendo possível que a pista já tenha sido previamente adicionada e sofra apenas uma atualização, o que seria identificado como um erro no modelo atual. 
Segurança: Essa especificação visa evitar duplicação de pistas causada pelo sistema. Caso o módulo de Detecção esteja no estado de espera, o ciclo do radar se inicie e uma nova pista é recebida com o indicativo AAA, essa pista poderá ser guardada em apenas uma posição do banco de dados. A propriedade exemplificada (Propriedade 5.3) é parcial, sendo que a propriedade completa contempla todas as combinações de pista (um total de 3 combinações possíveis).

$$
\begin{gathered}
\forall \square((\text { s.DET }=\text { hold \& s.radar_cycle }=0 \text { \& DET_run.new_track }=A A A) \rightarrow \\
\forall \diamond((\text { s.track1.csn }=A A A \& \text { s.track } 2 . c s n !=A A A \& \text { s.track } 3 . c s n !=A A A) \\
(\text { s.track1.csn } !=A A A \& \text { s.track } 2 . c s n=A A A \& \text { s.track3.csn } !=A A A) \\
(\text { s.track1.csn } !=A A A \& \text { s.track2.csn } !=A A A \& \text { s.track3.csn }=A A A))
\end{gathered}
$$

\subsubsection{Correlação entre plano de voo e pista}

O algoritmo de correlação de plano e pista pode ser realizado de diversas maneiras. Por simplificação, a ativação é feita apenas por um gatilho, que é a recepção de pistas, indicada pela variável radar_cycle. A busca no banco de dados por planos com o mesmo indicativo poderia ser feita por um algoritmo de varredura convencional (pela utilização de um loop de iteração), porém em SMV é possível especificar essa busca através de uma intervenção direta no estado da variável boolean $C R$, ou seja, por comparação do indicativo da nova pista recebida com o valor de cada FPL. Para o caso real, vale ressaltar que a ativação do algoritmo também poderia ocorrer pela recepção de uma atualização de um plano de voo, que também deveria ser levado em conta, mas foi suprimido no presente trabalho.

Vivacidade: Quando a informação de um plano no banco de dados é igual à informação de uma pista no banco de dados, sempre ocorrerá a correlação. A propriedade exemplificada (Propriedade 5.4) é parcial, sendo que a propriedade completa contempla todas as combinações de plano e pista (um total de 27 combinações possíveis).

$$
\forall \square((\text { s.FP }[1]=A A A \text { \& s.track1.csn }=A A A) \rightarrow \forall \diamond(s . C R[1]=T R U E))
$$


Segurança: Essa especificação visa evitar correlações incorretas entre pista e plano de voo. Caso o plano de indicativo AAA esteja salvo na primeira posição do banco de dados FPL e nenhuma pista AAA estiver presente no banco de dados de pistas, a correlação para a primeira posição sempre será falsa. A propriedade exemplificada (Propriedade 5.5) é parcial, sendo que a propriedade completa contempla todas as combinações de plano e pista (um total de 9 combinações possíveis).

$$
\begin{gathered}
\forall \square((\text { s.FP }[1]=A A A \& \text { s.track } 1 . c s n !=A A A \& \text { s.track } 2 . c s n !=A A A \\
\text { \& s.track3.csn } !=A A A) \rightarrow \forall \triangleright(\text { s.CR }[1]=F A L S E))
\end{gathered}
$$

\subsubsection{Verificação de todas as propriedades em cadeia}

Para esse exemplo, todas as propriedades apresentadas nas seções anteriores foram associadas com \& e verificadas em cadeia.

\subsection{Resultados}

Foi estabelecido um método de modelagem e verificação formal (capítulo 4) e foi feita sua aplicação no domínio específico de tráfego aéreo, através de um estudo de caso de três módulos diferentes: vigilância e detecção de aeronaves, recepção e difusão de planos de voo e correlação de planos de voo e pistas (capítulo 5).

Além disso, houve um esforço no estabelecimento de requisitos específicos para este domínio (seção 3.4), já que a maior parte deles abrange apenas requisitos implícitos ou muito genéricos.

As propriedades especificadas na seção 5.4 foram verificadas utilizando-se a ferramenta NuSMV. Todas elas foram confirmadas no modelo final especificado em SMV. Dessa maneira, pôde-se confirmar a corretude do sistema em relação aos aspectos que se propôs verificar. O processo de avaliação de contraexemplos possibilita a evolução do modelo e também o aperfeiçoamento das propriedades de interesse. O resultado mais significativo do trabalho está nas diretivas determinadas pela aplicação do método, que são apresentadas nas seções a seguir:

\subsubsection{Máquinas de estados}

A elaboração das máquinas de estados é feita a partir dos requisitos especificados, mas não há nenhum processo automático conhecido. De modo geral, a estratégia utilizada no presente trabalho foi determinar cada função atribuída ao módulo e isolar em um estado e 
determinar qual a condição para se atingir o novo estado e identificá-la em cada transição. Por se tratar de módulos cíclicos, sempre haverá um estado inicial de espera (hold).

A máquina de estados do DET (Figura 24) implementada em SMV pode ser encontrada na Listagem A.3 e a máquina de estados do REC (Figura 25 implementada em SMV na Listagem A.4. A estrutura referente à máquina de estados é declarada como um MODULE e pode possuir variáveis internas, que devem ser declaradas na seção $V A R$. Na seção $A S S I G N$, as variáveis são inicializadas e as transições de estados são declaradas. Uma transição de estados é feita através de uma estrutura condicional do tipo switch-case, que se inicia pela palavra-chave next, acompanhada do nome da variável. Em seguida, a palavra-chave case indica as transições de estados: em cada linha, lista-se condições que devem ser satisfeitas e qual o estado seguinte. Por exemplo, no DET (Listagem A.3), declara-se a transição de estados para as variáveis internas new_track e found_track e para as variáveis globais track1, track2, track3 e DET.

As variáveis utilizadas foram do tipo boolean para condições do tipo verdadeiro ou falso e variáveis do tipo enum para enumerações de conjuntos finitos de constantes atribuídas a um valor, podendo indicar um estado, um valor de contador ou outro valor em uma lista de valores possíveis. A utilização de uma variável do tipo enum ao invés de uma variável do tipo inteiro (integer) para um conjunto finito de valores se justifica por se restringir a gama de valores possíveis de serem assumidos, diminuindo assim a quantidade de estados que poderiam existir no caso de uma variável com todos os valores possíveis para um inteiro (de $-2^{31}+1$ a $\left.2^{31}-1\right)$. O exemplo de um contador é a variável radar_cycle e o MODULE Radar, que é responsável pela sua transição de valores (Listagem A.6) para um radar de 4 unidades de tempo.

É possível também utilizar um vetor de variáveis (array), como foi feito para o vetor de planos de voo FPL e o de correlação CR (declarados como variáveis globais na Listagem A.2), que possuem 3 posições possíveis.

Para o CORR, não foi declarada explicitamente uma variável representativa dos seus estados, mas optou-se por um MODULE diferente, responsável pela transição de estados do array de correlação CR (Listagem A.5).

No SMV, não há classes como em uma linguagem de programação orientada a objetos, porém é possível utilizar o MODULE com as variáveis internas para esse fim. Uma pista, por exemplo, é declarada no MODULE Track (Listagem A.7) e tem duas variáveis internas csn (indicativo) e number (número de pista). As pistas 1, 2 e 3 são declaradas e inicializadas como variáveis globais (Listagem A.2) e suas estruturas são modificadas no DET (Listagem A.3).

\subsubsection{Utilização do contraexemplo}

O contraexemplo é um resultado intermediário do processo e pode ser utilizado para identificar imprecisões tanto no modelo quanto na propriedade de interesse (erros de digitação 
ou situações inesperadas, por exemplo) e auxiliar na definição de outras propriedades (de vivacidade ou de segurança, por exemplo). A seguir, são apresentadas diretivas acompanhadas de contraexemplos para exemplificar como é a sua utilização no processo proposto.

\section{Identificação de novas propriedades}

O primeiro caso trata de duplicação de pistas e de planos de voo: identificou-se a necessidade de se verificar propriedades de duplicação de pistas através de um contraexemplo gerado em que diversas posições do banco de dados de planos eram preenchidas pela informação da mesma pista, o que bloqueava a inserção de novas pistas. O contraexemplo é apresentado na Listagem 5.1 e a sua leitura é feita em seguida. Os contraexemplos para as demais diretivas podem ser encontrados no Anexo B.

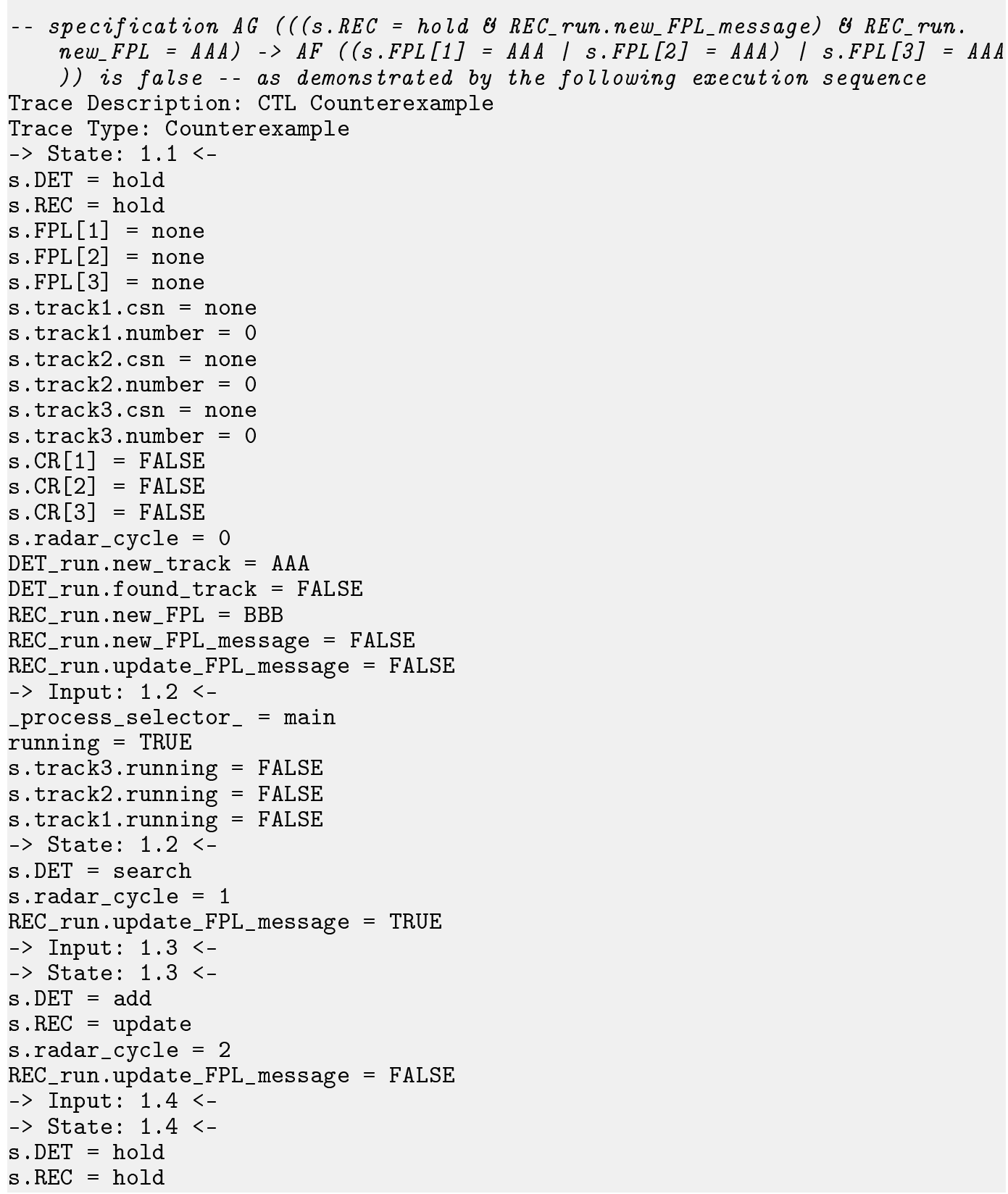




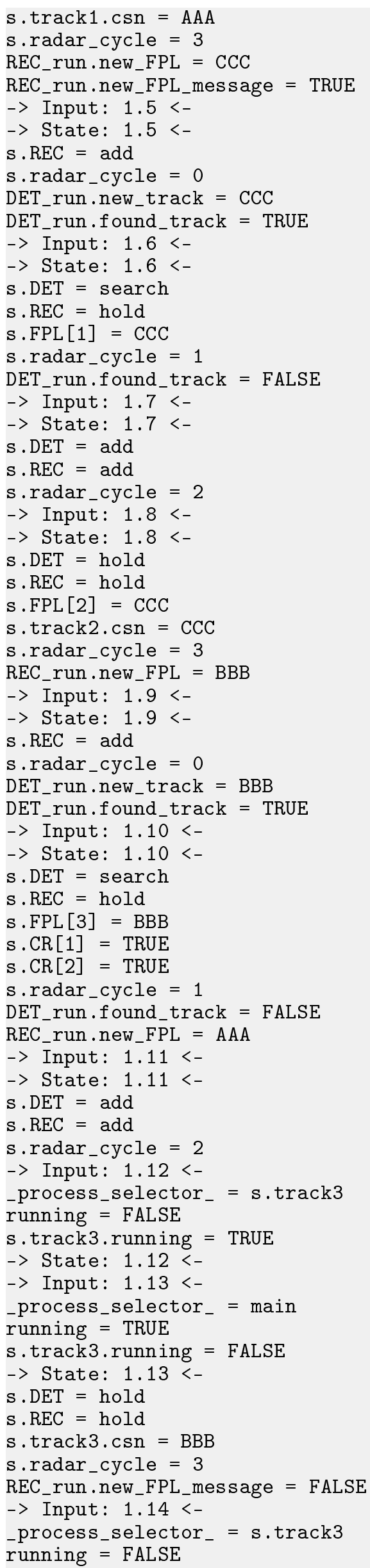




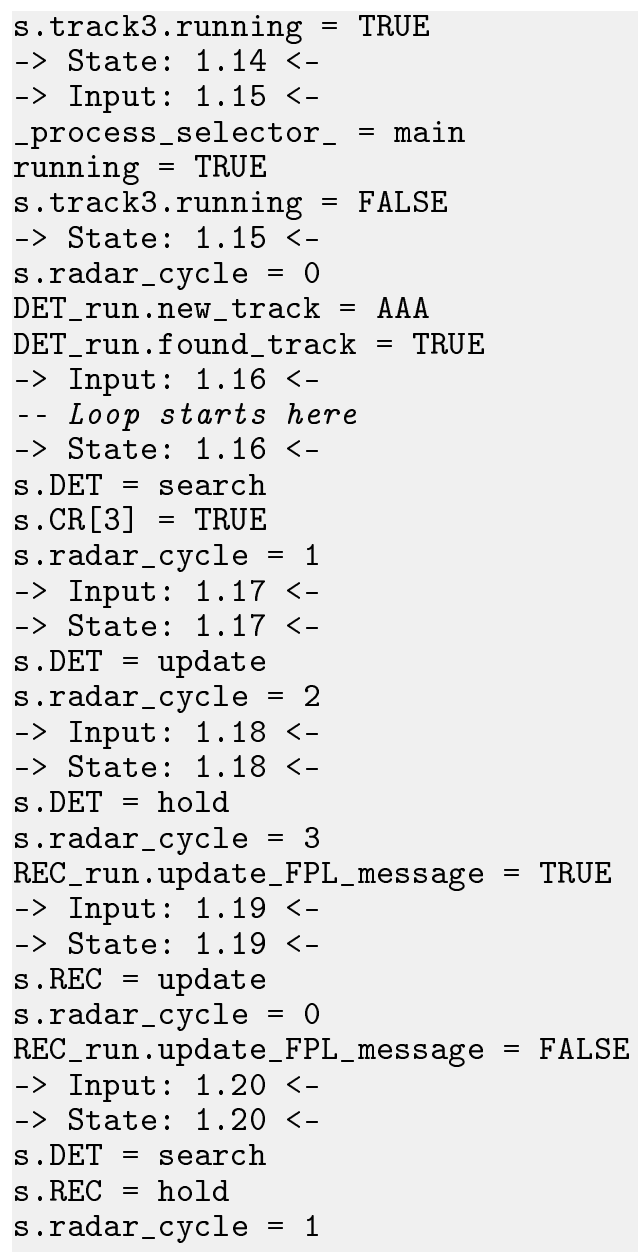

Listagem 5.1 - Identificação de novas propriedades - Contraexemplo.

A descrição do contraexemplo é apresentada abaixo:

Primeiramente, são inicializadas todas as estruturas, sendo que pista inicial contém o indicativo AAA e o plano inicial contém o indicativo BBB, porém a estrutura boolean REC_run.new_FPL_message indica que não houve ainda a recepção dessa mensagem pelo ATC. A detecção de pista é feita quando a estrutura s.radar_cycle indica valor 0, ou seja, no início de um ciclo de radar. No State 1.4, o plano de indicativo CCC é recebido e a pista de indicativo AAA é adicionada à posição 1 do banco de pistas (track1). No State 1.6, o plano de indicativo CCC é adicionado à posição 1 do banco de planos $(F P L[1])$. No State 1.8, o plano de indicativo CCC é adicionado à posição 2 do banco de planos (FPL[2]), a pista de indicativo CCC é adicionada à posição 2 do banco de pistas (track2) e o plano de indicativo BBB é recebido. No State 1.10, o plano de indicativo BBB é adicionado à posição 3 do banco de planos (FPL/3]), preenchendo assim todo o banco de planos, é feita a correlação dos planos 1 e 2 (CR[1] e $C R[2]$ - referentes a CCC) e o plano de indicativo AAA é recebido. No State 1.13, a pista de indicativo BBB é adicionada à posição 3 do banco de pistas (track3), preenchendo assim todo o banco de pistas. No State 1.16, é feita a correlação do plano 3 ( $C R[3]$ - referente a BBB).

A Figura 27 mostra o estado final do contraexemplo, destacando-se o estado do banco 
de pistas, do banco de planos e do banco de correlações, sendo TRUE a indicação de que houve uma correlação com o plano daquela posição e FALSE a indicação de que não houve correlação.

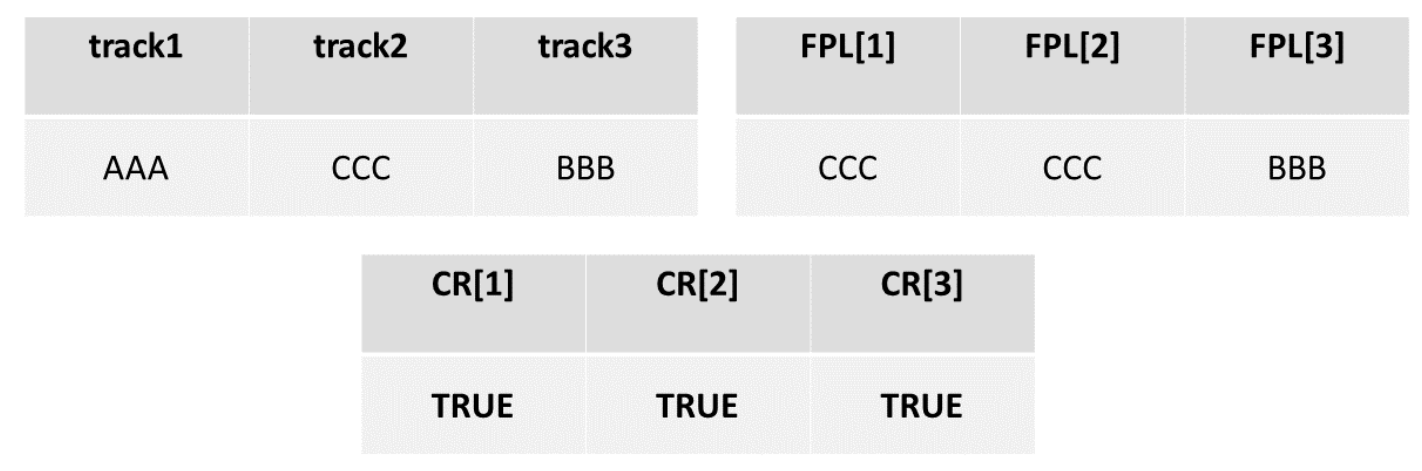

Figura 27 - Identificação de novas propriedades - Estado final.

Nesse caso, como não há checagem de plano e nem de pista já salvos em posições anteriores dos bancos de dados, nota-se que há duplicações causadas pelo próprio sistema. Esse comportamento é indesejado e pôde ser identificado ao se verificar a propriedade de vivacidade (Propriedade 5.1), em que se espera que um plano sempre seja adicionado caso seja recebida uma mensagem de novo plano (de indicativo AAA no exemplo). O contraexemplo se inicia com todas as premissas satisfeitas (REC no estado hold, mensagem de novo plano new_FPL_message TRUE e plano recebido com indicativo AAA), porém a conclusão não se verifica (o plano de indicativo AAA ser adicionado em uma das posições do banco), o que demonstra haver um erro no módulo do REC, já que o banco de dados de planos é totalmente preenchido com duplicações (plano CCC) e não suporta a adição do plano recebido AAA.

\section{Verificação de propriedade inversa}

O objetivo é garantir que a propriedade está sendo mesmo verificada e que ela reflete o requisito que se deseja verificar. Ao se descrever uma propriedade, inverter a consequência para garantir que seja gerado um contraexemplo. Em seguida, avaliar o caminho do contraexemplo para assegurar pelo inverso que a propriedade realmente reflete o que se deseja verificar.

O esperado para o caso demonstrado no contraexemplo da Listagem B.1 é que o resultado da verificação fosse falso, o que ocorreu (Figura 28). A propriedade original (Propriedade 5.4 tem como premissa que quando um plano de indicativo AAA for adicionado em FPL[1] e quando uma pista de indicativo AAA for adicionada em track1, ocorrerá a correlação ( $C R[1]$ relacionada ao plano em $F P L[1])$. O caso contrário supõe que não ocorrerá correlação. Caso esse contraexemplo fosse verdadeiro, seria necessário reavaliar o modelo ou a propriedade em questão para encontrar o que causou essa verificação inesperada. 


\begin{tabular}{|c|c|c|c|c|c|}
\hline track1 & track2 & & FPL[1] & FPL[2] & FPL[3] \\
\hline \multirow[t]{3}{*}{ AAA } & BBB & & AAA & & \\
\hline & & CR[2] & CR[3] & & \\
\hline & & FALSE & FALSE & & \\
\hline
\end{tabular}

Figura 28 - Verificação de propriedade inversa - Estado final.

\section{Verificação de consistência de propriedade}

Em caso de erros, o problema pode ser também na propriedade. É importante verificar se ela realmente é consistente e se traduz no que se deseja verificar.

O caso da Listagem B.2 exemplifica a definição de uma propriedade inconsistente (Propriedade 5.6.).

$$
\forall \square((s . F P L[1]=A A A \& \text { s.track1.csn } !=B B B) \rightarrow \forall \diamond(s . C R[1]=F A L S E))
$$

O motivo de sua inconsistência é a definição de a posição do CR depender apenas do plano armazenado na mesma posição. Por exemplo, se $F P L[1]=\mathrm{AAA}$ e track2=AAA, então a correlação $C R[1]$ será TRUE. A ideia original da propriedade era impedir correlações incorretas, porém essa propriedade foi mal formulada e o contraexemplo ajudou a identificar esse problema (Figura 29).

\begin{tabular}{|l|l|l|l|l|l|}
\hline track1 & track2 & track3 & FPL[1] & FPL[2] & FPL[3] \\
\hline BBB & AAA & & AAA & CCC \\
\hline & & & & \\
\hline & CR[1] & CR[2] & CR[3] & \\
\hline & TRUE & FALSE & FALSE \\
\hline
\end{tabular}

Figura 29 - Verificação de consistência de propriedade - Estado final.

Verificação de uma propriedade com múltiplos casos

Para se realizar a verificação de uma propriedade com múltiplos casos, expandir a propriedade em todos os casos, realizar a verificação de cada um independentemente e depois em 
cadeia com \&. Por praticidade, é possível se utilizar inicialmente uma propriedade parcial para fazer a verificação. Por exemplo, verificar apenas situações com plano/pista de indicativo AAA e posteriormente verificar todas as situações possíveis. Assim, é possível identificar algum estado inesperado que pode ser alcançado por algum erro na modelagem.

A Figura 30 ilustra a quantidade de casos possíveis para a Propriedade 5.5, que é aquela com mais possibilidades no caso de estudo. É possível iniciar a verificação com pistas e planos de indicativo AAA guardados na primeira posição dos respectivos bancos para depois expandir para os outros casos.

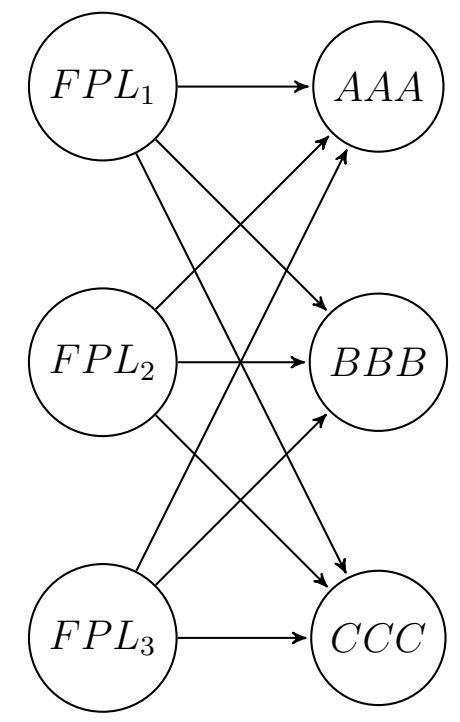

Figura 30 - Análise combinatória de indicativos de plano de voo referentes à equação 5.5 .

\section{Verificação de propriedade parcial}

A propriedade parcial também pode ser utilizada para se fazer uma verificação indireta, como ilustrado no caso da Listagem B.3. O objetivo da propriedade original (Propriedade 5.3 é evitar a duplicação de pistas causada pelo sistema e, logo, supõe que, caso a pista seja salva em uma posição do banco de dados de pistas, ela não será salva também em outra posição. A propriedade original (Propriedade 5.3) foi modificada para a Propriedade 5.7. que supõe que a pista de indicativo AAA sempre será adicionada na primeira posição do banco de dados de pistas. Pela falha do contraexemplo (Listagem B.3), é possível verificar indiretamente que a posição da pista no banco de dados pode ser qualquer (Figura 31).

$$
\begin{aligned}
& \forall \square((\text { s.DET }=\text { hold \& s.radar_cycle }=0 \text { \& DET_run.new_track }=A A A) \rightarrow \\
& \forall \diamond((\text { s.track1.csn }=A A A \& \text { s.track2.csn } !=A A A \& \text { s.track3.csn } !=A A A))
\end{aligned}
$$




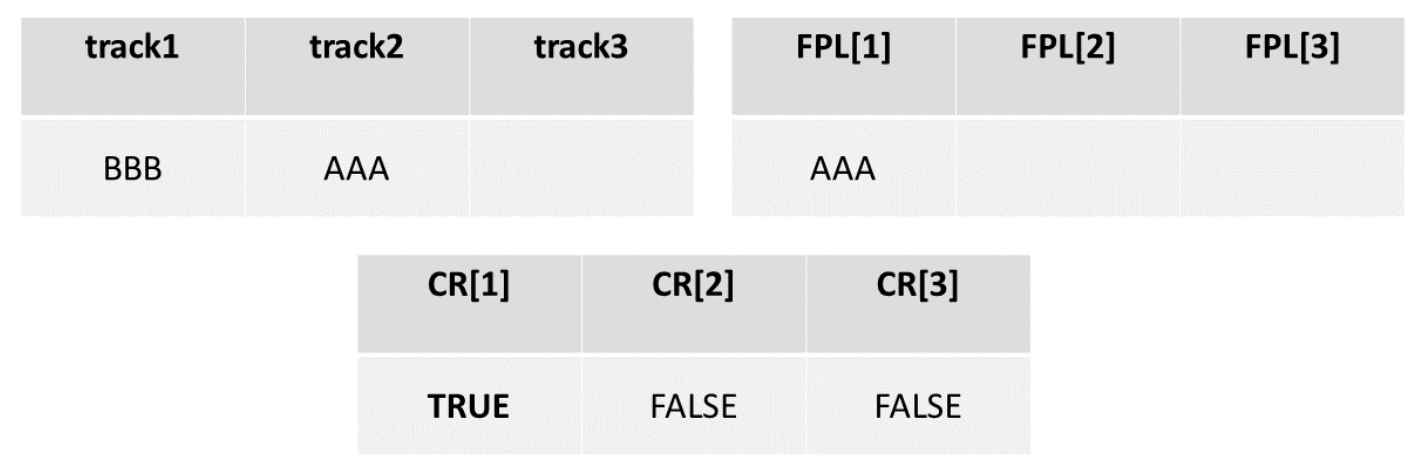

Figura 31 - Verificação de propriedade parcial - Estado final.

Graus de liberdade dados às variáveis

Há casos em que as variáveis não podem ser deixadas totalmente livres, com o risco de o modelo assumir algumas situações espúrias que não se verificariam na situação real. Como exemplo, o módulo REC sem a variável radar_cycle para regular a recepção de pistas incorria em situações em que as pistas eram modificadas a cada segundo e, logo, a correlação plano-pista não era funcional. No caso real, a presença de ciclos para recepção de pistas se verifica e também se mostrou necessária no modelo do presente trabalho.

Verificação de mais de uma propriedade

Após verificar inicialmente cada propriedade independentemente, deve-se verificar todas em cadeia com \&, como foi feito na seção 5.4 .4 . 


\section{Conclusões}

O presente trabalho propôs um método de modelagem e verificação formal para sistemas críticos, com aplicação ao domínio de tráfego aéreo. Forneceu-se diretivas para a aplicação do método através de um estudo de caso, baseado em três módulos de um sistema ATC em baixo nível de abstração para a validação do funcionamento de módulos de software. Não foi possível encontrar nenhum outro trabalho aplicado a sistemas de tráfego aéreo, baseado em requisitos nesse nível de abstração.

A primeira contribuição do trabalho foi a formulação desse método de modelagem e verificação formal para sistemas críticos, baseado em outros trabalhos de referência (capítulo 4). Uma segunda contribuição foi a síntese de requisitos principais exigidos pelos sistemas de tráfego aéreo, com baixo nível de abstração (capítulo 3).

Em termos gerais, o método é baseado nas seguintes fases: especificação de requisitos do sistema, modelagem do sistema na linguagem SMV e especificação de propriedades nas lógicas LTL/CTL, verificação formal e simulação em NuSMV. O foco do presente trabalho foi na modelagem baseada em requisitos preestabelecidos e na especificação e na verificação de propriedades de Segurança e Vivacidade na lógica CTL.

Outra contribuição foi a aplicação do método em um estudo de caso com três módulos de um sistema de tráfego aéreo (capítulo 5) que, como pré-requisito, deveriam funcionar em paralelo e com dependências entre si, como apresentado na Figura 26. Os módulos são: i) Módulo de vigilância e detecção de aeronaves (DET), ii) Módulo de recepção e difusão de planos de voo (REC), iii) Módulo de correlação de planos de voo e pistas (CORR). O modelo foi desenvolvido em SMV e as propriedades de Segurança e Vivacidade foram especificadas na lógica CTL e verificadas na ferramenta NuSMV.

Uma contribuição importante foi a formulação de diretivas para aplicação do método pela utilização do contraexemplo (seção 5.5.2 para identificar imprecisões e auxiliar na definição de propriedades. Em resumo, as diretivas referem-se a identificar a necessidade de criação de novas propriedades, verificar a propriedade inversa, verificar a consistência de propriedade, verificar uma propriedade com múltiplos casos, verificar a propriedade parcial, verificar mais de uma propriedade e atentar-se aos graus de liberdade dado às variáveis.

Por fim, acrescenta-se que a execução do cenário que engloba três módulos distintos, com dependências entre si e funcionamento em paralelo pôde ser executado em um tempo reduzido (por volta de 12 minutos na verificação de todas as propriedades em cascata seção 5.4.4 . Ressalta-se, porém, que o modelo não é muito grande em número de estados e a escalabilidade é uma questão importante que deve ser levada em conta. É possível que o sistema fique muito grande e que não seja possível verificá-lo, ou seja, como o tempo de verificação tende ao infinito, logo haverá um momento em que ele não poderá mais ser 
verificado. Imagina-se que esse problema possa ser contornado com a simplificação das máquinas de estados: uma solução é projetar um modelo mais genérico que trate de uma visão macro ou ainda projetar outros modelos com visões mais específicas que possam ser verificados independentemente.

Para trabalhos futuros, sugere-se a aplicação do método e de suas diretivas para outros tipos de sistemas e também realizar a conversão de modelos do modelo atual de comportamento (modelagem em SMV e verificação com LTL/CTL) para modelos de implementação (por exemplo SPARK ou Java).

Especificamente para o domínio de tráfego aéreo, sugere-se estender o modelo atual para incorporar outros aspectos do sistema, como por exemplo adicionar mais sistemas ATC e realizar a troca de mensagens de planos de voo entre eles e incorporar a progressão de estados dos planos de voo. Outra sugestão é incorporar outros módulos que possuam dependências com os módulos selecionados.

Outro aspecto é verificar a explosão do espaço de estados com o aumento na quantidade de estados do modelo e aplicar alguma das soluções sugeridas anteriormente. 


\section{Referências}

AGUCHIKU, F. S. et al. The model-driven development approach \& formal specification for air-traffic control system operations: Practical comments and case studies. In: SITRAER Air Transportation Symposium. São José dos Campos, SP, Brasil: Instituto Tecnológico de Aeronáutica, 2015. ISSN 2448-1912. Disponível em: <http://media.wix.com/ugd/6638c8_0c14032f310d488da67ef56670cbf974.pdf $>$.

ASSIS, F. H. de. Checagem de Arquiteturas de Controle de Veículos Submarinos: uma abordagem baseada em especificações formais. Dissertação (Mestrado) — Escola Politécnica da Universidade de São Paulo, 2009.

AZZOPARDI, M. A. Computational Air Traffic Management. Tese (Doutorado) CRANFIELD UNIVERSITY, 52015.

BAE, K. et al. Synchronous AADL and its formal analysis in real-time maude. In: QIN, S.; QIU, Z. (Ed.). Formal Methods and Software Engineering. Springer Berlin Heidelberg, 2011, (Lecture Notes in Computer Science, v. 6991). p. 651-667. ISBN 978-3-642-24558-9. Disponível em: <http://dx.doi.org/10.1007/978-3-642-24559-6_43>.

BAIER, C.; KATOEN, J.-P. Principles of Model Checking (Representation and Mind Series). Cambridge, MA, USA: The MIT Press, 2008. ISBN 026202649X, 9780262026499.

BARBACCI, M. et al. Quality Attributes. Pittsburgh, PA, USA, 1995. Disponível em: $<$ http://resources.sei.cmu.edu/library/asset-view.cfm?AssetID $=12433>$

BARNAT, J. et al. Employing multiple CUDA devices to accelerate LTL model checking. In: Parallel and Distributed Systems (ICPADS), 2010 IEEE 16th International Conference on. Shanghai, China: IEEE, 2010. p. 259-266. ISSN 1521-9097.

BARNAT, J. et al. CUDA accelerated LTL model checking. In: Parallel and Distributed Systems (ICPADS), 2009 15th International Conference on. Shenzhen, China: IEEE, 2009. p. 34-41. ISSN 1521-9097.

BASS, L.; CLEMENTS, P.; KAZMAN, R. Software Architecture in Practice (2nd Edition). Boston, MA, USA: Addison-Wesley Professional, 2003. ISBN 0-321-15495-9.

BESSAM, A.; KIMOUR, M. Multi-view description of real-time systems' architecture. World Academy of Science, Engineering and Technology, International Journal of Computer, Electrical, Automation, Control and Information Engineering, v. 2, n. 2, p. 339-346, 2008.

BOZZANO, M. et al. Safety, dependability and performance analysis of extended AADL models. The Computer Journal, v. 54, n. 5, p. 754-775, 2011. Disponível em: $<$ http://comjnl.oxfordjournals.org/content/54/5/754.abstract $>$.

COIMBRA, W. A. et al. Analysis and simulation of non-functional requirements applied to an air-traffic control system. In: International Conference on Information Systems and Technology Management. São Paulo, SP, Brasil: Faculdade de Economia, Administração e Contabilidade da Universidade de São Paulo, 2007. v. 4, n. 2007. 
DECEA. RPA / Drone - Autorização de voo. 2018. <https://www.decea.gov.br/?i= utilidades $\& p=$ rpa-drone $>$. [Online; acessado em 02/09/2018].

ERZBERGER, H. Transforming the NAS: The Next Generation Air Traffic Control System. Moffett Field, CA, USA: National Aeronautics and Space Administration, 2004.

FICCO, M. et al. Hybrid simulation of distributed large-scale critical infrastructures. In: 2014 International Conference on Intelligent Networking and Collaborative Systems. Salerno, Italy: IEEE, 2014. p. 616-621.

GIBBS, W. W. Software's chronic crisis. Scientific American, v. 271, n. 3, p. 72-81, 1994.

HANSSON, J. et al. Architectural modeling to verify security and nonfunctional behavior. Security Privacy, IEEE, v. 8, n. 1, p. 43-49, Jan 2010. ISSN 1540-7993.

HEMER, D.; DING, Y. Specifying software architectures using a formal-based approach. In: Software Engineering, 2008. ASWEC 2008. 19th Australian Conference on. Perth, WA, Australia: IEEE, 2008. p. 279-288. ISSN 1530-0803.

HU, K. et al. Exploring AADL verification tool through model transformation. Journal of Systems Architecture, v. 61, n. 3-4, p. 141-156, 2015. ISSN 1383-7621. Disponível em: <http://www.sciencedirect.com/science/article/pii/S1383762115000144>.

HUGUES, J. et al. From the prototype to the final embedded system using the ocarina AADL tool suite. ACM Trans. Embed. Comput. Syst., ACM, New York, NY, USA, v. 7, n. 4, p. 42:1-42:25, ago. 2008. ISSN 1539-9087. Disponível em: $<$ http://doi.acm.org/10.1145/1376804.1376810>.

ICAO. Global Air Traffic Management Operational Concept. 2005. Doc 9854 - AN/458.

ICAO. Amendment no. 1 to the procedures for air navigation services. 2007. Doc 4444 $\operatorname{ATM} / 501$.

ICAO. Asia/Pacific Regional Interface Control Document (ICD) for ATS Interfacility Data Communications (AIDC). 2007. Version 3.0 - September 2007.

ICAO. Manual on Air Traffic Management System Requirements. 2008. Doc 9882 $\mathrm{AN} / 467$.

ICAO. Global Air Navigation Plan. 2016. Doc 9750 - AN/963.

ICAO. Economic Development of Air Transport / Facts and Figures / World Aviation and the World Economy. 2018. <https://www.icao.int/sustainability/Pages/ Facts-Figures_WorldEconomyData.aspx $>$. [Online; acessado em 30/09/2018].

JOHNSEN, A. et al. Automated verification of AADL-specifications using UPPAAL. In: High-Assurance Systems Engineering (HASE), 2012 IEEE 14th International Symposium on. Omaha, NE, USA: IEEE, 2012. p. 130-138. ISSN 1530-2059.

KAMAL, A. W.; AVGERIOU, P. An evaluation of ADLs on modeling patterns for software architecture. In: Proceedings of the 4th International Workshop on Rapid Integration of Software Engineering Techniques. Luxemburg: Springer, 2007. 
KANOUN, K. et al. Availability of CAUTRA, a subset of the french air traffic control system. IEEE Transactions on Computers, v. 48, n. 5, p. 528-535, May 1999. ISSN 0018-9340.

MALAVOLTA, I. et al. What industry needs from architectural languages: A survey. Software Engineering, IEEE Transactions on, v. 39, n. 6, p. 869-891, June 2013. ISSN 0098-5589.

MCCOnNELL, S. Code Complete, Second Edition. Redmond, WA, USA: Microsoft Press, 2004. ISBN 0735619670, 9780735619678.

MEDVIDOVIC, N.; TAYLOR, R. A classification and comparison framework for software architecture description languages. Software Engineering, IEEE Transactions on, v. 26, n. 1, p. 70-93, Jan 2000. ISSN 0098-5589.

MUÑOZ, C. A.; DOWEK, G.; CARREÑO, V. Modeling and verification of an air traffic concept of operations. SIGSOFT Softw. Eng. Notes, ACM, New York, NY, USA, v. 29, n. 4, p. 175-182, jul. 2004. ISSN 0163-5948. Disponível em: $<$ http://doi.acm.org/10.1145/1013886.1007536>.

NAVARRETE, M. de C. Modelo de previsão de posição de aeronaves para uso em sistemas de vigilância do espaço aéreo. Dissertação (Mestrado) - Escola Politécnica da Universidade de São Paulo, 2006.

NAVASA, A.; PÉREZ-TOLEDANO, M. A.; MURILlO, J. M. An ADL dealing with aspects at software architecture stage. Inf. Softw. Technol., Butterworth-Heinemann, Newton, MA, USA, v. 51, n. 2, p. 306-324, fev. 2009. ISSN 0950-5849. Disponível em: $<$ http://dx.doi.org/10.1016/j.infsof.2008.03.009>.

OLIVEIRA, Í. R. de. Análise de risco da operação de espaçamento temporal aerotransportado por meio de um modelo em rede de Petri estocástica e dinamicamente colorida. Tese (Doutorado) — Escola Politécnica da Universidade de São Paulo, 2007.

PIZZO, W. N. Avaliação da disponibilidade de sistemas computacionais críticos para o controle do espaço aéreo por meio de modelo analítico da teoria de filas. Dissertação (Mestrado) — Escola Politécnica da Universidade de São Paulo, 2008.

POHL, K. Requirements engineering fundamentals: a study guide for the certified professional for requirements engineering exam-foundation level-IREB compliant. San Rafael, CA, USA: Rocky Nook, Inc., 2015. ISBN 978-1-937538-77-4.

ROSSI, V.; KANASHIRO, A. Destino: soberania, o dominio brasileiro da tecnologia no tráfego aéreo. São Paulo, SP, Brasil: Editora Segmento, 2010.

RUGINA, A. et al. Software dependability modeling using an industry-standard architecture description language. In: Proceedings of the 4th International Congress on Embedded Real-Time Systems. New York, NY, USA: ACM, 2008. abs/0809.4109. Disponível em: <http://arxiv.org/abs/0809.4109>.

SIMSOFT. ATMIS - Simulator Subsystems. 2018. <http://simsoft-atc.com/ atmis-simulator-subsystems.html $>$. [Online; acessado em: 13/01/2018]. 
SOBEIH, A.; VISWANATHAN, M.; HOU, J. Check and simulate: a case for incorporating model checking in network simulation. In: Formal Methods and Models for Co-Design, 2004. MEMOCODE '04. Proceedings. Second ACM and IEEE International Conference on. San Diego, CA, USA: IEEE, 2004. p. 27-36.

SOKOLSKY, O.; LEE, I.; CLARKE, D. Schedulability analysis of AADL models. In: Parallel and Distributed Processing Symposium, 2006. IPDPS 2006. 20th International. Rhodes Island, Greece: IEEE, 2006. p. 8 pp.-.

STILLMAN, R. B. AIR TRAFFIC CONTROL Complete and Enforced Architecture Needed for FAA Systems Modernization. Washington, DC, USA, 1997.

VARDI, M. Y.; WOLPER, P. An automata-theoretic approach to automatic program verification (preliminary report). In: Proceedings of the Symposium on Logic in Computer Science (LICS '86), June 16-18, 1986. Cambridge, Massachusetts, USA: IEEE Computer Society, 1986. p. 332-344.

WINTER, K. Model checking for abstract state machines. Journal of Universal Computer Science, v. 3, p. 689-701, 1997.

ZHANG, Y. et al. A study of the AADL mode based on timed automata. In: Software Engineering and Service Science (ICSESS), 2011 IEEE 2nd International Conference on. Beijing, China: IEEE, 2011. p. 224-227.

ZHAO, Y.; ROZIER, K. Y. Formal specification and verification of a coordination protocol for an automated air traffic control system. Science of Computer Programming, Elsevier, v. 96, p. 337-353, 2014. 


\section{ANEXO A - Modelos}

\section{MODULE state}

VAR

DET : \{hold, search, add, update\}; --Detector

REC : \{hold,add,update\};--Receiver

FPL : array $1 \ldots 3$ of \{none, $\mathrm{AAA}, \mathrm{BBB}, \mathrm{CCC}\}$;

track1 : process Track(0,FALSE);

track2 : process Track(0,FALSE);

track3 : process Track(0,FALSE);

$\mathrm{CR}$ : array $1 . .3$ of boolean;

radar_cycle: $\{0,1,2,3\}$;

Listagem A.1 - Variáveis globais.

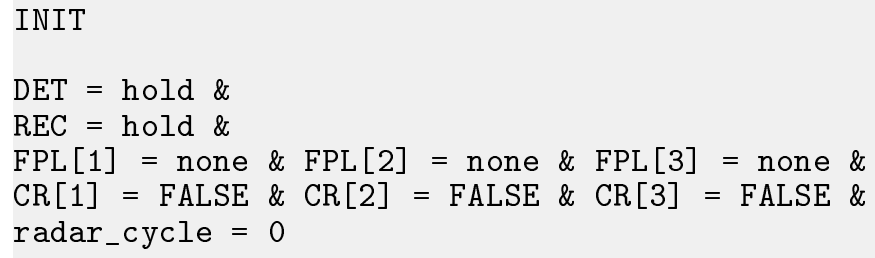

Listagem A.2 - Inicializações. 


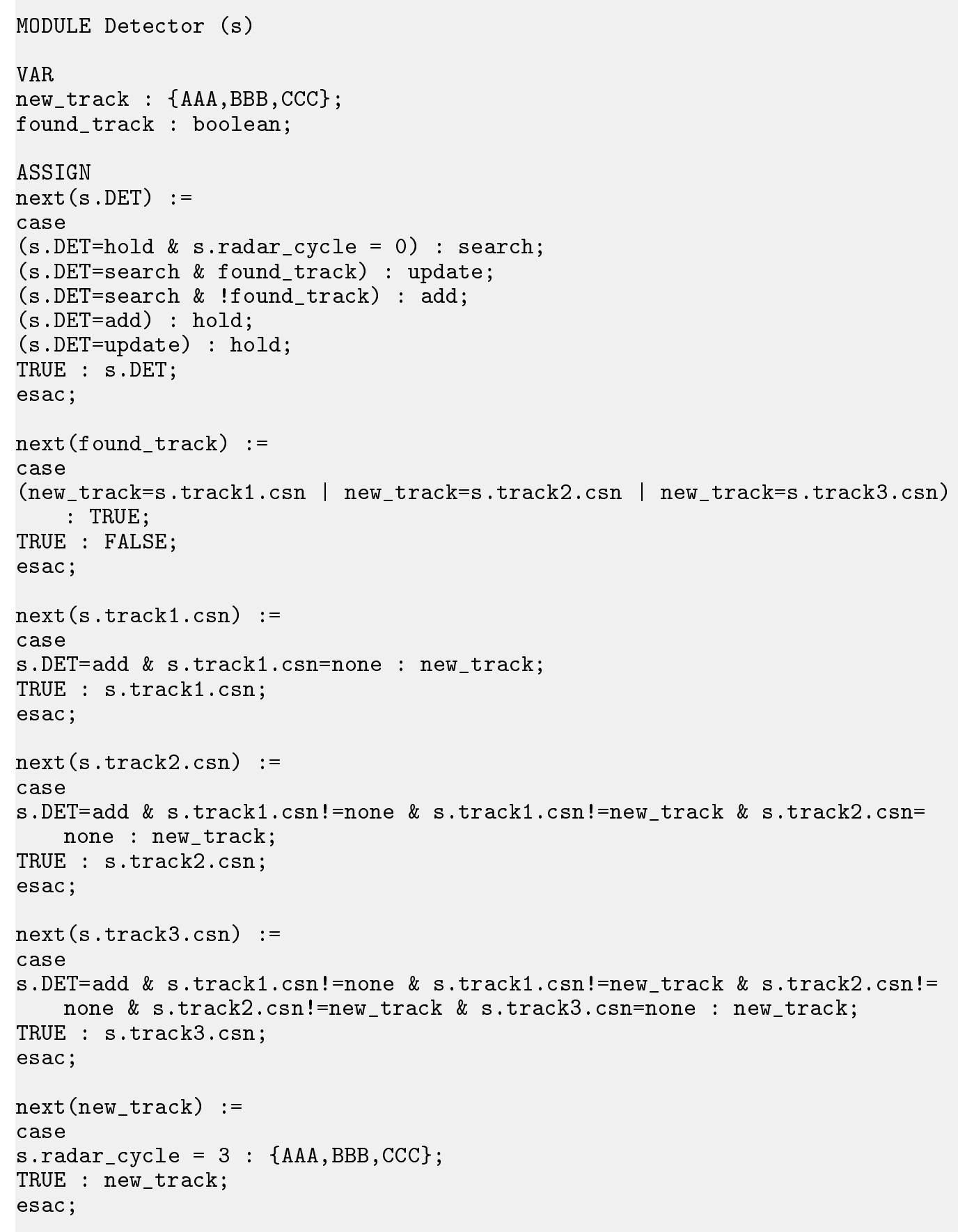

Listagem A.3 - Módulo DET. 
MODULE Receiver (s)

VAR

new_FPL : $\{$ AAA, BBB,$C C C\}$;

new_FPL_message : boolean;

update_FPL_message : boolean;

ASSIGN

init (new_FPL) $:=\{\mathrm{AAA}, \mathrm{BBB}, \mathrm{CCC}\}$;

next $(\mathrm{s} \cdot \mathrm{REC}) \quad:=$

case

(s.REC=hold \& new_FPL_message) : add;

(s.REC=hold \& update_FPL_message) : update;

(s.REC=add) : hold;

(s.REC=update) : hold;

TRUE : s.REC;

esac;

$\operatorname{next}(\mathrm{s} . \mathrm{FPL}[1]):=$

case

s.REC=add \& s.FPL $[1]=$ none : new_FPL;

TRUE : s.FPL [1];

esac;

$\operatorname{next}(\mathrm{s} . \mathrm{FPL}[2]):=$

case

s.REC=add \& s.FPL[1]!=none \& s.FPL[1]!=new_FPL \& s.FPL[2]=none : new_FPL;

TRUE : s.FPL [2];

esac;

next (s.FPL [3]) :=

case

s.REC=add \& s.FPL[1]!=none \& s.FPL[1]!=new_FPL \& s.FPL[2]!=none \& s.FPL

[2] !=new_FPL \& s.FPL[3]=none : new_FPL;

TRUE : s.FPL $[3]$;

esac;

next (new_FPL) :=

case

s. $R E C=$ add $\mid$ s. REC=update : $\{A A A, B B B, C C C\}$;

TRUE : new_FPL;

esac;

next (new_FPL_message) :=

case

s.REC=add | s.REC=update : \{TRUE, FALSE\};

TRUE : new_FPL_message;

esac;

Listagem A.4 - Módulo REC. 


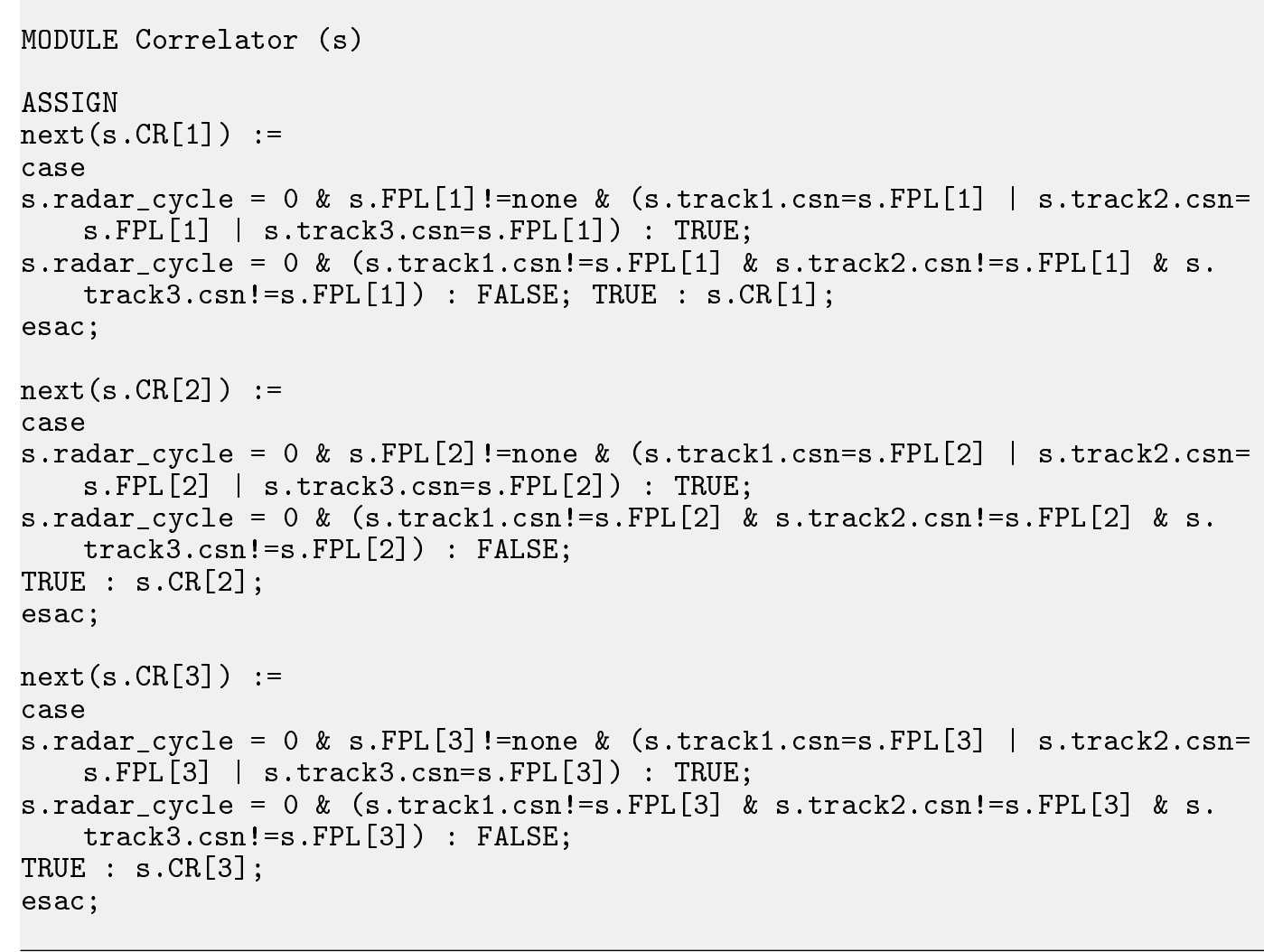

Listagem A.5 - Módulo CORR.

MODULE Radar (s)

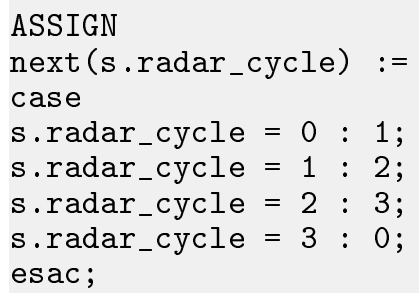

Listagem A.6 - Módulo Radar.

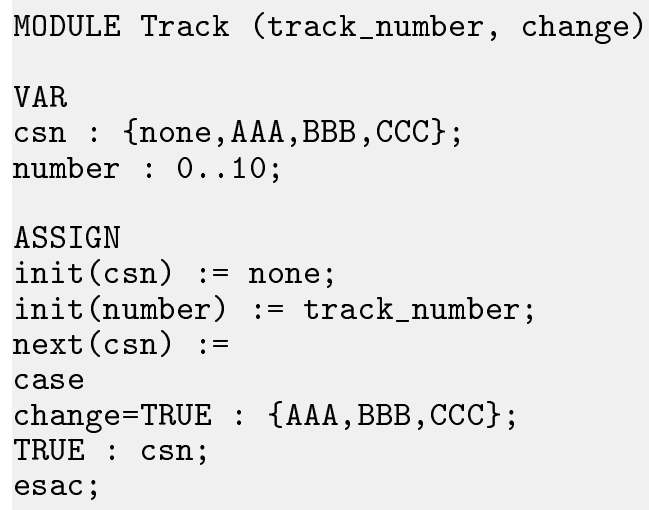




\section{ANEXO B - Contraexemplos}

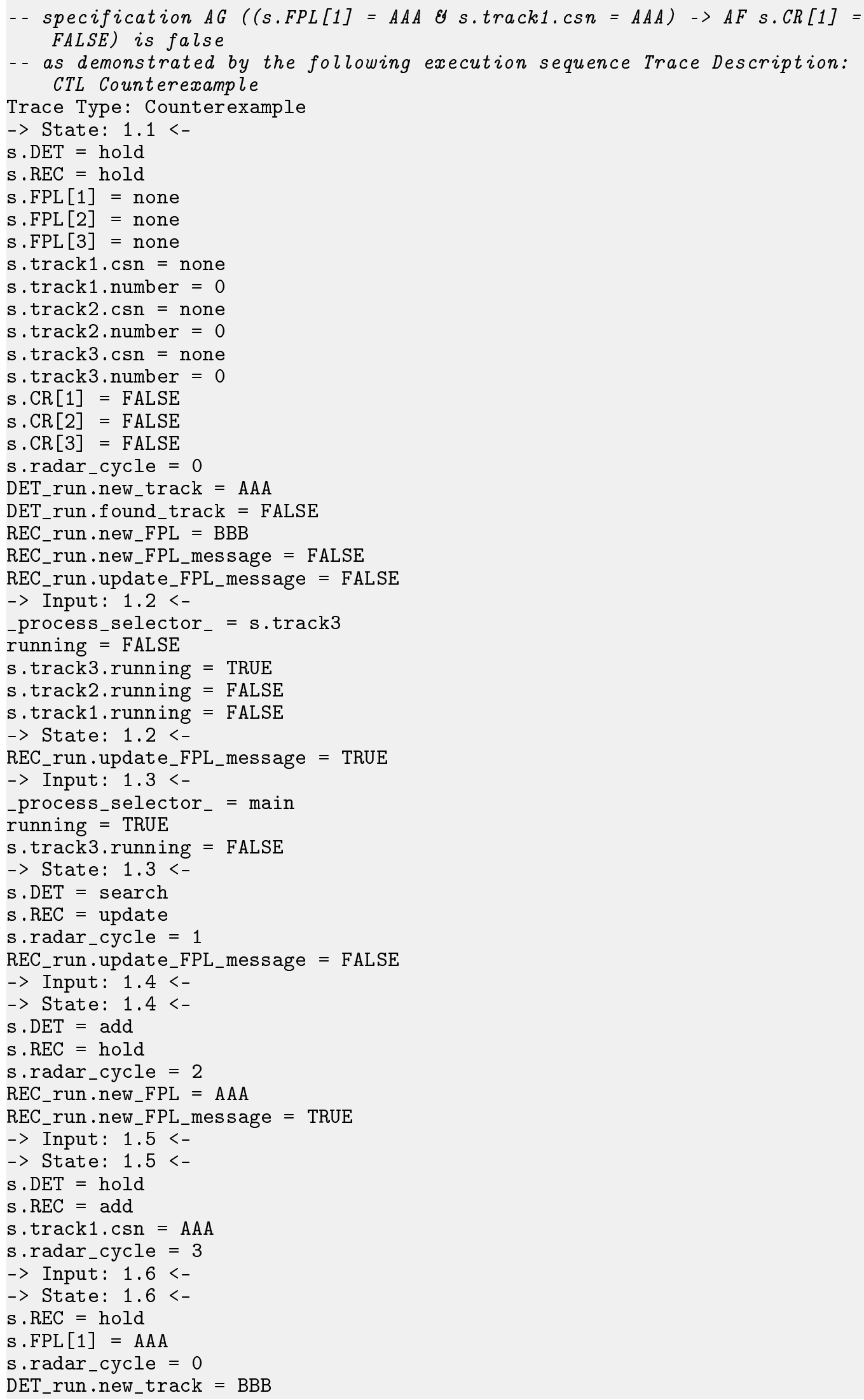




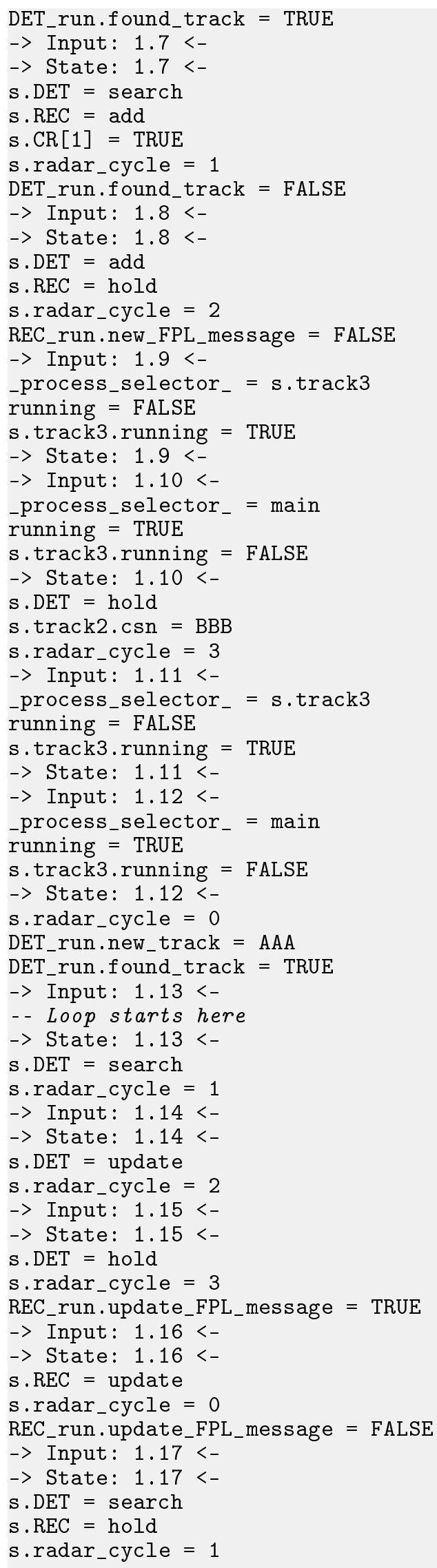

Listagem B.1 - Verificação de propriedade inversa - Contraexemplo. 
-- specification $A G((s . F P L[1]=A A A$ \& s.track1.csn = BBB) ->AF s.CR[1]

FALSE) is false -- as demonstrated by the following execution sequence Trace Description: CTL Counterexample

Trace Type: Counterexample

$\rightarrow$ State: $1.1<-$

s.DET $=$ hold

s. REC = hold

s.FPL $[1]=$ none

s.FPL $[2]=$ none

s.FPL $[3]=$ none

s.track $1 . \operatorname{csn}=$ none

s.track1. number $=0$

s.track $2 . \operatorname{csn}=$ none

s.track2. number $=0$

s.track $3 . \operatorname{csn}=$ none

s.track3. number $=0$

s.CR $[1]=$ FALSE

s.CR [2] = FALSE

s.CR $[3]=$ FALSE

s.radar_cycle $=0$

DET_run.new_track $=$ BBB

DET_run.found_track $=$ FALSE

REC_run.new_FPL $=$ BBB

REC_run.new_FPL_message $=$ FALSE

REC_run.update_FPL_message $=$ FALSE

-> Input: $1.2<-$

_process_selector ${ }_{-}=$main

running = TRUE

s.track3.running $=$ FALSE

s.track2.running $=$ FALSE

s.track1.running $=$ FALSE

$\rightarrow$ State: $1.2<-$

s.DET = search

s.radar_cycle $=1$

-> Input: $1.3<-$

$\rightarrow$ State: $1.3<-$

s.DET $=$ add

s.radar_cycle $=2$

REC_run.update_FPL_message $=$ TRUE

$\rightarrow$ Input: $1.4<-$

-> State: $1.4<-$

s.DET $=$ hold

s. REC = update

s.track1.csn $=\mathrm{BBB}$

s.radar_cycle $=3$

REC_run.update_FPL_message $=$ FALSE

-> Input: $1.5<-$

-> State: $1.5<-$

s. REC = hold

s.radar_cycle $=0$

DET_run.new_track $=$ AAA

DET_run.found_track $=$ TRUE

REC_run.new_FPL $=$ AAA

REC_run.new_FPL_message $=$ TRUE

-> Input: $1.6<-$

-> State: $1.6<-$

s.DET = search

s. REC = add

s.radar_cycle $=1$

DET run.found track $=$ FALSE

$\rightarrow$ Input: $1.7^{<-}$

-> State: $1.7<-$

s.DET = add

s. REC = hold

s.FPL [1] = AAA

s.radar_cycle $=2$

REC_run.new_FPL $=$ CCC

$\rightarrow$ Input: $1.8<-$ 


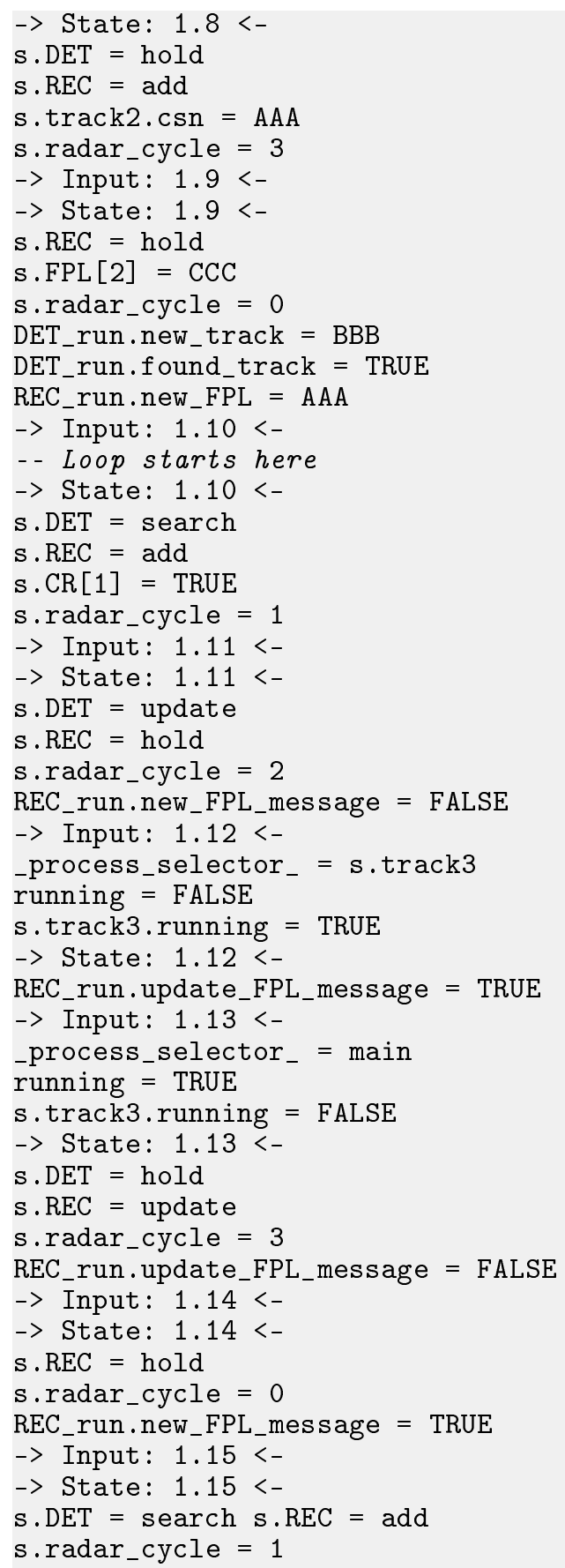

Listagem B.2 - Verificação de consistência de propriedade - Contraexemplo. 
-- specification $A G(((s . D E T=$ hold \& s.radar $c y c l e=0)$ \& DET_run.

new_track = AAA) $\rightarrow A F(($ s.track1.csn $=A A A$ \& s.track2.csn $!=A A A) \& s$. track3.csn $!=A A A)$ ) is false

- - as demonstrated by the following execution sequence

Trace Description: CTL Counterexample

Trace Type: Counterexample

-> State: $1.1<-$

s.DET $=$ hold

s. REC $=$ hold

s.FPL $[1]=$ none

s.FPL [2] = none

s.FPL $[3]=$ none

s.track $1 . \operatorname{csn}=$ none

s.track1.number $=0$

s.track $2 \cdot \operatorname{csn}=$ none

s.track2. number $=0$

s.track3.csn $=$ none

s.track3. number $=0$

s.CR $[1]=$ FALSE

s.CR [2] = FALSE

s.CR $[3]=$ FALSE

s.radar_cycle $=0$

DET_run.new_track $=$ BBB

DET_run.found_track $=$ FALSE

REC_run.new_FPL $=$ AAA

REC_run.new_FPL_message $=$ FALSE

REC_run.update_FPL_message $=$ FALSE

$\rightarrow$ Input: $1.2<-$

_process_selector $=$ main

running = TRUE

s.track3.running $=$ FALSE

s.track2.running $=$ FALSE

s.track1.running $=$ FALSE

-> State: $1.2<-$

s.DET = search

s.radar_cycle $=1$

REC_run.update_FPL_message $=$ TRUE

$\rightarrow$ Input: $1.3<-$

$\rightarrow$ State: $1.3<-$

s.DET = add

s. REC = update

s.radar_cycle $=2$

REC_run.update_FPL_message $=$ FALSE

$\rightarrow$ Input: $1.4<-$

$\rightarrow$ State: $1.4<-$

s.DET $=$ hold

s. $\mathrm{REC}=$ hold

s.track1.csn $=$ BBB

s.radar_cycle $=3$

REC_run.new_FPL_message $=$ TRUE

$\rightarrow$ Input: $1.5<-$

$\rightarrow$ State: $1.5<-$

s. $\mathrm{REC}=$ add

s.radar_cycle $=0$

DET_run.new_track $=$ AAA

DET_run.found_track $=$ TRUE

-> Input: $1.6<-$

-> State: $1.6<-$

s.DET = search

$\mathrm{s} \cdot \mathrm{REC}=$ hold

s.FPL $[1]=\mathrm{AAA}$

s.radar_cycle $=1$

DET_run.found_track $=$ FALSE

REC_run.new_FPL_message $=$ FALSE

$\rightarrow$ Input: $1.7<-$

_process_selector _ $_{-}$s.track3

running $=$ FALSE

s.track3.running $=$ TRUE 


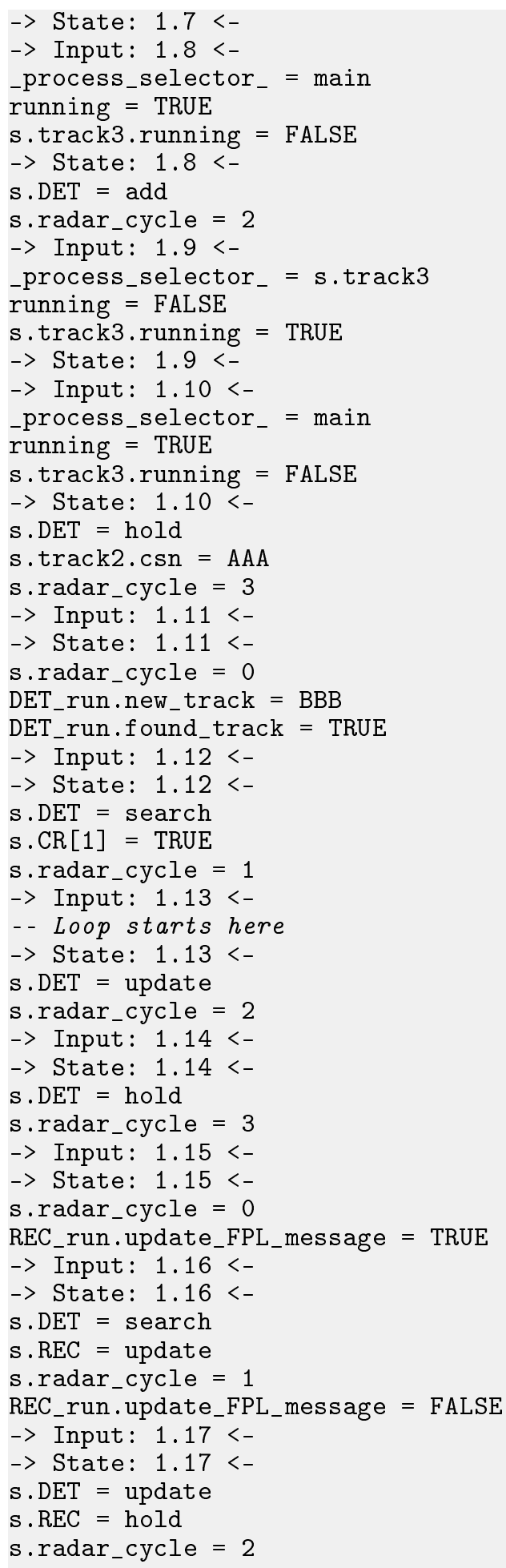

Listagem B.3 - Verificação de propriedade parcial - Contraexemplo. 